Análise estrutural e dinâmica de redes biológicas

\author{
Henrique Ferraz de Arruda
}



SERVIÇO DE PÓS-GRADUAÇÃO DO ICMC-USP

Data de Depósito:

Assinatura:

\title{
Análise estrutural e dinâmica de redes biológicas
}

\author{
Henrique Ferraz de Arruda
}

Orientador: Prof. Dr. Luciano da Fontoura Costa

Dissertação apresentada ao Instituto de Ciências Matemáticas e de Computação - ICMC-USP, como parte dos requisitos para obtenção do título de Mestre em Ciências - Ciências de Computação e Matemática Computacional. VERSÃO REVISADA

USP - São Carlos

Maio de 2015 
Ficha catalográfica elaborada pela Biblioteca Prof. Achille Bassi e Seção Técnica de Informática, ICMC/USP, com os dados fornecidos pelo(a) autor(a)

\begin{tabular}{|c|c|}
\hline \multirow[t]{3}{*}{ F773a } & $\begin{array}{l}\text { Ferraz de Arruda, Henrique } \\
\text { Análise estrutural e dinâmica de redes biológicas } \\
\text { / Henrique Ferraz de Arruda ; orientador Luciano da } \\
\text { Fontoura Costa. -- São Carlos, } 2015 \text {. } \\
\quad 85 \text { p. }\end{array}$ \\
\hline & $\begin{array}{l}\text { Dissertação (Mestrado - Programa de Pós-Graduação } \\
\text { em Ciências de Computação e Matemática } \\
\text { Computacional) -- Instituto de Ciências Matemáticas } \\
\text { e de Computação, Universidade de São Paulo, } 2015 .\end{array}$ \\
\hline & $\begin{array}{l}\text { 1. expressão gênica, . 2. neurônios. 3. redes } \\
\text { complexas. 4. rede neuronal. I. da Fontoura Costa, } \\
\text { Luciano, orient. II. Título. }\end{array}$ \\
\hline
\end{tabular}




\section{Agradecimentos}

Primeiramente agradeço a Deus, por todas as oportunidades que tive na vida.

Agradeço a toda a minha família, principalmente os meus pais, Ana Sylvia e Juarez e meu irmão Guilherme.

Ao meu orientador Luciano da Fontoura Costa, pela ajuda, apoio e amizade durante a orientação do trabalho.

A todos os professores, que foram responsáveis pela minha formação, principalmente ao professor Francisco Aparecido Rodrigues, pelo apoio e incentivo.

A minha namorada, Caroline, que sempre me incentivou e nunca reclamou dos finais de semana estudando.

Aos meus amigos da USP, Andre Luiz Barbieri, César Henrique Comin, Cynthia Villar, Didier V. Oliveros, Diego Raphael Amancio, Edmilson Roque dos Santos, Filipi N. Silva e Thomas Peron.

Aos meus amigos desde o período da graduação, Alan (Peixinho), André Pilastri, Carlos Gulo, Carmen, Daniel (Stand), Daniel (Zuna), Felipe (baiano), Filipe (X), Gustavo (Lâmpada), Hiroaki (Hiro), Ivan, Jorge (José), Lucas (Salomão) e Marcel, que sempre me incentivaram.

Ao porteiro Anesio, por todas as nossas conversas e pelo incentivo.

E, não menos importantes, os amigos que sempre me incentivaram fora do mundo acadêmico, Carlos Eduardo R. C. Nogueira, Fernando F. dos Santos, Gabriel G. Ribeiro, Heitor D. Crepaldi, Elton Luiz Tsuchida, Henrique Cesar Musetti e Lucas M. Junho.

Ao CNPq (Processo: 132363/2013-5) e a Capes (Processo: DS-7122242/M), pelo apoio financeiro. 
Ao Instituto de Ciências Matemáticas e de Computação (ICMC), por me acolher e ao Instituto de Física de São Carlos (IFSC), pela estrutura. 


\section{Resumo}

Diferentes tipos de neurônios possuem formas distintas, um fator importante para a regulação da forma é a expressão gênica. Além disso, esta característica também está relacionada com a conectividade entre as células nervosas, formando redes. Por meio delas ocorrem as dinâmicas, como por exemplo o aprendizado. Neste trabalho foi desenvolvido um arcabouço de modelagem e simulação neuronal, para analisar a integração das etapas desde a expressão gênica, passando pela geração dos neurônios até as dinâmicas, permitindo o estudo do sistema e relacionamento entre as partes. Na etapa de geração, foram utilizados diferentes padrões de expressão gênica. Por meio dos neurônios, foram criadas as redes, caracterizadas utilizando medidas de centralidade. Ademais, foram executadas as dinâmicas integra-e-dispara, que simula a comunicação entre os neurônios, e o desenvolvimento hebiano, que é uma dinâmica aplicada para simular o aprendizado. Para quantificar a influência da expressão gênica, foram utilizadas as medidas de correlação de Pearson e a informação mútua. Por meio destes testes, foi possível observar que a expressão gênica influencia todas as etapas, sendo que nelas, exceto na geração da forma neuronal, os padrões de expressão com que os neurônios foram organizados também são um fator importante. Além disso, na medida de centralidade betweenness centrality, foi possível observar a formação de caminhos, denominados caminhos do betweenness. Para descrever os caminhos, foram feitas comparações entre as redes neuronais e outras redes espaciais. Assim, foi possível observar que estes caminhos são uma característica comum em redes geográficas e estão relacionados com as comunidades da rede.

Palavras-chave: expressão gênica, neurônios, redes complexas e rede neuronal. 


\section{Abstract}

Different types of neurons have distinct shapes. An important factor for shape regulation is gene expression, which is also related to the connectivity between nervous cells, creating networks. Dynamics, such as learning, can take place in those networks. In this work we developed a framework for modeling and simulating neurons allowing an integrated analysis from gene expression to dynamics. It will allow the study of the system as a whole as well as the relationships between its parts. In the neuron generation step, we used different patterns of gene expression. The networks were created using those neurons, and several centrality measures were computed to characterize them. Moreover, the dynamic processes considered were the integrate-and-fire model, which simulates communication between neurons, and the hebbian development, which is applied to simulate learning. During every step, Pearson's correlation and mutual information between the level of expression was measured, quantifying the influence of gene expression. Through these experiments it was observed that the gene expression influences all steps, which is in all cases, except in the generation of neuronal shape, an important factor. In addition, by analyzing the betweenness centrality measure, it is possible to observe the formation of paths. To study these paths, comparisons between models and other spatial networks were performed. Thus, it was possible to observe that paths are a common feature in other geographical networks, being related to the connections between network communities. Keywords: complex networks, gene expression, neuronal networks and neurons. 


\section{Conteúdo}

Agradecimentos

Resumo iii

\begin{tabular}{lll}
\hline Abstract & V
\end{tabular}

Conteúdo vii

Lista de Figuras $\quad$ xi

Lista de Tabelas $\quad$ xvii

Lista de Abreviaturas $\quad$ xix

Lista de Símbolo $\quad$ xxi

1 Introdução 1

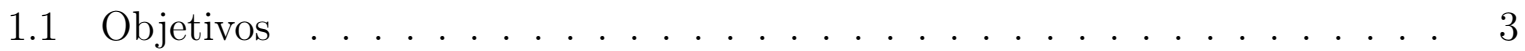

2 Aspectos biológicos 5

2.1 Expressão gênica . . . . . . . . . . . . . . . . . . . 5

2.2 Neurônios . . . . . . . . . . . . . . . . . . . . . . . . . . . . . . . . . 8

2.2 .1 Medidas . . . . . . . . . . . . . . . . . . . . 9

2.2 .2 Redes neuronais . . . . . . . . . . . . . . . . . . . . . . . . 11

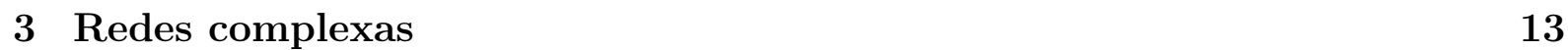

$3.1 \quad$ Caracterização de redes complexas . . . . . . . . . . . . . . . . . . . . 13 
3.2 Medidas de centralidade . . . . . . . . . . . . . . . . . . . . . 14

$3.2 .1 \quad$ Medidas de centralidade baseadas no grau . . . . . . . . . 14

3.2 .2 Medidas baseadas em ciclos $\ldots \ldots \ldots \ldots \ldots \ldots$

3.2 .3 Medidas de centralidade baseadas em caminhos . . . . . . . . 16

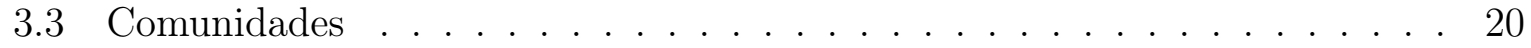

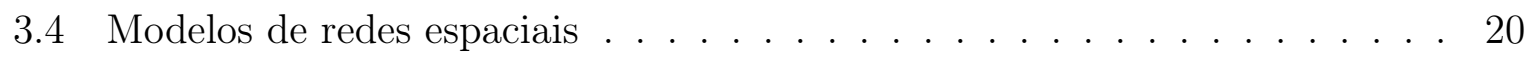

3.4 .1 Grafo geométrico aleatório . . . . . . . . . . . . . . 21

3.4 .2 Modelo de Waxman . . . . . . . . . . . . . . . . . . . 21

3.5 Processos dinâmicos $\ldots \ldots \ldots \ldots \ldots \ldots \ldots \ldots \ldots$

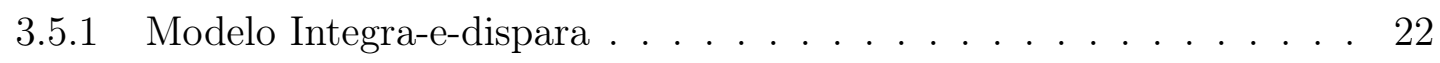

3.5 .2 Desenvolvimento hebbiano . . . . . . . . . . . . . . . . 23

3.6 Análise por componentes principais $\ldots \ldots \ldots \ldots \ldots \ldots \ldots$

3.7 Análise dos resultados $\ldots \ldots \ldots \ldots \ldots$

3.7 .1 Correlação de Pearson . . . . . . . . . . . . . . . . 24

3.7 .2 Informação mútua $\ldots \ldots \ldots \ldots \ldots \ldots \ldots \ldots$

4 Framework para a análise do relacionamelto da expressão gênica $\quad 27$

4.1 Modelo de criação de forma neuronal . . . . . . . . . . . . . . . 28

4.1 .1 Criação de neurônios artificiais $\ldots \ldots \ldots \ldots \ldots \ldots$

4.1 .2 Adaptações do modelo de criação da forma neuronal $\ldots . . . .30$

4.1.3 Expressão gênica aplicada ao modelo de criação da forma neuronal 31

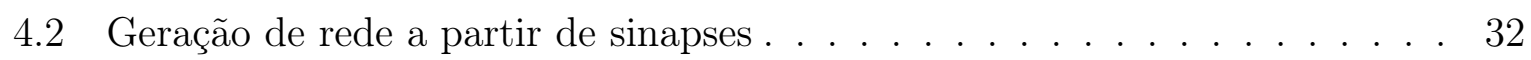

$4.2 .1 \quad$ Medidas topológicas $\ldots \ldots \ldots \ldots \ldots$

4.3 Execução de dinâmicas $\ldots \ldots \ldots \ldots \ldots \ldots \ldots$

$4.3 .1 \quad$ Integra-e-dispara $\ldots \ldots \ldots \ldots \ldots \ldots$

4.3 .2 Desenvolvimento hebbiano . . . . . . . . . . . . . . . 38

4.4 Caminhos do betweenness . . . . . . . . . . . . . . 38

\begin{tabular}{|lll}
5 & Resultados e discussão & 41
\end{tabular}

5.1 Criação das redes utilizando padrões de expressão gênica $\ldots . . . \ldots . .44$ 
5.2 Informação mútua e correlação entre expressão gênica e características neu-

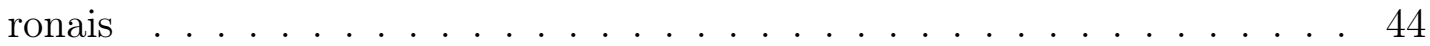

5.3 Medidas de centralidade nas redes neuronais . . . . . . . . . . . . . . . . . 48

5.4 Simulação da dinâmica neuronal integra-e-dispara . . . . . . . . . . . . . . 52

5.5 Simulação do desenvolvimento hebbiano $\ldots \ldots$. . . . . . . . . . . . 55

5.6 Caminhos mínimos entre comunidades . . . . . . . . . . . . . . . . . 57

5.6 .1 Caminhos nas redes neuronais . . . . . . . . . . . . . . . . . . . . 59

5.6 .2 Outras redes espaciais . . . . . . . . . . . . . . . . 59

5.6 .3 Modelo de rede com caminhos . . . . . . . . . . . . . . . . . . 62

5.6 .4 Rede de comunidades . . . . . . . . . . . . . . . . . 67

\begin{tabular}{lll}
\hline & Conclusões e trabalhos futuros & 71
\end{tabular}

6.1 Conclusões . . . . . . . . . . . . . . . . . . . . . . . . . . 71

6.2 Principais contribuições $\ldots \ldots \ldots \ldots$. . . . . . . . . . . . . 73

6.3 Trabalhos Futuros . . . . . . . . . . . . . . . . . . . . . . . . . 74

6.4 Publicações . . . . . . . . . . . . . . . . . . . . . 75

\begin{tabular}{ll}
\hline Referências bibliográficas & 77
\end{tabular} 


\section{Lista de Figuras}

2.1 Alguns tipos de neurônios classificados de acordo com os seus prolongamentos (dendritos e axônios) $\ldots \ldots \ldots \ldots \ldots$

2.2 Partes típicas dos neurônios. . . . . . . . . . . . . . . . . . . . 9

2.3 Exemplo de medidas de um neurônio . . . . . . . . . . . . . . . . . . . . . 10

3.1 Exemplo de rede fracamente conectado, contendo dois componentes forte-

mente conectados, sendo que cada componente é representado por vértices da mesma cor. . . . . . . . . . . . . . . . . . . . 14

3.2 Exemplos da medida de grau em redes direcionadas e não direcionada. . . . 15

3.3 Exemplo da medida de neighborhood connectivity para o vértice vermelho, \begin{tabular}{|c|c|}
\hline onde os vértices azuis são os vizinhos diretos (chamados de ordem 0) e os \\
\hline
\end{tabular}

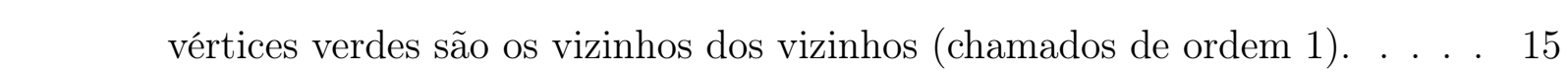

3.4 Exemplos do cálculo de clustering coefficient. Os exemplos mostram o valor do clustering coefficient para o vértice representado pela cor vermelha. . . 16

3.5 Exemplo da medida de betweenness centrality onde o vértice vermelho, que está conectando duas comunidades distintas, é o mais central. . . . . . . . 18

3.6 Exemplo da medida de Closeness Centrality onde os valores para cada vértice são representados de acordo com o mapa de cor. . . . . . . . . . . . . 19

3.7 Exemplo da medida de excentricidade para o vértice representado pela cor vermelha. Para cada vértice, os valores representam a distância entre cada um deles e o vértice vermelho. . . . . . . . . . . . . . . . . . . . . . . . 19

3.8 Diagrama representando o modelo integra-e-dispara para cada vértice da

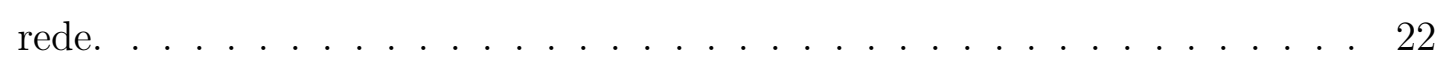


3.9 Diagrama de venn mostrando a relação entre entropia, entropia condicional e informação mútua. . . . . . . . . . . . . . . . . . . . . . . 25

4.1 Pipeline de desenvolvimento do trabalho. A seta mostra que os passos podem ocorrer tanto da esquerda para a direita, quanto da direita para a esquerda. . . . . . . . . . . . . . . . . . . . . . . . 28

4.2 Exemplo de construção de um neurônio artificial. O círculo vermelho representa o primeiro segmento de reta, que é o soma do neurônio. . . . . . . . 30

$4.3 \quad$ Exemplos de neurônios de acordo com os respectivos valores de $\eta$. . . . . . 32

4.4 Padrões de expressão gênica utilizados nos testes, o item (a) representa o padrão plano e o item (b) representa o padrão circular. . . . . . . . . . . . 33

4.5 Exemplo do PCA aplicado em um neurônios. . . . . . . . . . . . . . . . . . 34

4.6 Exemplos de neurônios normalizados. . . . . . . . . . . . . . . . . . . . 34

4.7 Exemplo da formação da rede de acordo com as sinapses. . . . . . . . . . . 35

4.8 Exemplos aonde ocorre ou não a sinapse, com os pontos $a$ e $b$ não tendo a distância menor que $d_{s}$. Em (a) não ocorre e em (b) ocorre. . . . . . . . . 36

5.1 Rede gerada por neurônios artificias, utilizando a expressão gênica no padrão plano. . . . . . . . . . . . . . . . . . . . . . . . . 42

5.2 Rede gerada por neurônios artificias, utilizando a expressão gênica no padrão circular. . . . . . . . . . . . . . . . . . . . . . . . 43

5.3 Comprimento médio das arestas (distância euclidiana entre os neurônios que se conectam) por coluna da rede, os neurônios têm uma posição fixa em na grade (nos eixos $x$ e $y$ ), assim, as colunas são os conjuntos de neurônios que possuem a mesma posição no eixo $x$. . . . . . . . . . . . . . . . . 43

5.4 Relação entre medidas morfológicas e o nível de expressão do gênica do respectivo neurônio, considerando a rede RP. A curva representada na cor preta representa a média das medidas morfológica para cada valor de $\eta$ (expressão gênica). . . . . . . . . . . . . . . . . . . 45 
5.5 Relação entre medidas morfológicas e o nível de expressão do gênica do respectivo neurônio, considerando a rede RC. A curva representada na cor preta representa a média das medidas morfológica para cada valor de $\eta$ (expressão gênica). . . . . . . . . . . . . . . . . . . . . . . 46 46

5.6 Informação mútua entre o valor de $\eta$ e as medidas morfológicas, o item (a) representa a rede $\mathrm{RP}$ e o item (b) representa a rede $\mathrm{RC}$. . . . . . . . . . . 47

5.7 Correlação de Pearson (em módulo) entre o valor de $\eta$ e as medidas morfológicas, o item (a) representa a rede RP e o item (b) representa a rede $\mathrm{RC}$.

5.8 Relação entre os níveis de $\eta$ e as medidas topológicas para cada um dos vér-

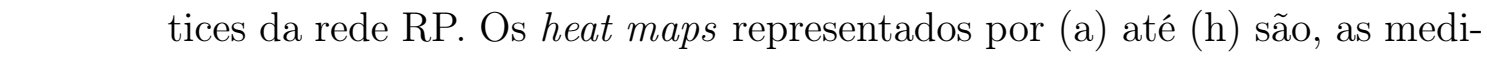
das de closeness centrality, neighborhood connectivity (saída), neighborhood connectivity (entrada), grau (entrada), grau (saída), excentricidade, betweenness centrality e clustering. . . . . . . . . . . . . . . . . . . . 49

5.9 Relação entre os níveis de $\eta$ e as medidas topológicas para cada um dos vértices da rede RC. Os heat maps representados por (a) até (h) são, as medidas de closeness centrality, neighborhood connectivity (saída), neighborhood connectivity (entrada), grau (entrada), grau (saída), excentricidade, betweenness centrality e clustering. . . . . . . . . . . . . . . . . . . . . 50

5.10 Informação mútua entre o valor de $\eta$ e as medidas morfológicas, o item (a) representa a rede $\mathrm{RP}$ e o item (b) representa a rede $\mathrm{RC} . \quad$. . . . . . . . . . 51

5.11 Correlação de Pearson (em módulo) entre o valor de $\eta$ e as medidas topológicas, o item (a) representa a rede RP e o item (b) representa a rede $\mathrm{RC}$

5.12 Gráfico mostrando o tempo pela quantidade média de disparos. O item

(a) representa a rede RP e o item (b) representa a rede RC. As ampliações dos gráficos mostram o momento em que a dinâmica ainda não entrou em estado estacionário . . . . . . . . . . . . . . . . . . . . . . . . . 52 
5.13 Gráficos de dispersão das medidas da dinâmica integra-e-dispara, nas redes RP e RC. Em todos os mapas de dispersão, o eixo x representa $\eta$ (expressão gênica) e os eixos y são: (a)Taxa de disparos em RP, (b) Entropia do intervalo entre disparos em RP, (c) Maior intervalo entre disparos (log) em RP, (d)Taxa de disparos RC, (e) Entropia do intervalo entre disparos em RC, (f) Maior intervalo entre disparos (log) em RC. As curvas representadas na cor preta são médias. . . . . . . . . . . . . . . . . . . . . . 53

5.14 Informação mútua das medidas da dinâmica integra-e-dispara nas duas grades, onde item (a) representa a rede RP e o item (b) representa a rede RC. O valor da entropia do intervalo entre disparos não foi apresentado para a escala logarítmica, pois para medida os resultado é igual, independente da escala. . . . . . . . . . . . . . . . . . . . . 54

5.15 Correlação de Pearson (em módulo) das medidas da dinâmica integra-edispara nas duas grades, onde item (a) representa a rede RP e o item (b) representa a rede RC. . . . . . . . . . . . . . . . . . . . 54

5.16 As figuras mostram as redes antes e depois do desenvolvimento hebbiano (para ambas as imagens foi considerado o componente gigante fracamente conectado), cada quadrado branco representa um vértice (neurônio) da rede. As Figuras (a) e (b) representam a rede RP antes e depois do desenvolvimento hebbiano, respectivamente e as Figuras (c) e (d) representam a rede $\mathrm{RC}$ antes e depois do desenvolvimento hebbiano, respectivamente. . . 56

5.17 Gráficos de dispersão das medidas da dinâmica integra-e-dispara (contida no desenvolvimento hebbiano), nas redes RP e RC. Em todos os mapas de dispersão, o eixo x representa $\eta$ (expressão gênica) e os eixos y são:

(a)Taxa de disparos em RP, (b) Entropia do intervalo entre disparos em RP, (c) Maior intervalo entre disparos (log) em RP, (d)Taxa de disparos RC, (e) Entropia do intervalo entre disparos em RC, (f) Maior intervalo entre disparos (log) em RC. As curvas representadas na cor preta são médias. 57 
5.18 Informação mútua das medidas da dinâmica integra-e-dispara (contida no desenvolvimento hebbiano) nas duas grades, onde item (a) representa a rede RP e o item (b) representa a rede RC. O valor da entropia do intervalo entre disparos não foi apresentado para a escala logarítmica, pois para medida os resultado é igual, independente da escala. . . . . . . . . . . . . . . . . 58

5.19 Correlação de Pearson (em módulo) das medidas da dinâmica integra-edispara (contida no desenvolvimento hebbiano) nas duas grades, onde item (a) representa a rede RP e o item (b) representa a rede RC. . . . . . . . . 58

5.20 Histogramas mostrando a distância entre os vértices e os caminhos do betweenness. O item (a) representa a rede RP e o item (b) representa a rede RC. .

5.21 Redes geográficas, os círculos representados pela cor preta são os caminhos do betweenness (o limiar utilizado foi de 20\%). O item (a) representa a rede \begin{aligned} \hline gerada pelo modelo de Waxman, o item (b) representa a rede gerada pelo \\ \hline\end{aligned} modelo do grafo geométrico aleatório e o item (c) representa a rede de ruas de Oldenburg, neste grafo as cores representam as comunidades (exceto a cor preta).

5.22 Histogramas mostrando a distância entre os vértices e os caminhos preferenciais. O item (a) representa a rede do modelo de Waxman, o item (b) representa a rede do modelo do grafo geométrico aleatório, o item (c) representa a rede de Oldenburg e o item (d) representa a rede de San Joaquin County. . . . . . . . . . . . . . . . . . . . 62

5.23 A imagem do item (a) representa o heat map da medida de betweenness centrality nos vértices da rede do modelo proposto (nas regiões sem vértices o valor do betweenness centrality é considerado como zero). O item (b) mostra as comunidade, sendo que cada uma delas possuí uma cor distinta, a cor preta mostra os caminhos (com um limiar de 20\%) e a cor branca mostra as regiões sem vértices. . . . . . . . . . . . . . . . . . . . 63 
5.24 Histogramas mostrando a distância entre os vértices e os caminhos preferenciais no modelo de rede. . . . . . . . . . . . . . . . . . . . . . . . 64

5.25 A imagem (a) mostra a comparação entre entre o grau dos vértices internos das comunidades e os vértices das bordas geográficas, a imagem (b) mostra a comparação entre entre o grau dos vértices da borda topológica das comunidades e os vértices das bordas geográficas e a imagem (c) mostra o betweenness centrality mostra a comparação entre entre o grau dos vértices da borda topológica das comunidades e os vértices das bordas geográficas. Os índices das comunidades foram ordenados em ordem crescente, de acordo com o grau das bordas geográficas. . . . . . . . . . . . . . . . . . 65

5.26 Exemplo de comunidade e os seus respectivos caminhos do betweenness. A região em destaque representa a comunidade e os vértices vermelhos representam os caminhos do betweenness. . . . . . . . . . . . . . . . 66

5.27 Gráfico de dispersão mostrando a relação entre a soma do stress de todos os vértices que conetam as comunidades e o perímetro de adjacência. O valor da correlação de Pearson é de $0,27$. . . . . . . . . . . . . . . . . . . 67

5.28 Heat map mostrando a rede criada pela adjacência das comunidades. Os círculos vermelhos representam os vértices e as arestas variam entre a cor preta até branca (preto é zero e branco é um), representando os pesos das ligações. . . . . . . . . . . . . . . . . . . . . . . . . . . . . 68

5.29 Gráficos de dispersão comparando medidas geográficas e topológicas na rede de comunidades. Os itens (a), (b), e (c) representam a medida de grau (sem peso) pelas características geográficas e os itens (d), (e), e (f) representam o strength pelas características geográficas. . . . . . . . . . . . 69 


\section{Lista de Tabelas}

4.1 Medidas de rede utilizadas . . . . . . . . . . . . . . . . . . . . . . . 37

5.1 Modularidade das redes. . . . . . . . . . . . . . . . . . . . . . . 64 


\section{Lista de abreviaturas}

\section{Abreviatura Descrição}

DNA DesoxiRibonucleic Acid (Ácido DesoxirRibonucleico)

L1 Altura/Largura

L2 Profundidade/Largura

L3 Profundidade/Altura

M1 Média do ângulo de bifurcação local

M2 Média do ângulo de bifurcação remoto

M3 Fragmentação

PCA Principal Component Analysis (Análise por componentes principais)

RC Rede gerada pelo padrão de expressão gênica circular

RNA RiboNucleic Acid (Ácido RiboNucleico)

RP Rede gerada pelo padrão de expressão gênica plano 


\section{Lista de símbolos}

\begin{tabular}{|c|c|}
\hline Símbolo & Descrição \\
\hline$A$ & Matriz de adjacência \\
\hline$B_{u}$ & Betweenness Centrality do vértice $u$ \\
\hline$a_{i j}$ & Elemento na posição $i, j$ da matriz de adjacência \\
\hline$c$ & Constante de aprendizagem \\
\hline$c_{i}$ & Comunidade do vértice $i$ \\
\hline$C_{i}$ & Closeness Centrality do vértice $i$ \\
\hline$c c_{i}$ & Clustering coefficient do vértice $i$ \\
\hline $\operatorname{Cor}_{X, Y}$ & Correlação de Pearson \\
\hline $\operatorname{cov}(X, Y)$ & Covariância entre as distribuições $X$ e $Y$ \\
\hline$d$ & Distância euclidiana \\
\hline$d_{i j}$ & Distância entre os vértices $i$ e $j$ \\
\hline$d_{s}$ & Distância até o soma \\
\hline$E$ & Esperança \\
\hline$E_{i}$ & eccentricity (Excentricidade) \\
\hline$f$ & É a constante de esquecimento \\
\hline$h$ & Ordem \\
\hline$H(X)$ & Entropia \\
\hline$H(X, Y)$ & Entropia conjunta \\
\hline$H(X \mid Y)$ & Entropia condicional \\
\hline$I(X, Y)$ & Informação mútua \\
\hline$k_{i}$ & Grau do vértice $i$ \\
\hline
\end{tabular}




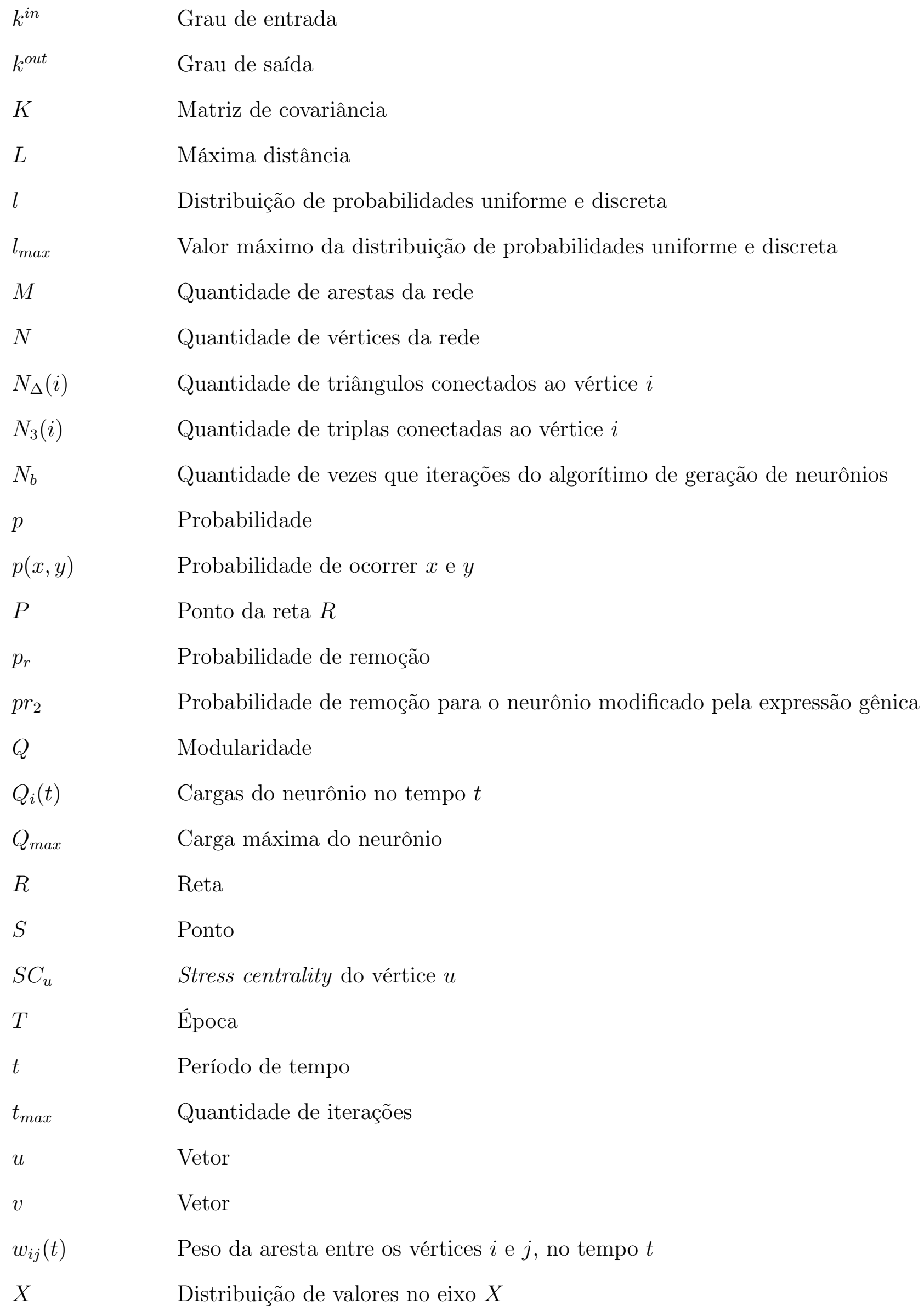




$\begin{array}{ll}\bar{X} & \text { Média da distribuição } X \\ Y & \text { Distribuição de valores no eixo } Y \\ \bar{Y} & \text { Média da distribuição } Y \\ \alpha & \text { Ângulo entre os troncos } \\ \alpha_{m a x} & \text { Máximo ângulo entre os troncos } \\ \sigma(i, j) & \text { Quantidade total de menores caminhos entre } i \text { e } j \\ \sigma(i, u, j) & \text { Quantidade de menores caminhos entre os pontos } i \text { e } j \text {, que passam por } u \\ \delta & \text { Delta de Kronecker } \\ \theta & \text { Ângulo de bifurcação } \\ \bar{\theta} & \text { Média de } \theta \\ \overline{\theta_{2}} & \text { Média de } \theta \text { para o neurônio modificado pela expressão gênica } \\ \sigma_{\theta}^{2} & \text { Variância de } \theta \\ \varphi & \text { Ângulo de rotação } \\ \bar{\varphi} & \text { Média de } \varphi \\ \bar{\varphi} \sigma_{\theta} & \text { Média de } \varphi \text { para o neurônio modificado pela expressão gênica de variação de peso } \\ \eta w_{i j} & \text { Intensidade de expressão gênica } \\ & \text { Ea }\end{array}$




\section{Capítulo 1}

\section{Introdução}

Alguns estudos mostram como os neurônios se desenvolvem, descrevendo quais são os mecanismos biológicos que geram a sua forma (Jan \& Jan, 2003; Scott \& Luo, 2001). Os neurônios podem ser classificados por diversas maneiras distintas, pois sua estrutura pode ser complexa, variando de acordo com diferentes características, como por exemplo, regiões do sistema nervoso ou expressão gênica (Bota \& Swanson, 2007).

Baseando-se em características de neurônios reais, foram criados modelos para gerá-los artificialmente (Ascoli \& Krichmar, 2000). Entre os modelos existentes, há a possibilidade de gerar neurônios genéricos, ou seja, sem considerar um tipo específico Costa et al., 2010), ou modelos que geram neurônios provenientes de determinada região cerebral (Wen \& Chklovskii, 2008).

As conexões entre os neurônios podem ser restringidas por suas características morfológicas (Pérez-Reche et al., 2010; Marconi et al., 2012). Assim, é importante estudar qual a relação entre as formas neuronais e as sinapses. Uma possibilidade é simular a criação de redes, neste caso as sinapses são criadas a partir da morfologia neuronal. Desta forma, é possível entender a influência de propriedades microscópicas no comportamento macroscópico da rede, como por exemplo a ativação total do sistema (Roxin et al., 2004).

As redes neuronais podem ser representadas por um conjunto de vértices, representando os neurônios, e um conjunto de arestas, representando as sinapses. Assim, o sistema passa a ser descrito por uma estrutura denominada grafo. Em casos nos quais o sistema é composto por muitos elementos, a estrutura gerada pode ser chamada de rede complexa 
(Newman, 2010). Por meio de tal representação torna-se possível utilizar uma grande quantidade de ferramentas, que foram desenvolvidas nas últimas décadas para o estudo de redes (Boccaletti et al. 2006; Costa et al. 2007, Newman, 2010). Além disso, medidas topológicas podem ser utilizadas para quantificar as suas características (Pérez-Reche et al. 2010, Marconi et al., 2012; Costa et al., 2007). Por exemplo, o grau de cada vértice que, em uma rede neuronal, representa a quantidade de sinapses que um determinado neurônio faz.

Além de medir características topológicas da rede, é possível simular dinâmicas específicas para o sistema que foi modelado. Assim, a topologia influencia a dinâmica (Sporns et al., 2000, Pernice et al., 2011). No caso de simulações neuronais, um modelo muito utilizado é o modelo de dinâmica integra-e-dispara (Roxin et al., 2004; Guardiola et al., 2000). Por meio dele é possível simular o comportamento de disparos dos neurônios. Ademais, existem dinâmicas que modificam a topologia, como a simulação da teoria hebbiana, sobre plasticidade das sinapses, proposta por Hebb (1949). Esta teoria consiste no fortalecimento ou enfraquecimento das ligações sinápticas, que ocorre a partir dos disparos dos neurônios (Brown et al., 1990).

Outra característica importante na determinação da morfologia é a expressão gênica (Lee \& Luo, 1999, Lein et al., 2007). Os genes definem características em todos os organismos vivos. Eles também modificam o formato dos neurônios, influenciando indiretamente a topologia e a dinâmica das redes neuronais.

De maneira geral, as etapas de expressão gênica, forma neuronal, redes de neurônios, aprendizado e dinâmicas neuronais, são estudadas separadamente. Neste trabalho foi desenvolvido um arcabouço de modelagem e simulação que permite estudar a integração entre as partes e o relacionamento entre elas. Com este intuito, foram implementados separadamente os componentes da simulação neuronal, desde a geração de neurônios artificiais (influenciados pela expressão gênica) até a simulação de dinâmicas. Assim, é possível trocar algumas das etapas por outras simulações ou dados reais. Além disso, foram feitas medidas em todos estes componentes e o nível de influência da expressão gênica foi calculado para cada um deles. Desta maneira, é possível obter um nível de compreen- 
são que poderia ser mais difícil em dados reais, devido à dificuldade na aquisição de tais dados.

Por meio da medida de centralidade betweenness centrality foi possível observar a formação de caminhos preferenciais. Para compreender como estes caminhos se formam, foram feitas comparações entre a rede de nerônios e outras redes espaciais (dois modelos e duas redes de ruas). Assim, foi possível observar que esta é uma característica comum nas redes geográficas. Ademais, há indícios de que estes caminhos são induzidos pelas comunidades das redes.

Esta dissertação é organizada como segue. O capítulo 1 mostra a introdução e os objetivos. O capítulo 2 caracteriza os aspectos biológicos necessários para o entendimento da dissertação. O Capítulo 3 descreve as redes complexas, diversas medidas para caracterizálas, os processos dinâmicos e as formas de análise dos resultados. O capítulo 4 descreve os métodos para a criação do framework de análise da expressão gênica. No capítulo 5 são apresentados os resultados e discussões. O capítulo 6 mostra as conclusões, as principais contribuições e os trabalhos futuros.

\section{$1.1 \quad$ Objetivos}

As etapas de expressão gênica, geração de neurônios, criação de rede neuronal por meio de sinapses e dinâmicas neuronais, têm sido amplamente estudadas na literatura. Todavia, de maneira geral, elas são estudadas separadamente. Um trabalho anterior, integrando esses componentes foi apresentado por Miazaki (2012). O objetivo do presente trabalho é estender e complementar em vários aspectos aquele trabalho. Desse modo, implementar, de forma estendida e complementar, todas as etapas do pipeline utilizado por Miazaki (2012) para estudos de interações gênicas em neurônios, desde a expressão gênica até a atividade neuronal, permitindo diversos novos experimentos relacionados.

O pipeline é formado por quatro etapas, sendo elas a expressão gênica, a criação de neurônios artificiais que são gerados de acordo com a expressão gênica, a criação da rede neuronal que é caracterizada por medidas topológicas e, por fim, a simulações de dinâmicas específicas para redes de neurônios. 
Objetivos específicos:

- Incorporar um parâmetro de expressão gênica no modelo de criação neuronal e, a partir do modelo proposto por Costa et al. (2010), anexar funções que variam de acordo com um parâmetro de expressão gênica;

- Criar redes complexas baseadas nos neurônios gerados utilizando padrões distintos de expressão gênica (no formato de grades);

- Investigar a forma e a interação entre os neurônios, a partir dos neurônios e da rede gerada por eles;

- Caracterizar as redes complexas geradas por meio de medidas de centralidade;

- Aplicar a dinâmica integra-e-dispara nas redes geradas, para comparar os resultados encontrados em ambas as redes;

- Aplicar a dinâmica de desenvolvimento hebbiano nas redes geradas, para comparar os resultados encontrados em ambas as redes;

- Medir quanto a expressão gênica influencia cada uma das etapas;

- Investigar características encontradas em outros tipos de redes espaciais, além das redes neuronais, especialmente na medida de betweenness centrality, possibilitando comparar características em ambos os sistemas. 


\section{Capítulo 2}

\section{Aspectos biológicos}

Para modelar computacionalmente os sistemas biológicos é necessário entender como eles funcionam. Assim, neste capítulo são descritos os aspectos biológicos fundamentais para o desenvolvimento do trabalho.

\subsection{Expressão gênica}

Existem três partes envolvidas no processo de expressão gênica. Uma delas é o ácido desoxirribonucléico, chamado de DNA (em inglês desoxiribonucleic acid), que é responsável por armazenar as informações genéticas dos indivíduos. O segundo é o ácido ribonucléico, chamado de RNA (em inglês ribonucleic acid), que por sua vez é produzido pelo DNA e tem a função de sintetizar a terceira parte, que são as proteínas. Por meio destas três macromoléculas, o DNA, o RNA e as proteínas é que a expressão gênica é controlada (Lodish et al., 2007). Desta forma, a expressão gênica pode ser definida como o processo no qual a informação hereditária codificada por um gene é decodificada, resultando numa proteína.

Em todas as células dos organismos vivos o processo de expressão gênica ocorre, o que inclui as células nervosas, chamadas de neurônios. A influência da expressão gênica no sistema nervoso de diversas espécies de animais (vertebrados e invertebrados) foi amplamente estudada e descrita na literatura (Bertrand et al., 2002). Um exemplo é a descrição do sistema nervoso periférico do embrião de moscas do gênero drosophila, no qual foram 
classificados dois tipos principais de neurônios (Colosimo et al., 2004), originados por meio de genes distintos (Vervoort et al., 1997). Além disso, neurônios de diferentes regiões do cérebro de ratos foram caracterizados de acordo com a expressão gênica, influenciando o formato das células (Eberwine et al. 1992; Kriegstein \& Dichter, 1983). Ademais, por meio da comparações entre mecanismos de expressão gênica de especies de drosophila sp e vertebrados, foi possível mostrar que as regras que regulam a neurogênese são similares (Bertrand et al. 2002).

Os genes são o fator principal para a regulação da neurogênese (Bertrand et al., 2002). Entretanto, de acordo com a maior parte das classificações, os neurônios são agrupados de acordo com a sua estrutura e função (Bota \& Swanson, 2007). Outra abordagem é classificar de acordo com a expressão gênica (Bota \& Swanson, 2007, Bertrand et al., 2002). Uma das possibilidades é caracterizar estas células de acordo com o nível de expressão gênica, que pode ser feito por meio de marcadores de RNAm (RNA mensageiro), como por exemplo, utilizando a técnica de hibridização in situ (ISH), ou em inglês in situ hybridization (Eberwine et al., 1992). Assim, uma possível abordagem para a criação de modelos neuronais é utilizar parâmetros que permitam modificações na morfologia de acordo com a expressão gênica.

Além de mostrar as origens genéticas e a classificação dos neurônios, outro estudo importante é entender como a expressão gênica pode agir na morfologia dos neurônios (Bodmer \& Jan, 1987). Em alguns casos é possível identificar como determinados genes controlam diferentes aspectos do desenvolvimento das células nervosas. Alguns exemplos são: no desenvolvimento da drosophila sp (Gao et al., 1999); na regulação do tamanho dos neurônios, por meio da família de genes Hes (Hatakeyama et al., 2004); na identificação de doenças geradas por genes mutantes (Gao et al. 1999). Utilizando estes estudos, seria importante simular computacionalmente determinadas mudanças da morfologia de acordo a simulação de determinados genes.

Outra função importante dos genes é controlar a função dos neurônios Kiyasova et al. 2011). Para entender como a genética influencia a função neuronal, Campbell \& Holt (2001) propuseram um trabalho utilizando neurônios da retina, no qual um gene foi ini- 
bido, desta forma os axônios não foram guiados corretamente e perderam a sua capacidade de resposta (Qiu \& Ghosh, 2008). Outro estudo, feito com mamíferos, mostra uma relação indireta entre genes e o crescimento de dendrito, pois estes genes são capazes de influenciar a produção de determinado hormônio que, por sua vez, afetam o seu crescimento, limitando a capacidade do neurônio de fazer sinapses (Mong \& Pfaff, 2003).

A neurogênese não modifica apenas o desenvolvimento neuronal, ela também é importante para a formação de estruturas cerebrais (Peper et al., 2007). Um exemplo é a família de genes Hes, que não é considerável apenas para o tamanho e a forma neuronal, mas também é parte importante na manutenção da integridade de estruturas cerebrais, pois estes genes são necessários na diferenciação e controle das células nervosas (Hatakeyama et al. 2004). Outra característica da neurogênese, cujo principal fator são os genes, é o volume cerebral (Baaré et al., 2001).

Além disso, estudos com seres humanos mostram que durante a puberdade ocorrem mudanças no comportamento e na morfologia do sistema nervoso (Sisk \& Foster, 2004). Outros estudos mostram que existem correlações entre o genótipo e características fenotípicas, como por exemplo o QI (Thompson et al., 2001), volume cerebral (Peper et al., 2007), entre outras característica fenotípicas (Ramakers, 2002, Lai et al., 2006).

Uma forma de estudar a relação entre o genótipo e as características cerebrais é por meio da comparação entre gêmeos monozigóticos e dizigóticos (Peper et al., 2007; Baaré et al. 2001), pois o código genético dos gêmeos monozigóticos é o mesmo, já nos dizigóticos o DNA é diferente. Assim, é possível isolar quais são as características geradas pelo código genético e quais são geradas pelo meio ambiente. Utilizando redes formadas por neurônios, por meio de modelo neuronal baseado em genes, é possível fazer medidas (que são previstas na teoria de redes complexas) e, desta forma, entender a implicação da mudança da expressão gênica na rede.

Outros estudos possuem o intuito de estabelecer uma relação entre a genética e doenças neurológicas (Barkovich et al. 2012). Alguns exemplos de doenças neurodegenerativas são as ceroid lipofuscinoses (NCLs), que consistem em doenças associadas ao acumulo excessivo de lipopigmentos. Foram relatados seis casos nos quais a doença é gerada por 


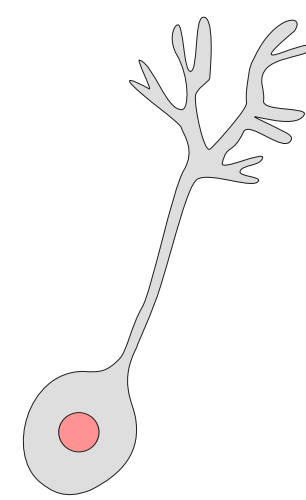

Unipolar

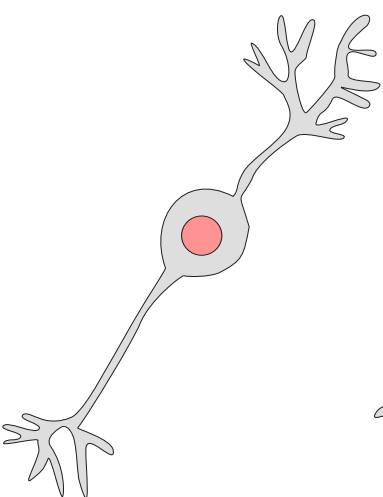

Bipolar

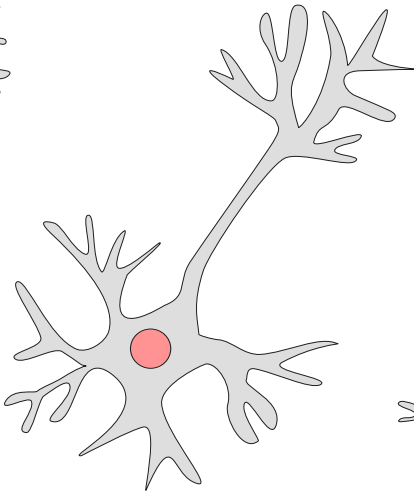

Multipolar

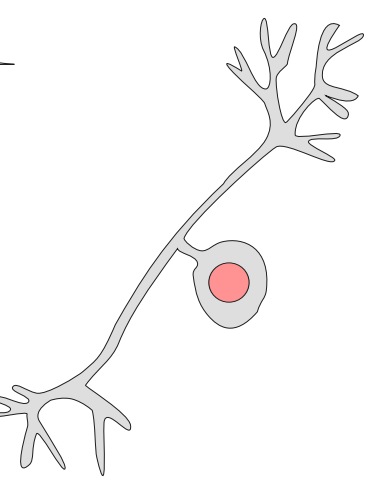

Pseudounipolar

Figura 2.1: Alguns tipos de neurônios classificados de acordo com os seus prolongamentos (dendritos e axônios).

mutações nos genes CLN1, CLN2, CLN3, CLN5, CLN6 and CLN8 (Mole et al., 2005). As origens genéticas de diversas doenças neurológicas foram descritas na literatura, como por exemplo a schizophrenia 1 (Duan et al., 2007, Blackwood et al., 2001), síndrome de Williams (Meyer-Lindenberg et al., 2006), doença de Alzheimer (Selkoe \& Podlisny, 2002), entre outras (Hedley et al., 2009).

A expressão gênica influencia a morfologia, conectividade e dinâmica do sistema neuronal. Todas estas etapas foram amplamente estudadas e estão documentadas na literatura, todavia, normalmente, estas etapas são descritas isoladamente. Para compreender melhor o sistema como um todo, uma possibilidade é simular todas as etapas unindo-as. Assim, é possível compreender o que a mudança em qualquer uma delas pode gerar nas demais.

\subsection{Neurônios}

Existem vários tipos de neurônios, sendo que eles podem ser classificados de acordo com diversas características diferentes, como por exemplo a sua função ou forma (Bota \& Swanson, 2007), alguns exemplos de neurônios classificados de acordo com a estrutura dos seus prolongamentos (dendritos e axônios) são mostrados na Figura 2.1 .

Os neurônios típicos possuem o soma (ou corpo celular), dendritos e axônios (Mason, 2011) (como é mostrado na Figura 2.2). O soma consiste na região com maior volume da célula, sendo o local aonde está situado o núcleo, os dendritos são estruturas que formam 


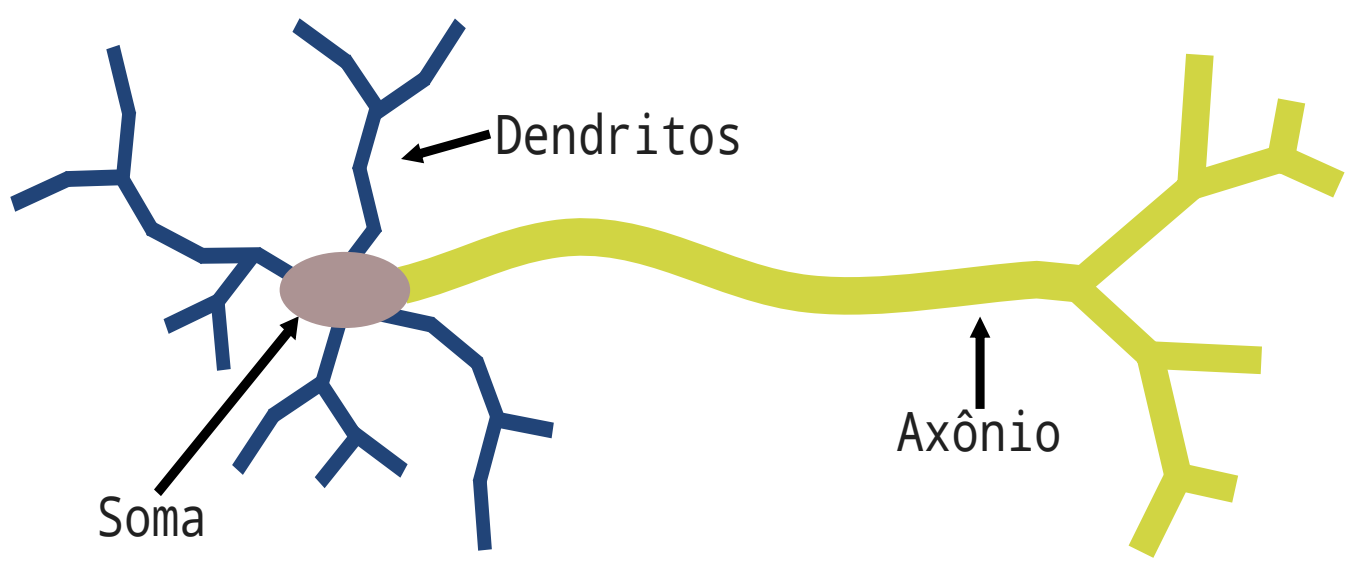

Figura 2.2: Partes típicas dos neurônios.

uma extensão da célula, sendo responsáveis por receber impulsos elétricos e os axônios são regiões responsáveis por emitir impulsos, tipicamente eles são longos e se originam de áreas um pouco espessas do corpo celular (Barrett et al., 2009). Ademais, o sentido pelo qual o impulso nervoso percorre é partindo dos dendritos, passa pelo corpo celular e sai pelos axônios (Kandel et al. 2000).

Para simular sistemas bio-inspirados é possível utilizar dados reais. Neste trabalho

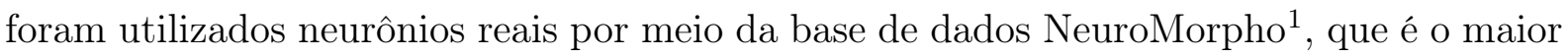
repositório de neurônios on-line. Todos os dados são disponibilizados no mesmo formato, com a extensão $s w c$, sendo eles de fácil leitura. Desta forma, é possível criar softwares para ler, escrever e fazer medidas. Outro recurso importante é a possibilidade de visualizar tridimensionalmente toda a base no próprio site (Halavi et al., 2008). Atualmente a base disponibiliza 27385 neurônios de diversos tipos e diversas regiões (Halavi et al., 2014).

\subsubsection{Medidas}

Para computar medidas dos neurônios foi utilizado o software L-Measurę que foi desenvolvido pelo mesmo grupo de pesquisa que criou a base de dados NeuroMorpho Scorcioni et al. 2008). Este software possibilita, de forma simples, fazer mais de quarenta medidas distintas, com diferentes extensões de arquivos, entre elas o formato swc. A interface gráfica foi implementada na linguagem Java e as funções principais foram implementadas

\footnotetext{
${ }^{1}$ Disponível em: $<$ www.neuromorpho.org $>$

${ }^{2}$ Disponível em: <http://cng.gmu.edu:8080/Lm/>
} 

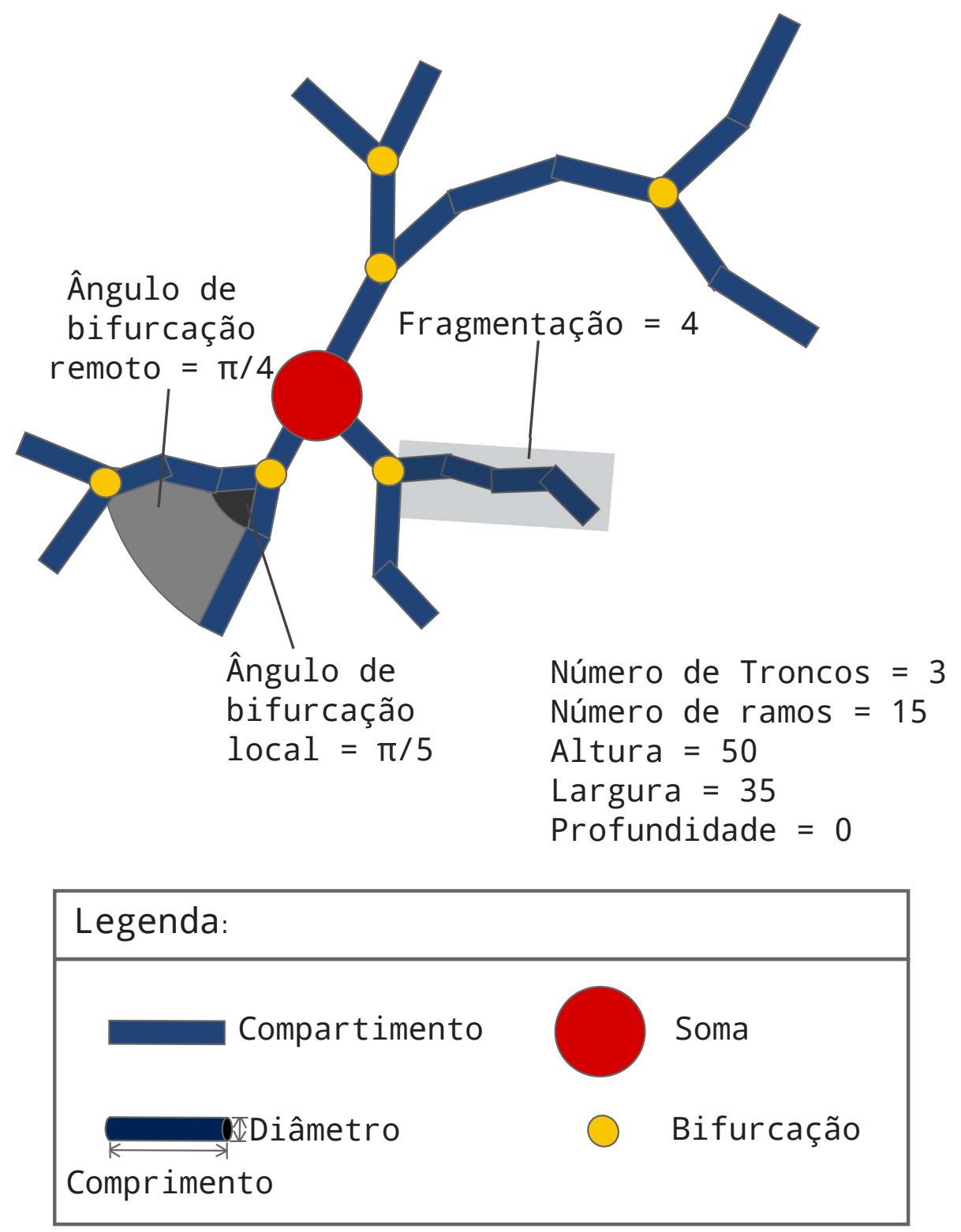

Figura 2.3: Exemplo de medidas de um neurônio.

em $\mathrm{C}++$, existem versões para Linux, Windows e Mac. Exemplos das medidas utilizadas neste trabalho são mostradas na Figura 2.3 .

Com a extensão de arquivos swc, os neurônios são representados por um conjunto de cilindros, também chamados de compartimentos, sendo que cada um deles possui determinado diâmetro (Halavi et al. 2008). Podem haver bifurcações, que são formadas por dois ou mais compartimentos distintos, que se originam do mesmo ponto inicial. Há também a representação do soma, que é o primeiro compartimento. A partir do soma, todos os compartimentos ligados diretamente a ele são os troncos, que, por sua vez, originam as árvores dendríticas. Estas que são formadas por todos os ramos originários 
do mesmo tronco. Um conjunto de compartimentos que se origina de uma bifurcação e termina em outra, ou em um compartimento que não possui mais ligações é chamado de ramo e pode formar uma curvatura.

A partir desta estrutura, várias medidas foram definidas. A quantidade de compartimentos presentes entre duas bifurcações subsequentes, ou entre uma bifurcação e o último compartimento (ponto terminal), é chamada de fragmentação. Para cada uma das bifurcações são definidos dois tipos de ângulos, o ângulo de bifurcação local e remoto. O primeiro consiste no ângulo formado por um par compartimentos que formam a bifurcação. Já o ângulo de bifurcação remoto é medido a partir dos dois pontos de bifurcação ou entre o ponto de bifurcação e ponto terminal.

Outras medidas utilizadas no trabalho são as dimensões do neurônio (altura, largura e profundidade) que são feitas considerando todo ele, sendo que a maior distância entre o par de pontos mais distantes é a altura. Considerando o sentido perpendicular ao da altura a maior distância entre dois pontos é a largura, já a profundidade é considerada como a maior distância entre dois pontos que pertencem ao sentido perpendicular à altura e à largura.

As medidas neuronais utilizadas nesta dissertação foram: média do ângulo de bifurcação local (M1), média do ângulo de bifurcação remoto (M2), fragmentação (M3), altura/largura (L1), profundidade/largura (L2) e profundidade/altura (L3).

\subsubsection{Redes neuronais}

Os neurônios podem comunicar-se entre si e com estruturas periféricas por meio de sinapses (Mason, 2011). Existem diversos tipos de contato, entretanto, neste trabalho foi considerado apenas a conexão axo-dendrítica (entre um axônio e um dendrito). Além

disso, há dois tipos de sinapse, a química e a elétrica (Kandel et al., 2000). Sendo que na sinapse química os neurotransmissores passam da célula pré-sináptica para a pós-sináptica atravessando a fenda sináptica (este tipo é mais comum no sistema nervoso humano). Já na sinapse elétrica, há uma transferência direta de corrente elétrica da célula pré-sináptica para a pós-sináptica. Uma boa revisão sobre este assunto pode ser vista no livro Mason, 
2011).

Um conjunto de neurônios conectados entre si, por meio de sinapses, forma a estrutura de uma rede. A transmissão de impulsos elétricos são uteis para organizar as ações dos grandes grupos de neurônios, pois as células acopladas eletricamente possuem uma resistência menor do que uma célula individual, desta forma estas células possuem um limiar de disparo maior (Kandel et al., 2000). Os disparos podem ser simulados computacionalmente por meio da simulação do algoritmo integra-e-dispara (Roxin et al., 2004, Guardiola et al., 2000).

Outra característica das redes de neurônios é a sua capacidade de aprender. A hipótese introduzida por Hebb (1949), sobre aprendizagem, afirma que ela está associada com a plasticidade das sinapses. Desta forma, as sinapses podem se tornar mais fortes, ou mais fracas, de acordo com o nível de atividade de disparos dos neurônios que estão conectados entre si. Este conceito foi introduzido no Postulado 1.

Postulado 1 (Postulado de Hebb) "When an axon of cell $A$ is near enough to excite cell $B$ and repeatedly or persistently takes part in firing it, some growth process or metabolic change takes place in one or both cells such that A's efficiency, as one of the cells firing $B$, is increased." 3

Para que este fenômeno ocorra são necessários alguns fatores (Brown et al., 1990), como a atividade em dois neurônios conectados, que deve ser ao mesmo tempo. É necessário, também, que haja proximidade entre os neurônios envolvidos na sinapse, ou seja, os dendritos de um neurônio devem estar perto dos axônios do outro. Além disso, o nível de atividade de ambos os neurônios deve ser alta.

\footnotetext{
3"Quando um axônio da célula A está próximo o suficiente para excitar a célula B e, repetidamente ou persistentemente, participa com disparos, algum processo de crescimento ou alteração metabólica acontece em uma ou em ambas as células de modo que o efeito de A sobre B é aumentado." (Tradução nossa).
} 


\section{Capítulo 3}

\section{Redes complexas}

Neste capítulo são apresentadas definições de redes complexas, assim como a bibliografia fundamental para o desenvolvimento do trabalho.

\subsection{Caracterização de redes complexas}

Para representar computacionalmente uma rede complexa é utilizada a estrutura de dados denominada grafo (ou rede). Que é definido por um conjunto de vértices, também chamados de nós, que são interligados entre si por meio de arestas, ou links. A arestas podem possuir algumas características, sendo elas direção e peso.

Uma das possibilidades para armazenar um grafo computacionalmente é a matriz de adjacência, definida por $A$, em que a matriz é quadrada e cada elemento é representado por é $a_{i j}$ (Boccaletti et al., 2006). Desta forma se o vértice $i$ estiver ligado com o vértice $j, a_{i j}$ armazena um valor positivo e maior que zero contendo o peso da aresta, caso contrário possui o valor zero, determinando que não há ligação entre ambos. Além de ser um modo de armazenar a rede computacionalmente, a matriz de adjacência pode ser utilizada, também, para auxiliar na definição de algumas medidas da rede e para a sua visualização.

Um grafo sem peso nas arestas pode ser representado por essa matriz utilizando apenas pelos valores 0 e 1, onde 0 representa a ausência de ligação e 1 representa a presença de um vértice entre as duas arestas. Outra característica é que em uma rede não direcionada 


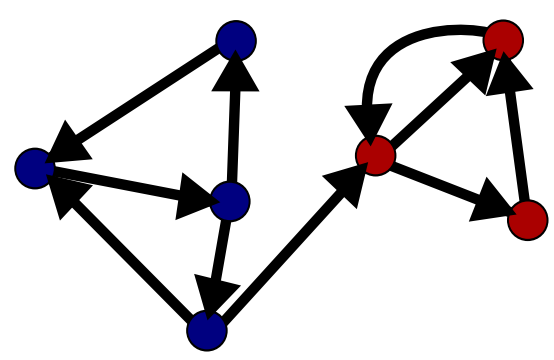

Figura 3.1: Exemplo de rede fracamente conectado, contendo dois componentes fortemente conectados, sendo que cada componente é representado por vértices da mesma cor.

a matriz de adjacência é simétrica.

Considerando rede direcionadas, existem duas definições de componentes conectados, os fortemente conectados e os fracamente conectados (como pode ser visto na Figura 3.1). No componente fortemente conectado, para cada par de vértices $u, v$ existe um possível passeio de $u$ até $v$ e de $v$ até $u($ Harary, 1969). Já no componente fracamente conectado não existe o passeio de $u$ até $v$ ou de $v$ até $u$ para um ou mais pares de vértices (Harary, 1969). Desta forma, em redes não direcionadas há apenas o conceito de componente conectado, sem a distinção entre fortemente e fracamente conectado.

\subsection{Medidas de centralidade}

As medidas de centralidade são utilizadas para caracterizar a importância de um vértice ou uma aresta da rede. Cada uma delas foi desenvolvida para verificar uma característica diferente da rede (Boccaletti et al., 2006). Nesta subseção são apresentadas as medidas de centralidade utilizadas no desenvolvimento do trabalho.

\subsubsection{Medidas de centralidade baseadas no grau}

Entre as medidas de centralidade está o grau $k_{i}$, também chamado de conectividade, que é simplesmente a quantidade de ligações que o vértice possui. Em redes direcionadas o grau pode ser medido considerando apenas os nós de entrada $k^{\text {in }}$ ou de saída $k^{\text {out }}$, já para redes não direcionadas não há distinção (Costa et al., 2007). A Figura 3.2 mostra exemplos do cálculo do grau para a rede não direcionada e para a rede direcionada $\left(k^{i n} \mathrm{e}\right.$ $\left.k^{\text {out }}\right)$. Nas redes ponderadas pode ser considerado o grau com peso, chamado de strength, 


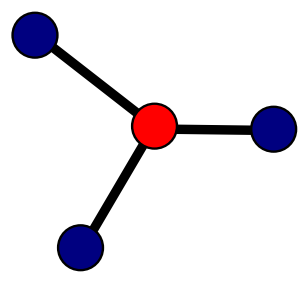

$k=3$

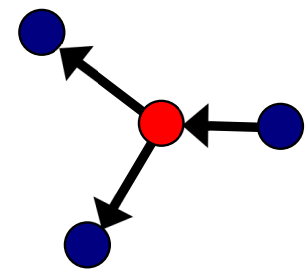

$\mathrm{k}_{\text {in }}=1$

$\mathrm{k}_{\text {out }}=2$

Figura 3.2: Exemplos da medida de grau em redes direcionadas e não direcionada.

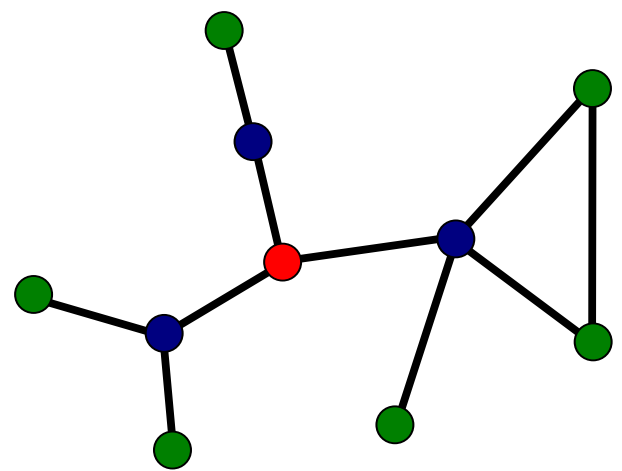

Ordem 0: 3

Ordem 1: 9

Figura 3.3: Exemplo da medida de neighborhood connectivity para o vértice vermelho, onde os vértices azuis são os vizinhos diretos (chamados de ordem 0 ) e os vértices verdes são os vizinhos dos vizinhos (chamados de ordem 1).

que é definido para cada vértice, pela soma dos pesos das arestas conectadas a ele.

Outra medida é o neighborhood connectivity, ou, em português conectividade dos vizinhos, que consiste na quantidade de vértices alcançáveis em um máximo de $h$ passos, chamado de ordem (neste trabalho foi utilizado $h=2$ ). Um exemplo do cálculo do neighborhood connectivity pode ser visto na Figura 3.3. Se $h=0$, o valor de neighborhood connectivity é igual ao grau. Para as rede direcionadas, podem ser considerados apenas os vértices de entrada, ou os vértices de saída.

\subsubsection{Medidas baseadas em ciclos}

Além das medidas baseadas no grau, existem outros tipos de medidas de centralidade, algumas delas analisam a rede de acordo com a quantidade de ciclos. Alguns exemplos de medidas baseadas em ciclo são a transitividade (Newman, 2001a) que é uma análise global da rede e o coeficiente de aglomeração também chamado de clustering coefficient (Watts \& Strogatz, 1998), que é uma medida local. 


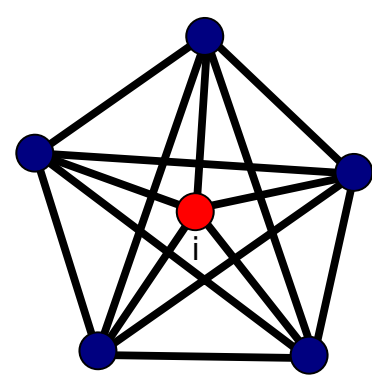

$\mathrm{Cc}_{\mathrm{i}}=1$

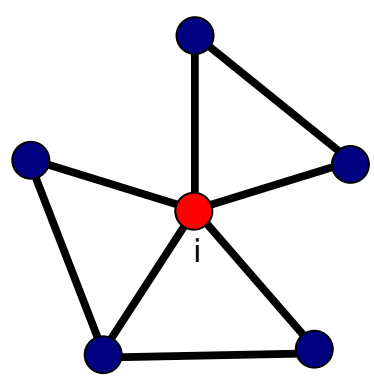

$\mathrm{cc}_{\mathrm{i}}=\frac{3}{10}$

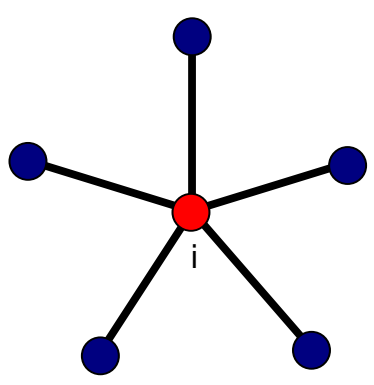

$\mathrm{Cc}_{\mathrm{i}}=0$

Figura 3.4: Exemplos do cálculo de clustering coefficient. Os exemplos mostram o valor do clustering coefficient para o vértice representado pela cor vermelha.

Neste trabalho foi utilizado o coeficiente de aglomeração, esta medida é calculada a partir da quantidade de triângulos e triplas conectadas para cada um dos vértices da rede. Sendo que as triplas conectadas são definidas para cada vértice como um par de vértices conectados a ele, já e os triângulos são triplas conectadas onde este par de vértices está conectado entre si. O coeficiente de aglomeração calcula a fração de triângulos existentes de acordo com todos as possibilidades de triângulos (triplas conectadas), como é mostrado na equação

$$
c c_{i}=\frac{3 N_{\Delta}(i)}{N_{3}(i)}
$$

onde $N_{\Delta}(i)$ representa a quantidade de triângulos conectados ao vértice $i$ e para cada vértice $N_{3}(i)$ representa a quantidade de triplas conectadas no vértice $i$.

A Figura 3.4 mostra três exemplos do cálculo do clustering coefficient. Sendo que a no primeiro exemplo, todas as triplas conectadas também são triângulos, resultado no maior valor possível, que é 1 . No segundo caso, existem 10 triplas conectadas e apenas 3 triângulos, resultando em 3/10, já no último exemplo são 10 triplas conectadas sem a presença de triângulos, resultando no menor valor possível para esta medida, que é 0 .

\subsubsection{Medidas de centralidade baseadas em caminhos}

O comprimento de um caminho é definido como a quantidade de arestas visitadas para chegar de um ponto a outro passando apenas uma vez em cada uma delas Newman, 2001b). Nas redes ponderadas é considerado o somatório dos pesos das arestas. Os menores caminhos entre todos os vértices podem ser representados por meio de uma 
matriz de distâncias. Estas distâncias são chamadas de distâncias geodésicas e o maior entre os menores caminhos da rede é chamado de diâmetro da rede (Boccaletti et al., 2006). Outra medida de caracterização importante é a média da distância dos menores caminhos.

Existem, também, diversas medidas de centralidade que consideram os menores caminhos da rede. Uma medida importante é o stress centrality $\left(S C_{u}\right)$ (Shimbel, 1953). Para cada vértice, o valor do stress é definido como a quantidade de menores caminhos que passam por ele. Esta medida é definida para cada vértice $u$ pela equação

$$
S C_{u}=\sum_{i \neq u \neq j} \sigma(i, u, j)
$$

onde $\sigma(i, u, j)$ é a quantidade de de menores caminhos entre $i$ e $j$ cruzando o vértice $u$. Desta forma, é possível observar que a retirada de um nó da rede pode afetar o stress de todos os demais.

Outra medida é o betweenness centrality (Freeman, 1977), que também considera a quantidade de menores caminhos que passam por um determinado vértice. Esta medida é definida por

$$
B_{u}=\sum_{i \neq u \neq j} \frac{\sigma(i, u, j)}{\sigma(i, j)},
$$

sendo $\sigma(i, j)$ é a quantidade total de menores caminhos entre $i$ e $j$. A Figura 3.5 mostra um exemplo de rede, onde o vértice destacado é o que possui o maior valor de betweenness centrality, pois este vértice conecta as duas comunidades da rede.

Devido ao alto custo computacional para medir todos os menores caminhos, foi desenvolvido um algoritmo rápido para calcular o betweenness centrality (Brandes, 2001, 2008). Por meio dele, também é possível encontrar o stress centrality.

A medida de Betweenness Centrality é frequentemente utilizada em estudos de fluxos em redes Newman, 2005, Borgatti, 2005, Freeman et al., 1991) e pode ser utilizada em muitas aplicações. Em redes sociais é utilizada para descrever trocas de mensagens, considerando que a comunicação ocorre por meio do caminho mais curto (Newman, 2010). Em redes de energia elétrica, o betweenness centrality pode quantificar a carga de cada 


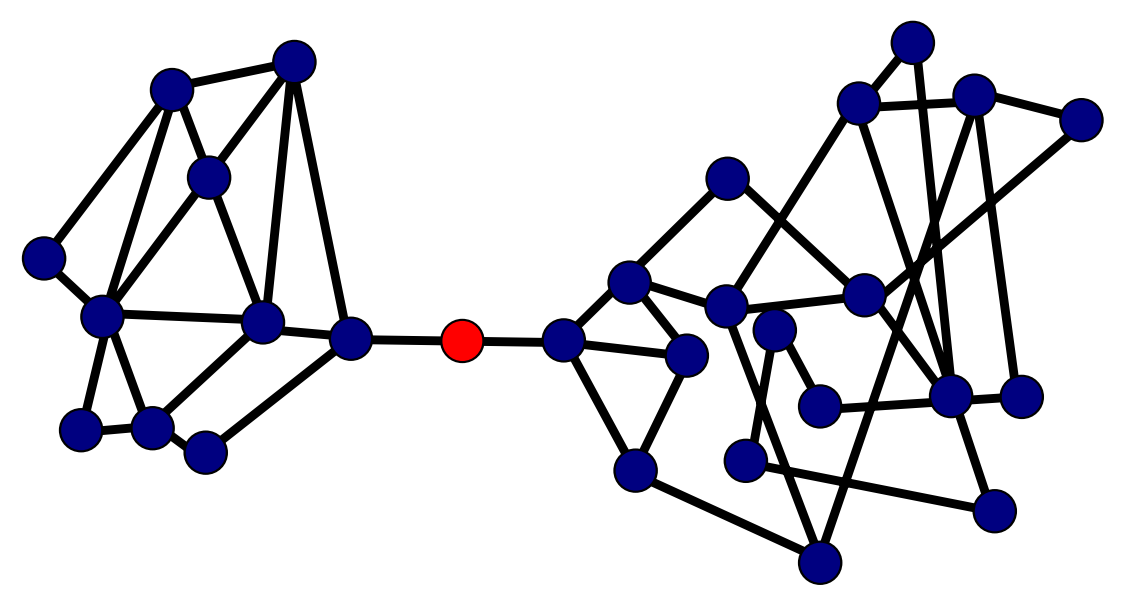

Figura 3.5: Exemplo da medida de betweenness centrality onde o vértice vermelho, que está conectando duas comunidades distintas, é o mais central.

vértice (Motter \& Lai, 2002). Além disso, este conceito também é aplicado na dinâmica de falha em cascata (Motter \& Lai, 2002, Mirzasoleiman et al., 2011).

Neste trabalho, a medida de Betweenness Centrality foi utilizada tanto para caracterizar redes neuronais quanto para descrever um fenômeno encontrado em redes geográficas, que são redes nas quais as posições dos vértices estão associadas com coordenadas espaço e as arestas estão relacionadas com a posição dos vértices.

O mesmo conceito aplicado ao Betweenness Centrality pode ser aplicado nas arestas da rede, assim, são utilizados os menores caminhos que passam por uma determinada aresta, este método é conhecido como Edge Betweenness Centrality (Newman \& Girvan, 2004).

Assim como o Betweenness Centrality, a medida de Closeness Centrality (Newman, 2010) também considera os menores caminhos da rede e é definida por

$$
C_{i}=\frac{N}{\sum_{j} d_{i j}},
$$

onde $N$ é o número de vértices e $d_{i j}$ é a menor distância entre os vértices $i$ e $j$. A Figura 3.6 mostra o exemplo de uma rede no formato de uma árvore (sem ciclos). Assim, é possível observar que o vértice mais central é a raiz.

Outra medida baseada em caminhos é a excentricidade (do inglês eccentricity), que é calculada para cada um dos vértices do grafo. Esta medida é definida como o maior valor 


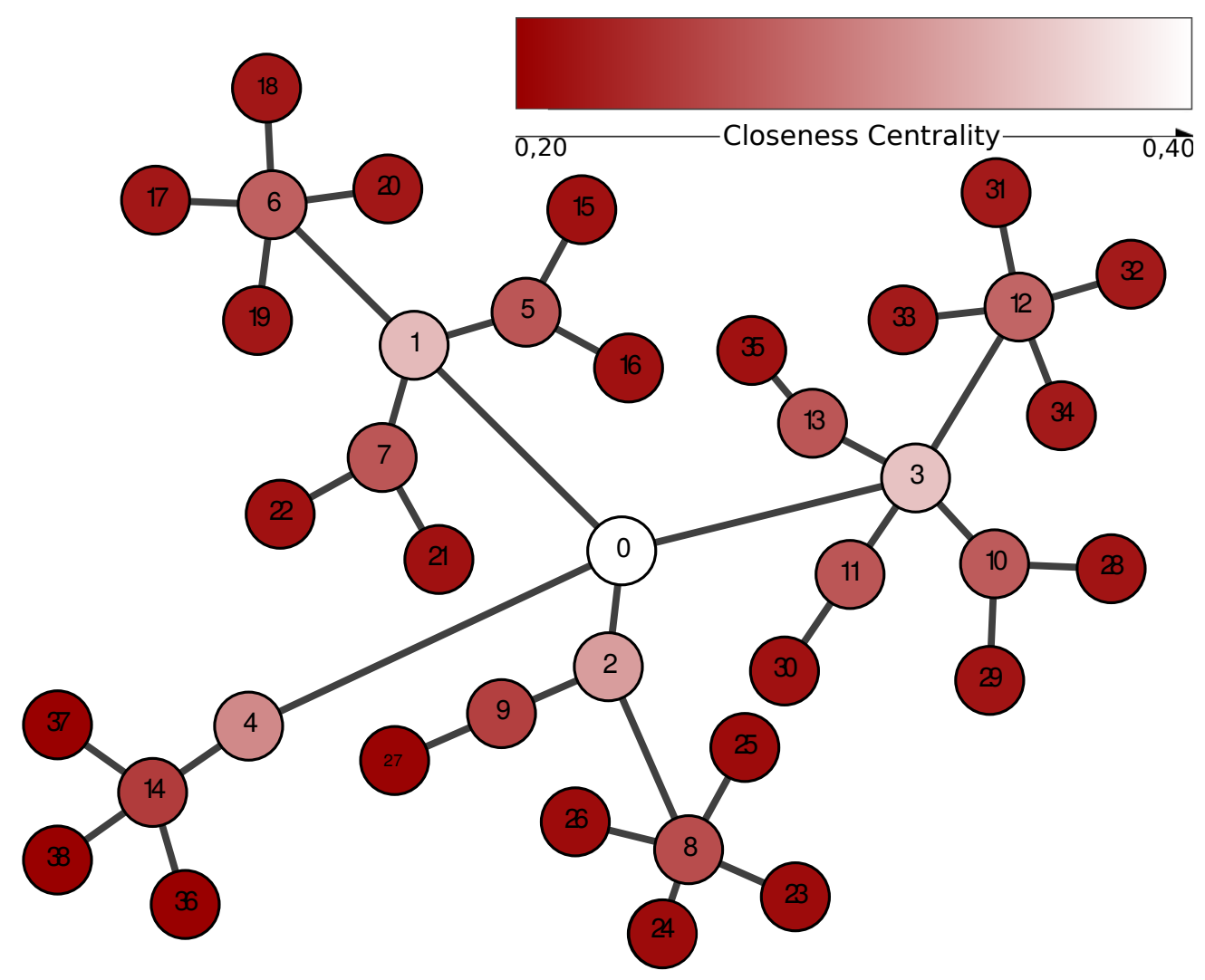

Figura 3.6: Exemplo da medida de Closeness Centrality onde os valores para cada vértice são representados de acordo com o mapa de cor.

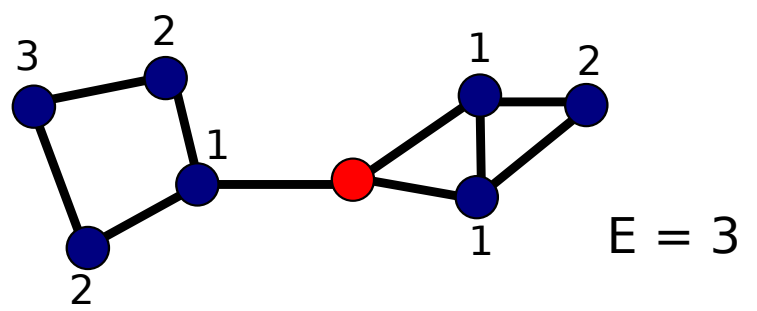

Figura 3.7: Exemplo da medida de excentricidade para o vértice representado pela cor vermelha. Para cada vértice, os valores representam a distância entre cada um deles e o vértice vermelho.

entre todos os menores caminhos Harary (1969) e pode ser descrita como

$$
E_{i}=\max (d(i, j)),
$$

Em uma rede em que exista apenas um componente conectado, utilizando esta medida, o menor valor é considerado como o nó mais central do grafo e o maior valor é o diâmetro. A Figura 3.7 mostra um exemplo desta medida, onde o vértice representado na cor vermelha possui excentricidade igual a um.

Uma aplicação comum para das medidas baseadas em caminhos é o estudo de conges- 
tionamentos de ruas em cidades (Zadeh \& Rajabi, 2013, Crucitti et al., 2006a.b).

\subsection{Comunidades}

Além das medidas de centralidade, outra forma de análise das redes complexas é medir quão modular esta estrutura é, ou seja, quão bem definidas são as comunidade. Uma possibilidade é utilizar o cálculo da modularidade (Newman, 2006), que considera as conexões inter-comunidade e intra-comunidade, ou seja, as conexões entre vértices da mesma comunidade e a conexão entre vértices de comunidades distintas, respectivamente. Esta medida é mostrada por

$$
Q=\frac{1}{2 M} \sum_{i, j}\left(A_{i j}-\frac{k_{i} k_{j}}{2 M}\right) \delta\left(c_{i}, c_{j}\right),
$$

onde $M$ é a quantidade de arestas, $A$ é a matriz de adjacência, $k_{i}$ e $k_{j}$ são os graus dos vértices $i$ e $j$, respectivamente, $c_{i}$ e $c_{j}$ são as comunidades as quais os vértices $i$ e $j$ pertencem e $\delta(x, y)$ é igual a zero se $x \neq y$ e igual a um se $x=y$. Ademais, uma das formas mais conhecidas para encontrar comunidades em uma rede é utilizar a otimização da medida de modularidade. Neste trabalho foi utilizado o algoritmo conhecido como fast greedy (Clauset et al. 2004), que utiliza a abordagem gulosa para otimizar a modularidade.

\subsection{Modelos de redes espaciais}

Além das redes obtidas por meio de sistemas reais, existem também modelos para criar redes aleatórias. Nesta seção serão apresentados dois modelos de redes aleatórias espaciais, que são redes onde os vértices possuem uma dependência espacial, com coordenadas bem definidas e as suas conexões estão relacionadas com a distância entre os vértices (Barthélemy, 2011). 


\subsubsection{Grafo geométrico aleatório}

Um dos modelos utilizados para a criação de redes espaciais aleatórias é o grafo geométrico aleatório (do inglês random geometric graph) (Penrose, 2003). Neste modelo as posições espaciais de um conjunto de $N$ vértices são definidas aleatoriamente em um espaço com uma quantidade pré-definida de dimensões (neste trabalho foram utilizadas duas dimensões). É utilizado um parâmetro para definir a distância de criação das arestas. Assim, as conexões são criadas de acordo com a distância euclidiana entre os vértices, ou seja, é medida a distância entre todos os pares de vértices, se esta é menor ou igual ao valor do parâmetro a aresta é criada.

\subsubsection{Modelo de Waxman}

Outro modelo, que é muito utilizado na geração de redes aleatórias espaciais, é conhecido como modelo de Waxman (Waxman, 1988). Assim como no modelo do grafo geométrico aleatório, os vértices são organizados aleatoriamente no espaço, todavia as conexões são criadas de acordo com uma probabilidade, que decai exponencialmente de acordo com a distância, conforme a equação

$$
p=\alpha \exp (-d /(\beta L))
$$

onde $\alpha$ e $\beta$ são parâmetros do modelo, possibilitando um ajuste da curva de acordo com o desejado, $d$ é a distância euclidiana e $L$ é máxima distância entre todos os vértices da rede.

\subsection{Processos dinâmicos}

As medidas de propriedades topológicas das redes são muito importantes para descrever uma rede, mas outra forma de se obter informações sobre o sistema são as simulações de dinâmicas. Assim, cada uma delas pode ser desenvolvida para extrair características específicas do sistema. Existem diversos modelos, entre eles estão os modelos de propaga- 


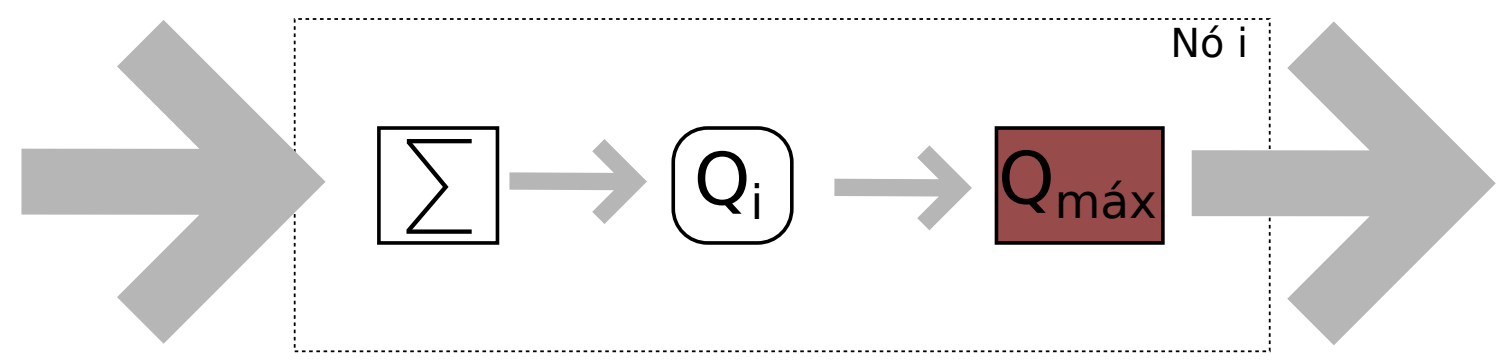

Figura 3.8: Diagrama representando o modelo integra-e-dispara para cada vértice da rede.

ção de epidemias, os mais tradicionais são SI (susceptível - infectado), SIS (susceptível infectado - susceptível) e SIR (susceptível - infectado - recuperado) (Barrat et al., 2008). Outras simulações são os modelos de falha em cascata, onde um dos principais trabalhos é o modelo baseado em sobrecarga (Motter \& Lai, 2002), que serve como base para outros modelos subsequentes. Existem também modelos que tentam imitar comportamentos biológicos dos neurônios, como o modelo integra-e-dispara (Roxin et al., 2004; Guardiola et al. 2000), que consiste em acumular as cargas de cada neurônio (representados pelos vértices) e quando um limiar é atingido o mesmo dispara, carregando seus os vizinhos.

Essas dinâmicas são aplicadas em redes artificiais ou reais sendo utilizadas para fazer simulações, simplificando fenômenos já conhecidos.

\subsubsection{Modelo Integra-e-dispara}

Uma simulação utilizada especificamente para redes neuronais é o modelo integra-edispara, que tenta imitar o comportamento real dos neurônios. Neste trabalho foi utilizada uma abordagem do método de variação discreta no tempo (Roxin et al., 2004; Guardiola et al. 2000 ).

Cada vértice da rede representa um neurônio, que possuí determinadas características. Sendo elas a unidade de soma, que representa a carga que o neurônio recebe, a variável $Q_{i}(t)$, que armazena a carga do neurônio no tempo $t$ e o limiar de disparo $Q_{\max }$, que é o valor no qual o neurônio dispara. Estas unidades são mostradas pelo diagrama da Figura 3.8

No início do algoritmo todos os vértices da rede são iniciados com uma carga $Q_{i}(0)$, geradas por meio de uma distribuição aleatória uniforme, variando no intervalo $\left[0, Q_{\max }\right]$. 
Para cada período de tempo $(t)$ os neurônios que possuem carga igual ou maior que $Q_{\text {max }}$ disparam, assim a carga do mesmo é igualada a zero e todos os seus vizinhos recebem um incremento. A constante $t_{\max }$ define a quantidade de iterações do algoritmo. A partir de determinado período de tempo o sistema tende a entrar em um regime estacionário, ou seja, a quantidade de disparos permanece constante (Roxin et al. 2004, Guardiola et al., 2000).

\subsubsection{Desenvolvimento hebbiano}

O desenvolvimento hebbiano é executado por meio de uma dinâmica integra-e-dispara. A hipótese criada por Hebb (1949) (mostrada na subseção 2.2.3) pode ser representada no tempo discreto de acordo com a equação (Brown et al. 1990)

$$
w_{i j}(t+1)=w_{i j}(t)+\Delta w_{i j}(t)
$$

onde

$$
\Delta w_{i j}(t)=F\left[a_{i}(t), a_{j}(t)\right]
$$

sendo $t$ o passo de tempo, $w_{i j}(t)$ é o peso da sinapse (aresta) entre cada par de neurônios (vértices) $i$ e $j$, onde $i$ e $j$ são os neurônios pré e pós sinápticos, $\Delta w_{i j}(t)$ é o peso da função de variação, $a_{i}(t)$ é a carga do neurônio $i$ na época $T$ (período de tempo) e $F[x, y]$ é uma função que depende da carga dos neurônios.

\subsection{Análise por componentes principais}

A análise por componentes principais, PCA (em inglês Principal Component Analysis), também conhecida como Karhunen-Loève Transform, é um método utilizado para a redução de dimensionalidade por meio de uma transformação linear (Jolliffe, 1986). A partir de um dado conjunto de $m$ elementos e $n$ dimensões é possível criar outro conjunto de $l$ dimensões (com a mesma quantidade de dados $m$ ), sendo $l<n$. Utilizando a técnica PCA, um conjunto de dados é projetado em novos eixos, maximizando a variância. 
Primeiramente é criada a matriz de covariância, sendo que para cada par de dimensões é utilizada a equação

$$
\operatorname{cov}(X, Y)=\frac{\sum_{i=1}^{n}\left(X_{i}-\bar{X}\right)\left(Y_{i}-\bar{Y}\right)}{n}
$$

onde $X_{i}$ e $Y_{i}$ são os elementos da posição $i$ das dimensões $X$ e $Y$, respectivamente e $\bar{X}$ e $\bar{Y}$ são suas respectivas médias. Desta forma, na diagonal principal da matriz de covariância $(K)$ estão presentes as variâncias de cada uma das variáveis.

Primeiramente, são encontrados os autovetores e autovalores da matriz $K$. Assim, é criada a matriz de transformação, onde as linhas da matriz são os autovetores da matriz K. Para reduzir a dimensão é possível selecionar os autovalores principais, ou seja, os maiores autovalores e, assim, utilizar os autovetores associados a eles.

Por fim, a matriz de transformação é multiplicada pelo vetor de atributos, gerando uma nova matriz transformada, em um novo espaço. Desta forma, é possível representar apenas as dimensões mais relevantes, ou seja, as dimensões que possuem uma maior variação.

\subsection{Análise dos resultados}

Os cálculos de correlação e informação mútua são muito importantes, pois por meio deles é possível saber se duas medidas, descritas por variáveis aleatórias, estão captando as mesmas características. Por esse motivo, estas foram as abordagens utilizadas neste trabalho.

\subsubsection{Correlação de Pearson}

Uma forma de determinar a correlação linear entre duas distribuições é o coeficiente da correlação de Pearson (LeBlanc, 2004), que é definido, para um par de variáveis aleatórias por

$$
\operatorname{Cor}_{X, Y}=\frac{E[(X-\bar{X})(Y-\bar{Y})]}{\sigma_{X} \sigma_{Y}}
$$




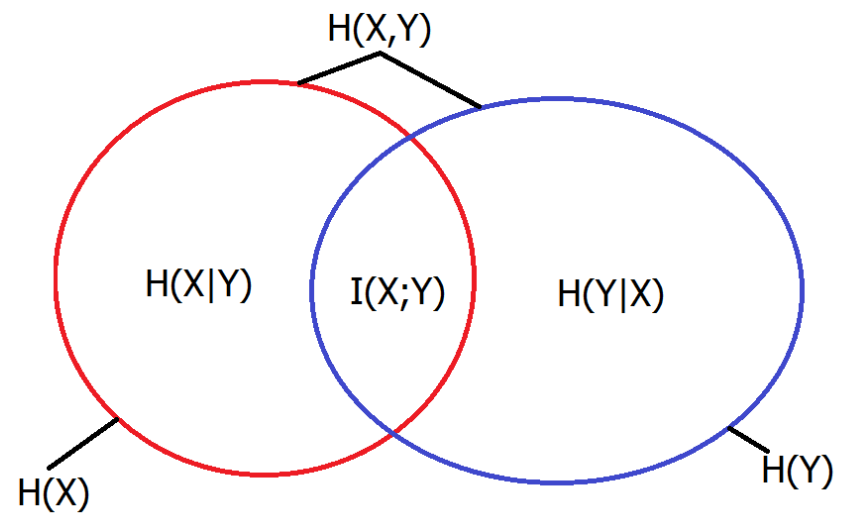

Figura 3.9: Diagrama de venn mostrando a relação entre entropia, entropia condicional e informação mútua.

onde $E[$.] é o operador de esperança, $X$ e $Y$ são as distribuições que estão sendo comparadas e $\bar{X}$ e $\bar{Y}$ são as médias de $X$ e $Y$, respectivamente.

Se o valor do coeficiente de Pearson for igual a zero as variáveis não estão correlacionadas, logo, se o valor for positivo, ou negativo elas estão correlacionadas entre si. Sendo 1 o maior número possível e -1 o menor possível, desta forma, as duas medidas estão totalmente correlacionadas, positivamente se o valor for 1 , ou negativamente se o valor for -1. Desta forma, se os valores de um dos conjuntos de dados aumenta conforme o outro também aumenta, então a correlação de Pearson é positiva, caso contrário, se os valores de um dos conjuntos de dados diminui conforme o outro aumenta, então a correlação de Pearson é negativa.

\subsubsection{Informação mútua}

A medida de informação mútua quantifica a informação que está contida em uma variável aleatória de acordo com outra. Ela está relacionada com outras medidas originadas da teoria da informação, que são medidas de entropia $(H(X))$, entropia conjunta $(H(X, Y))$ e entropia condicional $(H(X \mid Y))($ Cover \& Thomas, 2006). A Figura 3.9 mostra a relação entre estas medidas por meio do diagrama de venn.

O conceito de entropia da informação é originado da termodinâmica e mede a desordem de um sistema. Além disso, esta medida pode ser utilizada, também, para medir a incerteza de uma variável aleatória (Cover \& Thomas, 2006). 
O cálculo da entropia é definido como

$$
H(X)=-\sum_{k} p(x) \log p(x)
$$

onde $X$ é uma distribuição discreta e $p(x)$ é a probabilidade de ocorrer $x$ em $X$. É possível observar que o máximo valor da entropia é obtido quando a distribuição é uniforme e o mínimo valor é obtido quando todos os elementos de $X$ possuem o mesmo valor.

De modo semelhante ao $H(X)$ e considerando que $X$ e $Y$ são distribuições discretas e $p(x, y)$ é a probabilidade de ocorrer $x$ e $y$ conjuntamente é possível encontrar a entropia conjunta, por meio da equação

$$
H(X, Y)=-\sum_{x \in X} \sum_{y \in Y} p(x, y) \log p(x, y)
$$

Além dessas medidas, é necessário calcular, também, a entropia condicional, que é definida como

$$
H(Y \mid X)=H(Y, X)-H(Y)
$$

A Figura 3.9 mostra a relação entre todas as medidas, por meio dela é possível perceber que a partir dos cálculos de entropia $(H(X))$, entropia conjunta $(H(X, Y))$ e entropia condicional $(H(X \mid Y))$, é encontrada a informação mútua, como é mostrado na equação

$$
I(X, Y)=H(Y)-H(Y \mid X)=H(X)-H(X \mid Y) .
$$

Dessa forma sabe-se que $I(X, Y)=I(Y, X)$, diferente do cálculo de entropia condicional a ordem das distribuições não altera o resultado. Assim é possível medir quanta informação está contida em ambos os conjuntos, ou seja, se o resultado for zero as variáveis não possuem nada em comum e quanto maior o valor elas possuem mais informação em comum. O valor máximo de $I(X, Y)$ é o mínimo entre $H(X)$ e $H(Y)$. Por este motivo, pode ser feita uma normalização do resultado obtido, para que o mesmo varie entre 0 e 1 , por meio da divisão do mesmo pelo mínimo valor entre $H(X)$ e $H(Y)$ (esta normalização foi utilizada nos resultados deste trabalho). 


\section{Capítulo 4}

\section{Framework para a análise do}

\section{relacionamelto da expressão gênica}

A expressão gênica é um fator importante para a definição da morfologia, topologia e dinâmica do sistema neuronal, todas elas foram estudadas e descritas na literatura, no entanto elas foram estudadas separadamente. Este trabalho consiste em iniciar um arcabouço para modelar e simular a integração entre todas as etapas e mensurar o relacionamento entre elas.

Estre trabalho consiste em seguir as etapas do pipeline utilizado por Miazaki (2012), que são: expressão gênica, morfologia, topologia e dinâmica. Contudo, estas etapas foram estendidas para incorporar novas características e medidas diferentes.

A Figura 4.1 mostra todas as etapas, onde é possível observar que há uma influência direta entre as etapas adjacentes e indireta entre as demais. No trabalho proposto por Miazaki (2012) é considerado apenas o sentido da esquerda para a direita, onde a etapa de expressão gênica influencia todas as demais, sendo diretamente sobre a morfologia e indiretamente sobre as outras. A morfologia, por sua vez, influência diretamente a topologia e , por fim, a topologia influência a dinâmica. Diferente do que foi apresentado no trabalho proposto por Miazaki (2012), neste trabalho foi estudada, também, a influencia da dinâmica na topologia da rede, ou seja, também foi considerado o sentido da direita para a esquerda. 


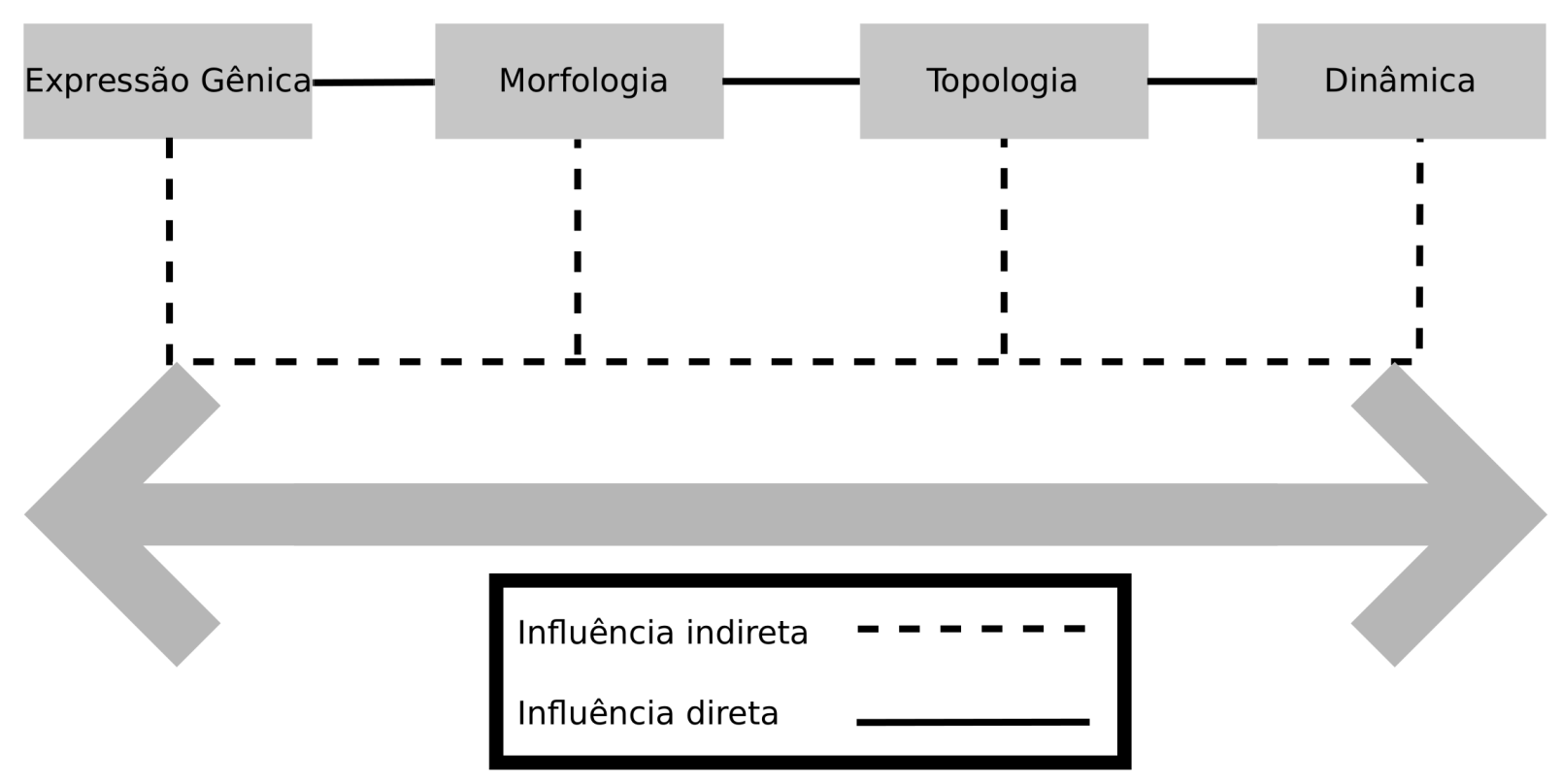

Figura 4.1: Pipeline de desenvolvimento do trabalho. A seta mostra que os passos podem ocorrer tanto da esquerda para a direita, quanto da direita para a esquerda.

\subsection{Modelo de criação de forma neuronal}

Existem diversos modelos computacionais para a criação de neurônios artificiais (Carnevale \& Hines, 2006), sendo que eles podem ser utilizados para a criação de redes neurais artificiais, ou para simulações computacionais com o intuito de melhorar o entendimento sobre a neurobiologia.

Segundo Haykin (1999), para os estudiosos das ciências exatas é importante compreender os sistemas neurais, pois a criação de redes neurais artificiais pode ser baseada neles. O cérebro possui processamento paralelo e é tolerante a falhas, características estas que são extremamente importantes para os sistemas computacionais. Em contrapartida, os neurocientistas utilizam o estudo das redes neurais artificiais para tentar compreender melhor os fenômenos neurobiológicos.

\subsubsection{Criação de neurônios artificiais}

Um modelo de criação de neurônios, que pode ser utilizado na compreensão de sistemas reais, foi descrito por Costa et al. (2010) e Miazaki (2012) e consiste em criar estruturas no formato de árvores, gerando neurônios genéricos, ou seja, possuindo características presentes em diversos tipos. 
O neurônio é iniciado com um ramo, representado por um segmento de reta de tamanho unitário, e é repetido $N_{b}$ vezes, sendo que $N_{b}$ é definido de forma aleatória, em uma distribuição uniforme, no intervalo $[1,8000]$.

No final de cada um dos ramos são criados dois novos, que são coplanares entre si, sendo simétricos os ângulos entre ambos os novos segmentos e o anterior. O ângulo de bifurcação $\theta$ entre eles é uma variável aleatória normal, definida pela função

$$
\rho(\theta)=\frac{1}{\sqrt{2 \pi \sigma_{\theta}^{2}}} \exp \left[-\frac{(\theta-\bar{\theta})^{2}}{2 \sigma_{\theta}^{2}}\right]
$$

sendo que $\bar{\theta}$ é a média de $\theta$, e $\sigma_{\theta}^{2}$ é a variância da distribuição.

Para gerar árvores tridimensionais também foi utilizada a Equação 4.1. Assim, de forma semelhante a anterior, a rotação dos segmentos de reta considera uma terceira dimensão, com o ângulo $\varphi$ (que substitui $\theta$ na equação), sendo que este varia no intervalo $\left[-\varphi_{*}, \varphi_{*}\right]$. Assim, também é possível criar neurônios planares, se o valor de $\varphi$ for igualado a zero.

Um dos dois segmentos formados pode ser removido, de acordo com uma probabilidade uniforme $p_{r}$. Desta forma, é possível criar ramos com curvaturas. O tamanho de cada um dos segmentos é calculado de acordo com uma distribuição de probabilidades uniforme e discreta $l_{i}$, com valor máximo definido por $l_{\max }$.

Nos trabalhos de Costa et al. (2010) e Miazaki (2012), os parâmetros de criação dos neurônios artificias foram obtidos por meio da base de dados de neurônios reais $\mathrm{Neu}$ roMorpho. Em todas as medidas apresentas por esse trabalho os resultados do modelo são muito próximos dos dados reais. Sendo que consistem em número de bifurcações, número de ramos, ordem dos ramo, ângulo de bifurcação remoto e, também, foram definidas medidas L1, L2 e L3, que representam Altura/Largura, Profundidade/Largura e Profundidade/Altura, respectivamente. 


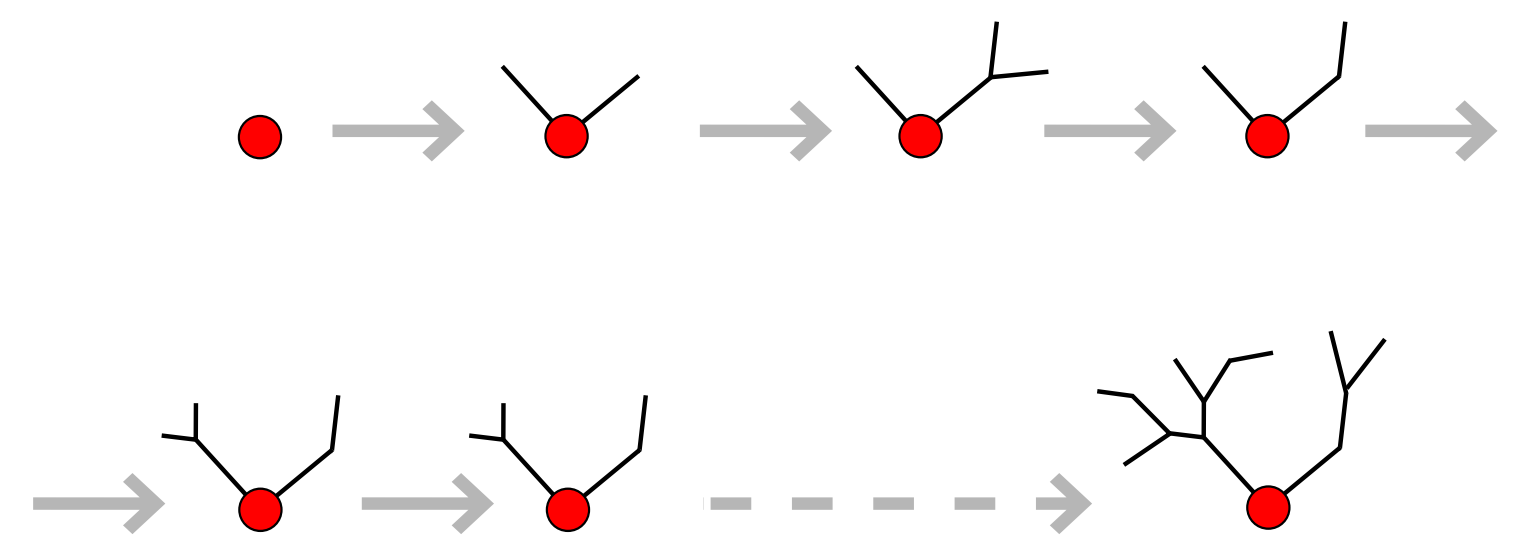

Figura 4.2: Exemplo de construção de um neurônio artificial. O círculo vermelho representa o primeiro segmento de reta, que é o soma do neurônio.

\subsubsection{Adaptações do modelo de criação da forma neuronal}

Foi feita uma modificação no modelo descrito na subseção anterior, que consiste na implementação de uma forma diferente de finalizar o crescimento dos dendritos. Ao invés de utilizar a quantidade de ramos, o crescimento é realizado com base na quantidade de compartimentos. Esta limitação segue os valores dos neurônios reais, ou seja, a quantidade máxima de compartimentos é escolhida aleatoriamente respeitando a distribuição real.

Outra modificação feita no modelo mostrado anteriormente, foi a incorporação da quantidade de troncos, como mais uma característica dos neurônios artificiais. Esta característica também foi baseada nos valores dos neurônios reais. Desta forma, os neurônios, que anteriormente tinham o formato de árvores com apenas uma bifurcação inicial, passaram a possuir quantidades variadas de troncos. Possibilitando uma forma diferente de preenchimento do espaço.

O ângulo inicial entre os troncos e primeiro segmento gerado foi criado pelas regras de expressão gênica que serão apresentadas na próxima seção. A Figura 4.2 mostra um exemplo de construção do neurônio, sendo que o primeiro segmento de reta (soma) é representado por um círculo vermelho. 


\subsubsection{Expressão gênica aplicada ao modelo de criação da forma neuronal}

Para simular a expressão gênica foram criadas regras empíricas de crescimento dos neurônios, que variam de acordo com valores da variável $\eta$, que é uma variável de intensidade de expressão gênica, que pertence ao intervalo $[0,1]$.

A regra para remoção de ramos foi modificada de acordo a equação

$$
p r_{2}=p r(1-\eta),
$$

onde $p r_{2}$ é o valor de $p r$ (probabilidade de remoção) para o neurônio modificado pela expressão gênica.

A expressão gênica também modifica o ângulo entre os ramos, de acordo com a equação

$$
\overline{\theta_{2}}=\eta \bar{\theta},
$$

onde $\overline{\theta_{2}}$ representa o novo ângulo médio para os neurônios modificados pela expressão gênica. A mesma equação é usada para definir o ângulo de rotação médio $(\bar{\varphi})$, que é representado por $\bar{\varphi}_{2}$.

Por fim, também foi definida a influência da expressão gênica nos ângulos de bifurcação entre os troncos dos neurônios. Primeiramente, foi definido o intervalo de ângulos nos quais os troncos foram gerados, de acordo com a expressão gênica, como é mostrado na equação

$$
\alpha_{\max }=2 \eta \pi
$$

desta forma, o intervalo de ângulos entre os troncos é $\left[0, \alpha_{\max }\right]$, ou seja, o valor de $\alpha_{\max }$ define o maior ângulo possível entre os troncos, variando de acordo com $\eta$.

Outros valores que foram fixados empiricamente são:

- Desvio padrão dos ângulos de bifurcação $\left(\sigma_{\theta}\right)$ : valor sorteado em uma distribuição uniforme no intervalo $[0, \pi / 3]$; 


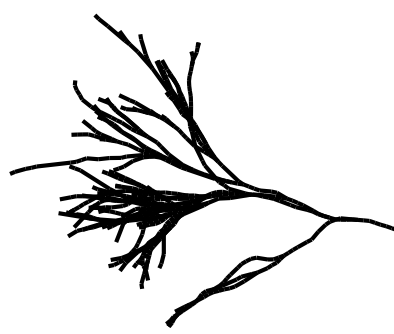

0,01

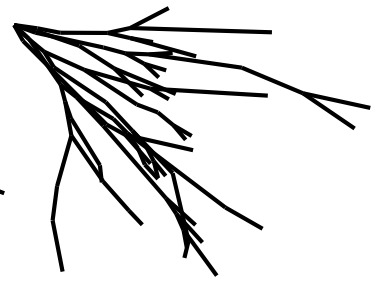

0,20

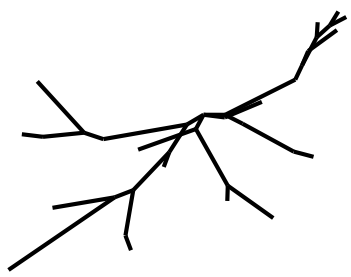

0,40

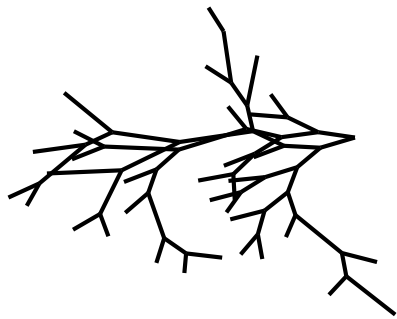

0,60

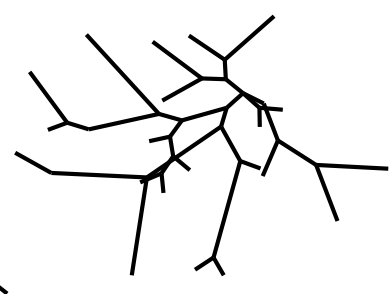

0,80

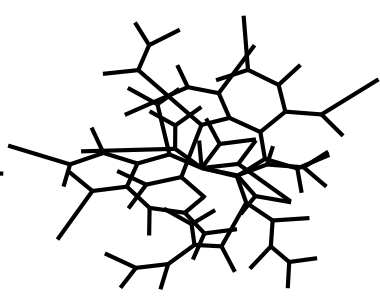

1

Figura 4.3: Exemplos de neurônios de acordo com os respectivos valores de $\eta$.

- Ângulo de bifurcação médio $(\bar{\theta}): 5 \pi / 9$;

- Intervalo do ângulos de bifurcação: $[0, \pi]$;

- Desvio padrão dos ângulos de rotação $\left(\sigma_{\varphi}\right)$ : valor sorteado em uma distribuição uniforme no intervalo $[0, \pi / 9]$;

- Ângulos de rotação médio $(\bar{\varphi}): 2 \pi / 9$;

- Intervalo do ângulos de rotação: $[-\pi, \pi]$.

Com este modelo, o formato dos neurônios é modificado de acordo com a variação do valor de $\eta$. É possível observar que quanto menores os valores de $\eta$, os neurônios ficam mais alongados (como pode ser visto na Figura 4.3).

\subsection{Geração de rede a partir de sinapses}

Os neurônios consistem nos componentes que formam uma rede neuronal, ou seja, cada um deles representa um vértice e as sinapses formam as arestas. Os seus tamanhos e 


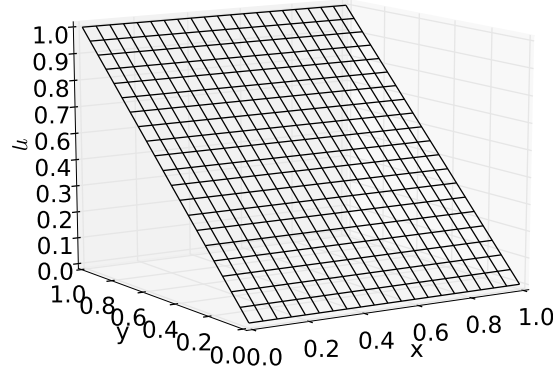

(a)

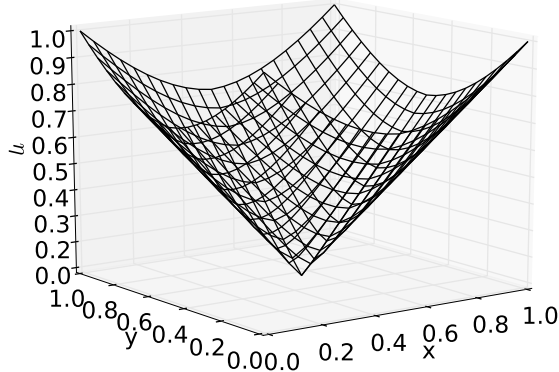

(b)

Figura 4.4: Padrões de expressão gênica utilizados nos testes, o item (a) representa o padrão plano e o item (b) representa o padrão circular.

formas são fatores importantes para a criação da topologia, pois é partir da ligação entre dendritos e axônios que as sinapses são definidas.

Para testar a expressão gênica, foram criados dois padrões distintos, ambos são grades quadradas com os lados de tamanho cem. O primeiro padrão é chamado de plano, cada uma das suas colunas possui um valor distinto, que varia de forma linear entre zero e um, como pode ser observado na Figura 4.4(a). O segundo padrão é chamado de circular e foi criado utilizando a distância de cada ponto até o ponto central, neste caso o ponto central possui valor zero e os quatro cantos possuem valor um, como é mostrado pela Figura $4.4(\mathrm{~b})$.

A partir dos padrões de expressão gênica foram criados os neurônios, no total de 10000 para cada padrão. Primeiramente, os neurônios foram normalizados para não ser levado em consideração o tamanho de cada um deles, apenas a sua forma, que é a característica estudada neste trabalho. Para isto foi aplicado o PCA, que encontra o sentido de maior dispersão, como pode ser visto na Figura 4.5. Desta forma, os valores de todas as coordenadas do neurônio foram divididas pelo desvio padrão da componente principal, ou seja, a raiz quadrada do maior autovalor. Na Figura 4.6 há alguns exemplos de neurônios normalizados. Utilizando esta metodologia, não foi necessário o uso de uma unidade de medida, pois os dados podem ser considerados adimensionais.

É importante ressaltar que com este tipo de normalização os neurônios finais não 


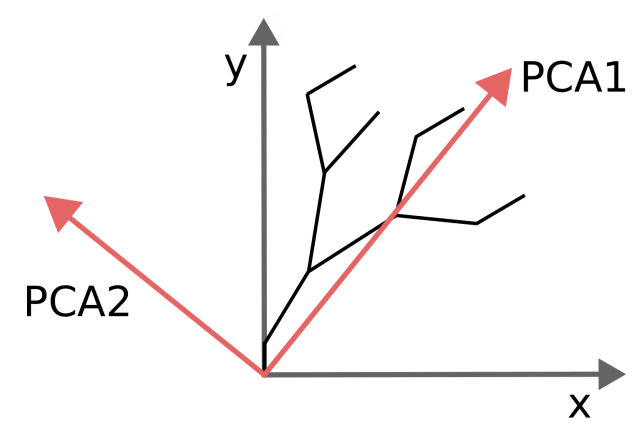

Figura 4.5: Exemplo do PCA aplicado em um neurônios.
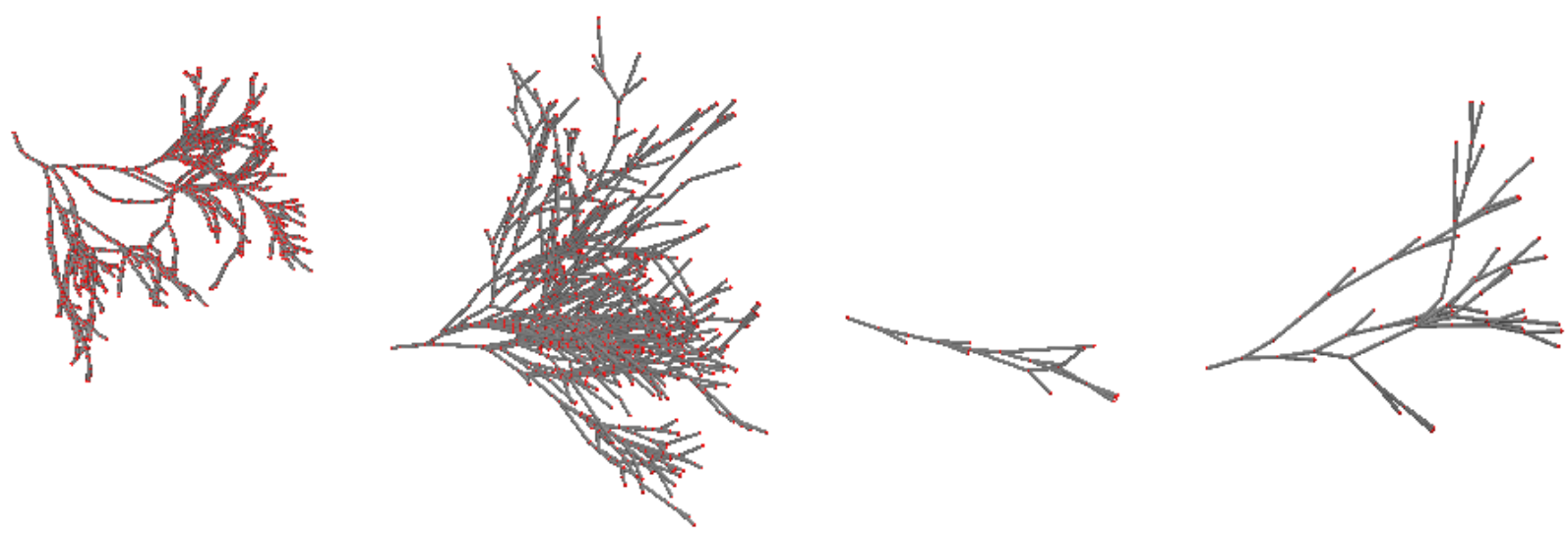

Figura 4.6: Exemplos de neurônios normalizados.

possuem o mesmo diâmetro, pois a normalização considera o desvio padrão dos pontos formados pelas coordenadas iniciais e finais de cada compartimento.

Para os dois casos, os neurônios foram colocados em uma grade regular (plana e circular) de dimensão 100x100, desta forma, o neurônio de cada uma das posições foi gerado utilizando o valor de $\eta$ da sua respectiva grade. O soma de cada um deles foi localizado no centro da sua célula, ou seja, as distâncias entre o soma de cada neurônio e os seu vizinhos também são unitárias.

As ligações entre os neurônios da rede foi baseada nas sinapses, respeitando o sentido dos disparos dos neurônios (dendritos $\rightarrow$ soma $\rightarrow$ axônio). Foi convencionado que a sinapse ocorre quando um dendrito está próximo do soma de outra célula neural, com uma determinada distância menor ou igual a $d_{s}$ (foi utilizado $d_{s}=1 / 5$ neste trabalho). Assim, os axônios são representados por uma esfera ao redor do soma, para simplificar o modelo. A Figura 4.7 mostra um exemplo de rede e seus respectivos neurônios.

Para criar as ligações entre os pares de neurônios, foram feitas medidas de distância 


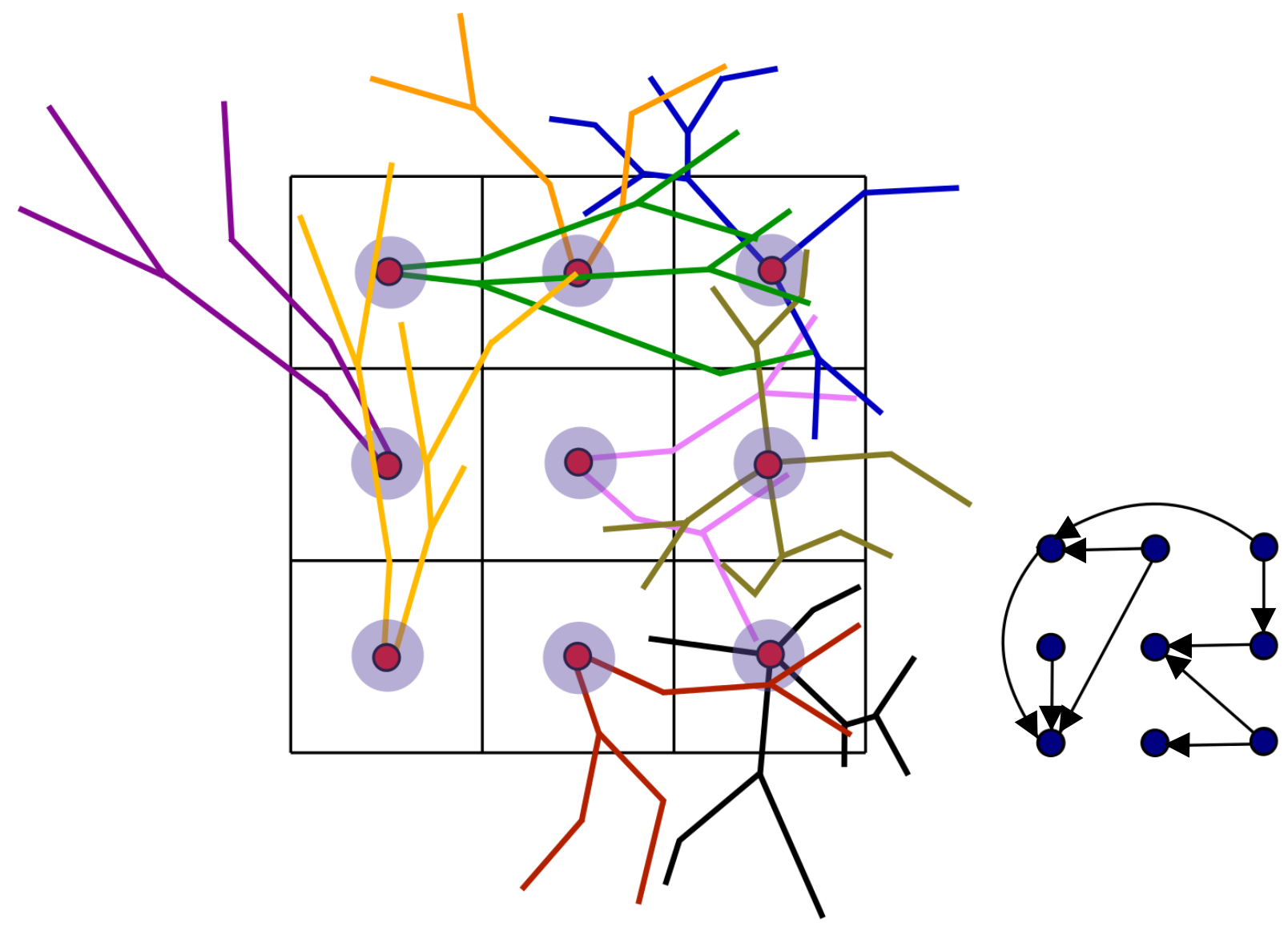

Figura 4.7: Exemplo da formação da rede de acordo com as sinapses.

entre o soma de cada um dos neurônios e os conjuntos de segmentos de retas (compartimentos) de todos os demais. Para cada um dos neurônios, foi feita a distância entre o soma e os pontos extremos de cada segmento de retas dos demais, se a distância entre um determinado ponto e o soma for menor ou igual a $d_{s}$, então a aresta é criada no grafo final. Caso contrário, se estes pontos não são menores que $d_{s}$, então a possibilidade que resta é da reta possuir um ou mais pontos, com a distância menor que $d_{s}$ entre os pontos testados, como é possível observar na Figura 4.8. Por este motivo foi feito o cálculo da distância entre o ponto $S$ a reta $R$

$$
d=\frac{|v \times P S|}{|v|}
$$

onde $P$ é um ponto da reta $R$ e $v$ é o vetor que define a direção da reta. Se esta distância é igual ou menor que $d_{s}$, então são calculados os ângulos entre os pontos extremos do segmento de reta e o ponto, para saber se o ponto pertence ao segmento de reta, por meio 


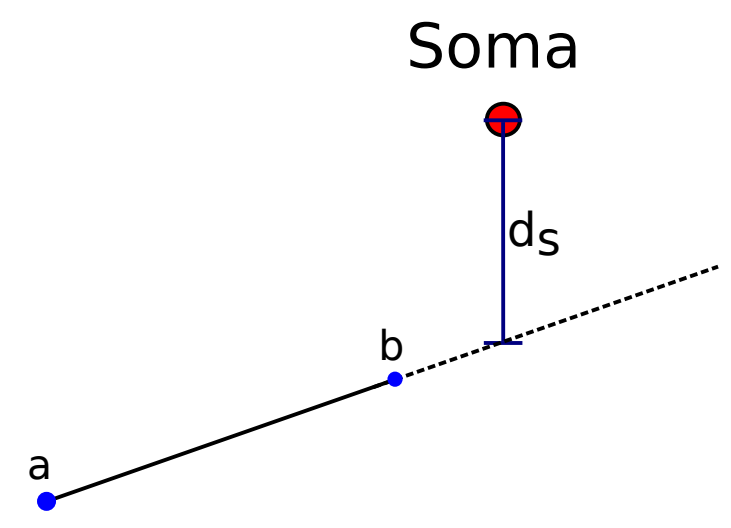

(a)

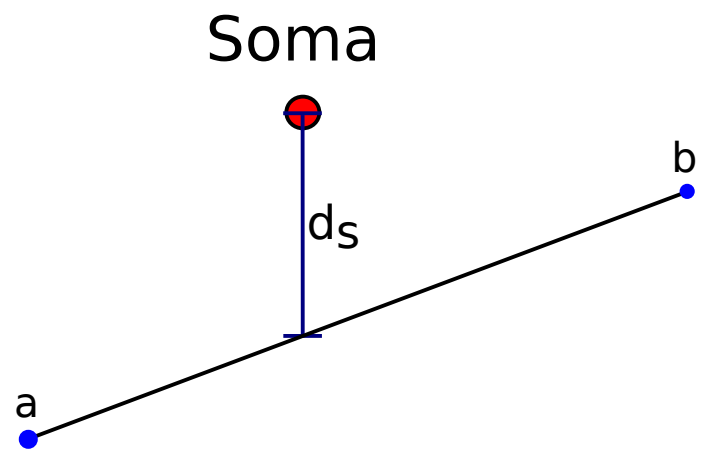

da equação

$$
\theta=\arccos \left(\frac{\langle u, v\rangle}{\|u\|\|v\|}\right)
$$

onde $\langle u, v\rangle$ é o produto escalar entre os vetores $u$ e $v$ e as normas dos vetores, $\|u\|$ e $\|v\|$, que são definidas por

$$
\|v\|=\sqrt{\sum x_{i}^{2}}
$$

sendo que $x_{i}$ são os elementos do vetor $v$. Desta forma se em ambos os ângulos forem maiores ou iguais a $\pi / 2$, então não deve ser criada uma conexão (como mostra a Figura 4.8(a)), caso contrário a conexão é criada (como mostra a Figura 4.8(b)).

Neste trabalho, as rotinas de geração de neurônios e medidas foram implementadas na linguagem python, com o auxílio das bibliotecas Igraph (Csardi \& Nepusz, 2006) e Networkx (Hagberg et al., 2008). Além disso, foi utilizado o Myavi (Ramachandran \& Varoquaux, 2010) para gerar visualizações científicas, como forma de validar o método. Para se obter um melhor desempenho computacional, a geração da rede o foi implementada na linguagem $\mathrm{C}++$, utilizando as bibliotecas GSL (Gough, 2009) e Igraph.

A fim de avaliar a influência da expressão gênica sobre as características neuronais, foram feitas as medidas de correlação e informação mútua, quantificando numericamente os resultados. 


\subsubsection{Medidas topológicas}

Foram feitas diversas medidas topológicas na rede, que estão listadas na Tabela 4.1 .

Tabela 4.1: Medidas de rede utilizadas

\begin{tabular}{c}
\hline Grau de entrada e de saída $\left(k^{\text {in }}\right.$ e $\left.k^{\text {out }}\right)$ \\
Neighborhood connectivity de entrada e de saída \\
Betwenness Centrality \\
Closeness Centrality \\
Excentricidade \\
Clustering Coeficient
\end{tabular}

Para todas as medidas de centralidade, foram gerados mapas de cor possibilitando visualizar os valores e as posições dos seus respectivos vértices e, assim como nas medidas neuronais, foram calculadas a correlação e informação mútua entre todas as medidas de centralidade e os seus respectivos valores de $\eta$.

\subsection{Execução de dinâmicas}

Nesta seção são apresentadas as dinâmicas e os parâmetros utilizados no trabalho.

\subsubsection{Integra-e-dispara}

A partir das redes descritas nas seções anteriores, foram feitas as simulações do modelo integra-e-dispara, descrito na Seção 3.5.1, que consiste em um modelo específico de simulação de dinâmica neuronal. O valor da variável $Q_{\max }$ foi fixado como $Q_{\max }=3$, pois este valor é o número inteiro que mais se aproxima do grau médio das redes testadas.

Computacionalmente foi criada uma matriz de tamanho $T_{\max } \times N$, onde $N$ é a quantidade de vértices da rede e $T_{\max }$ é a quantidade de períodos discretos de tempo, sendo que neste trabalho utilizamos $T_{\max }=1000$. Foram considerados os resultados depois que a dinâmica entra em estado estacionário.

Para caracterizar os resultados foram feitas três medidas: (i) a taxa de disparos, (ii) o maior intervalo entre os disparos e (iii) a entropia dos intervalos entre os disparos. 


\subsubsection{Desenvolvimento hebbiano}

A hipótese criada por (Hebb, 1949) pode ser representada no tempo discreto pela equação 3.8. Neste trabalho foi aplicada a função de variação de peso como

$$
F\left[a_{i}(t), a_{j}(t)\right]=c a_{i}(t) a_{j}(t)-f w_{i j}(t)
$$

onde $c$ é a constante de aprendizagem, $f$ é a constante de esquecimento, $w_{i j}$ é o peso da aresta de $i$ para $j$ e $a_{i}(t)$ é obtida por

$$
a_{i}(t)=\sum_{t-T}^{t} Q_{i}(t)
$$

sendo que $T$ é um a época, ou seja, uma janela temporal.

A dinâmica integrar-e-dispara foi modificada, para considerar as mudanças do peso das conexão descritas pela regra hebbiana. Quando a carga do neurônio $i$ atinge o valor $Q_{\text {max }}$, todos os vizinhos $j$ recebem a carga $w_{i j}(t)$. Além disso, a fim de evitar o resultado trivial, de todos os neurônios da rede disparando após alguns passos de tempo, foi incluída uma perda de carga antes de cada iteração, dada pela equação

$$
Q_{i}(t)=Q_{i}(t-1)-l \frac{\sum_{j \in \mathcal{V}_{i}} Q_{j}(t-1)}{k_{i}^{i n}}
$$

onde $\mathcal{V}_{i}$ é o conjunto dos vizinhos de entrada de $i, k_{i}^{i n}$ é o grau do vértice e $l$ é uma constante de perda de carga $(0<l<1)$.

Na condição inicial, em todas as arestas $w_{i j}(0)=1$. Os valores de $c, f$, e $l$ foram encontrados empiricamente como $c=0.05, f=0.2$ e $l=0.1$.

\subsection{Caminhos do betweenness}

Neste trabalho foi observado um fenômeno particular na medida de betweenness centrality, que consiste na formação de caminhos bem definidos. Estes foram chamados de caminhos do betweenness. Foi feita a medida de betweenness centrality em redes espaciais, utilizando 
um limiar para selecionar os vértices com valores maiores ou iguais a ele, considerando-os como os vértices que pertencem ao caminho (o limiar utilizado foi de 20\%). As redes analisadas foram dois modelos e duas redes de ruas. Sendo o primeiro o modelo de Waxman e o segundo o grafo geométrico aleatório, as redes de ruas foram de San Joaquin County nos Estados Unidos e a cidade de Oldenburg na Alemanha (Brinkhoff, 2002).

Por meio de algumas medidas, foi possível comparar os resultados encontrados nas demais redes com as redes formadas por neurônios. Para mensurar qual a capacidade dos caminhos de cobrir a rede, foi calculada a distância entre todos os vértices (que não fazem parte do caminhos) e os caminhos, gerando um histograma para cada uma delas. Ademais, com o intuito de compreender melhor este fenômeno, foi criado um modelo de uma rede espacial sem pesos e não direcionada, que gera o mesmo efeito. Para criar esta rede, primeiramente define-se algumas variáveis, que são: dimensões (foi utilizada uma grade de tamanho 200 x 200); probabilidade de remover arestas (foi utilizado o valor 0,65); máxima distância de conexão entre dois vértices, foi utilizado o valor $\sqrt{2}$, para que os vértices se conectem apenas com os oito vizinhos mais próximos.

O modelo consiste em executar as seguintes etapas:

- Os vértices são organizados na forma de uma grade, com condição de contorno toroidal;

- Para cada par de vértices $i$ e $j$, onde a distância entre eles é menor que a máxima distância de conexão, é criada uma conexão;

- Os vértices são removidos com uma determinada probabilidade de remoção.

Foi observado empiricamente que os caminhos se formam independente da presença de direção nas arestas da rede, assim o modelo considera a rede como não direcionada. Ademais, foram feitas algumas medidas para cada uma das comunidades da rede, são elas: grau médio da borda geográfica, grau médio da borda topológica, grau médio dos vértices que não fazem parte das bordas, betweenness centrality médio da borda geográfica e betweenness centrality médio da borda topológica.

Foi considerado como borda o conjunto de vértices pertencente a uma determinada 
comunidade, onde cada um dos vértices possui algum vizinho que está em uma comunidade diferente da dele. Desta forma, na borda topológica foram considerados como vizinhos os vértices conectados a pelo menos um vértice de outra comunidade, por meio de uma aresta, já na borda geográfica foram considerados como vizinhos os vértices adjacentes geograficamente (neste trabalho foi considerada a vizinhança dos oito vizinhos mais próximos).

Por meio da rede gerada a partir do modelo, foi criada uma nova rede, formada por comunidades. Neste caso, cada vértice da nova rede representa uma comunidade e o peso das ligações é criado a partir do somatório do stress centrality dos vértices que conectam as comunidades. Assim, apenas os vértices que representam comunidades adjacentes estão conectados.

Por meio desta rede foi possível comparar as características topológicas e geográficas, utilizando algumas medidas espacias: área, perímetro e diâmetro (que é a maior distância entre todos os pares de pontos). Além disso, foram feitas medidas topológicas: grau e strength (que é definido para cada vértice, como o somatório dos pesos de todas as arestas conectadas a ele). 


\section{Capítulo 5}

\section{Resultados e discussão}

Neste capítulo são apresentadas as medidas e simulações feitas em todas as etapas do pipeline de expressão gênica dos neurônios (apresentado na Figura 4.1) em dois casos distintos para exemplificar o funcionamento do framework. A morfologia neuronal, gerando o padrão de conexões, que é caracterizado pelas medidas de centralidade e, também, as simulações de dinâmicas integra-e-dispara e desenvolvimento hebbiano. Com os resultados obtidos em cada uma das etapas, são mostradas as medidas de informação mútua e correlação de Pearson, para quantificar o nível de influência da expressão gênica sobre as demais etapas. Além disso, uma particularidade encontrada na medida de betweenness centrality é descrita e comparada com outros tipos de redes espaciais.

\subsection{Criação das redes utilizando padrões de expressão gênica}

Foram geradas redes a partir dos 2 padrões de expressão gênica que variam os valores de $\eta$ (parâmetro que controla a expressão gênica no modelo de geração de forma neuronal) seguindo os padrões plano e circular, por meio do método descrito na Seção 4.2. A Figura 5.1 mostra a rede gerada pelo padrão de expressão gênica plano (RP) enquanto a Figura 5.2 mostra a rede gerada pelo padrão de expressão gênica circular (RC). Comparando essas imagens com a Figura 4.4, é possível notar que nas regiões onde os valores de 


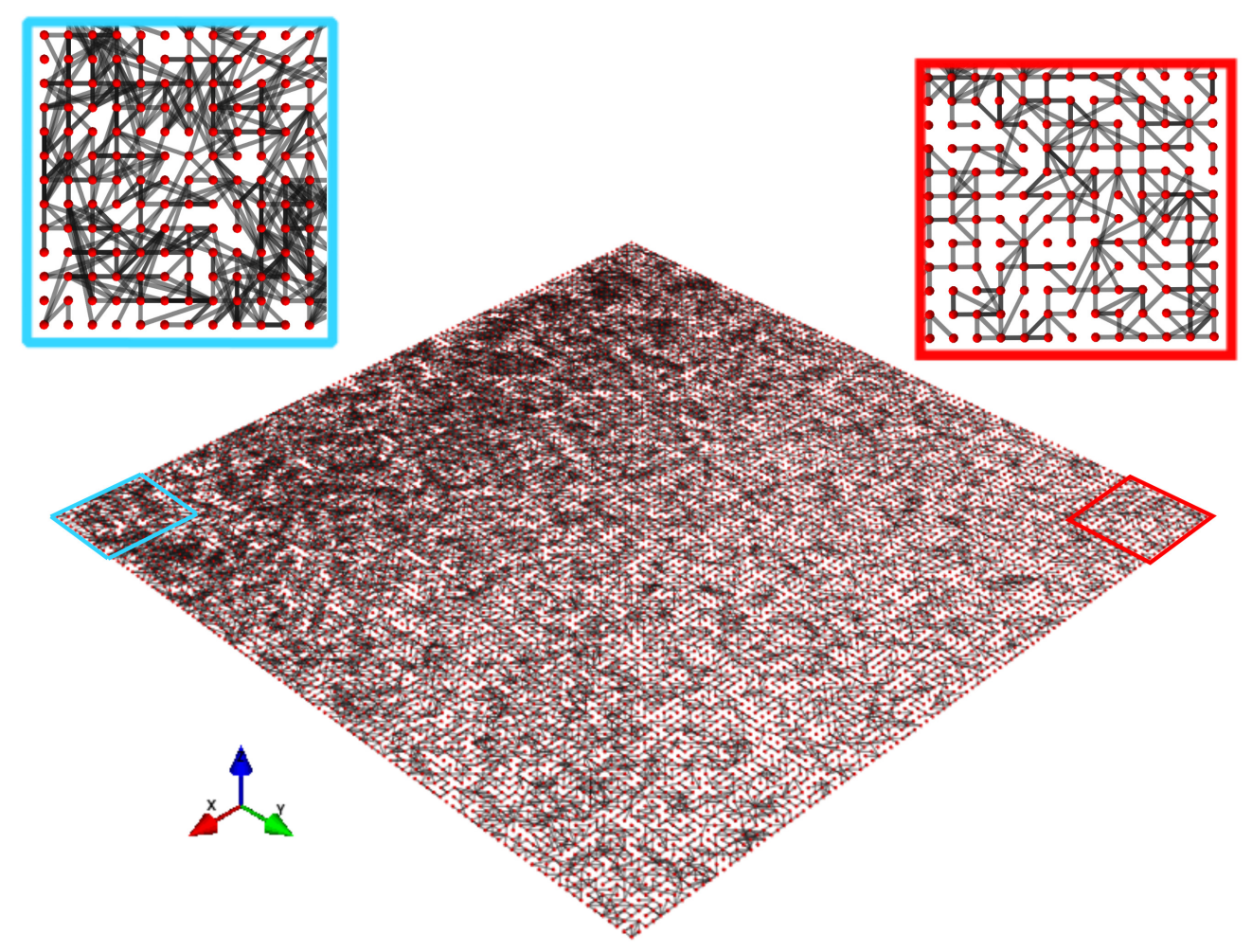

Figura 5.1: Rede gerada por neurônios artificias, utilizando a expressão gênica no padrão plano.

$\eta$ são mais baixos a rede é mais densa.

Uma possível explicação para este fenômeno é que as ligações mais longas, situadas nas regiões com valores de $\eta$ mais baixos, são devido a forma mais alongada dos neurônios, pois como as funções de expressão gênica influenciam o ângulo de abertura entre os ramos, os neurônios que possuem valores mais baixos de $\eta$ tendem a se ligar com outros que estão na mesma direção. Assim, mesmo normalizados e possuindo dimensões semelhantes, os neurônios com valores de $\eta$ mais baixos se conectam os vizinhos mais distantes, pois as suas árvores dendríticas tendem a possuir a mesma direção.

Uma medida utilizada para descrever este padrão de ligações foi o comprimento (distância euclidiana) médio das arestas, que nas regiões com um nível menor de expressão gênica é maior do que nas regiões com expressão maior, como pode ser observado na Figura 5.3(a), para a rede RP e na Figura 5.3(b), para a rede RC. 


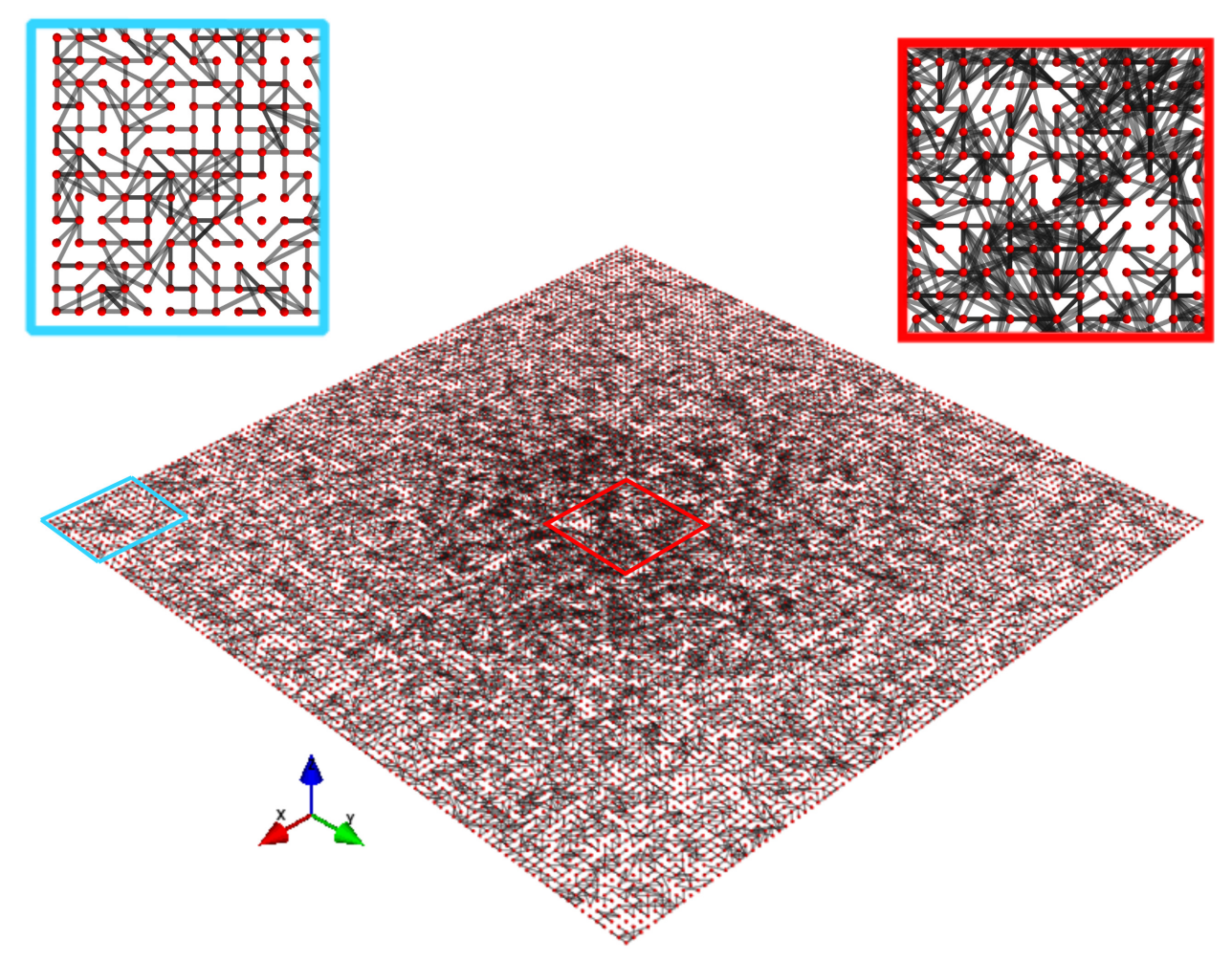

Figura 5.2: Rede gerada por neurônios artificias, utilizando a expressão gênica no padrão circular.

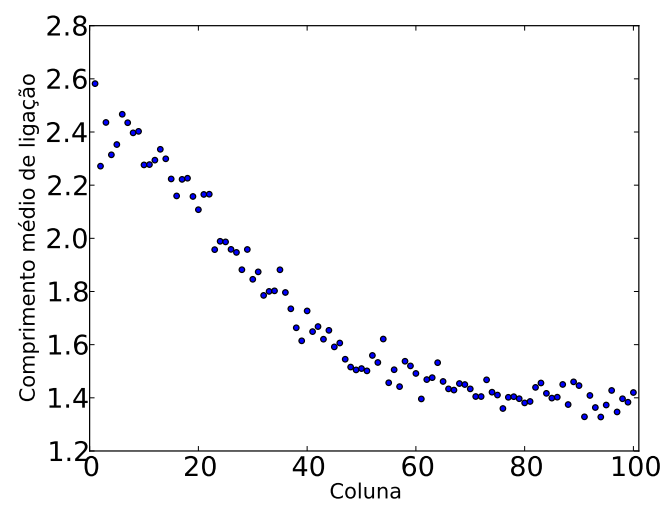

(a) Rede plana.

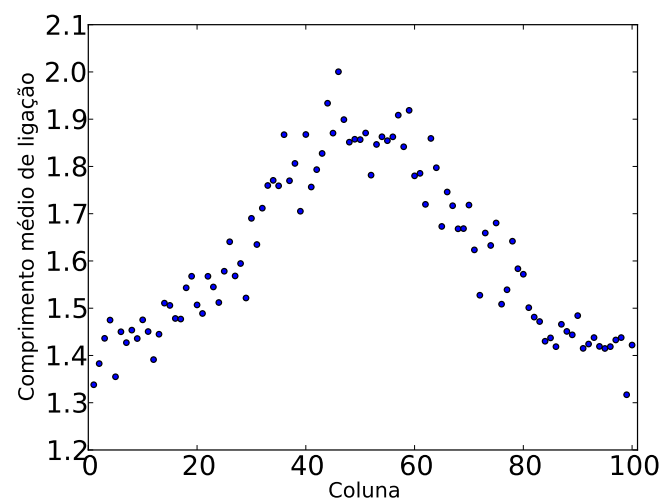

(b) Rede circular.

Figura 5.3: Comprimento médio das arestas (distância euclidiana entre os neurônios que se conectam) por coluna da rede, os neurônios têm uma posição fixa em na grade (nos eixos $x$ e $y$ ), assim, as colunas são os conjuntos de neurônios que possuem a mesma posição no eixo $x$. 


\subsection{Informação mútua e correlação entre expressão gê- nica e características neuronais}

Como mostrado na seção anterior, há indícios de que a rede gerada é influenciada pela forma neuronal. Assim, é necessário entender quais características neuronais são modificadas pela expressão gênica.

No modelo de geração dos neurônios foram criadas funções empíricas, sendo que cada uma delas pode afetar uma ou mais características morfológicas. A medida M1 (média do ângulo de bifurcação local) é diretamente afetada pela função de expressão gênica que gera $\overline{\theta_{2}}$. A medida M2 (média do ângulo de bifurcação remoto) é afetada pela expressão gênica, que gera $\overline{\theta_{2}}, \overline{\varphi_{2}}$ e $p r_{2}$. A medidas M3 (fragmentação) é influenciada apenas por $p r_{2}$. Já as medidas L1, L2 e L3, são influenciadas por todas as funções de expressão gênica.

A relação entre o nível de expressão gênica $(\eta)$ e as medidas morfológicas da rede podem ser vistas nas Figuras 5.4 e 5.5, representando as redes RP e RC, respectivamente. A relação entre a expressão gênica e a morfologia é similar para ambos os padrões de expressão gênica, que é uma consequência da ausência de qualquer interação entre os neurônios vizinhos no modelo de geração da forma.

Visto que não existem interações no momento de geração dos neurônios, um dado nível de expressão gênica irá gerar uma morfologia semelhante, independentemente do padrão global da rede. Entretanto, as medidas RC contém mais flutuações do que para RP, isso ocorre porque a quantidade de amostras para cada um dos níveis de expressão gênica é diferente em RC e igual em RP. Há menos pontos no centro e nas bordas da grade para o padrão de RC, enquanto que para o padrão RP cada uma das colunas da grade possui o mesmo número de pontos para os valores distintos de $\eta$.

Foram calculados os valores de informação mútua entre as medidas de morfologia, para identificar quais as medidas que refletem melhor a influência da expressão gênica (como pode ser visto na Figura 5.6). Os resultados das comparações entre $\eta$ e as medidas neuronais são parecidos nas duas redes (RP e RC). Ao analisar os gráficos juntamente com os valores de informação mútua (Figura 5.6)), para medidas M1, M2 e M3, representadas 


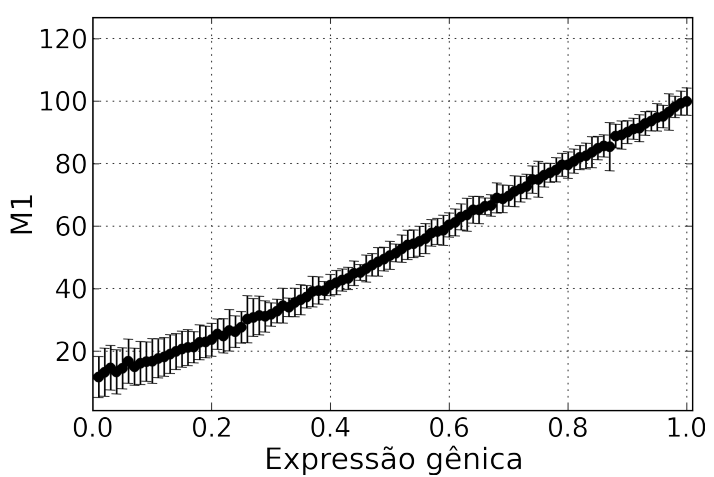

(a)

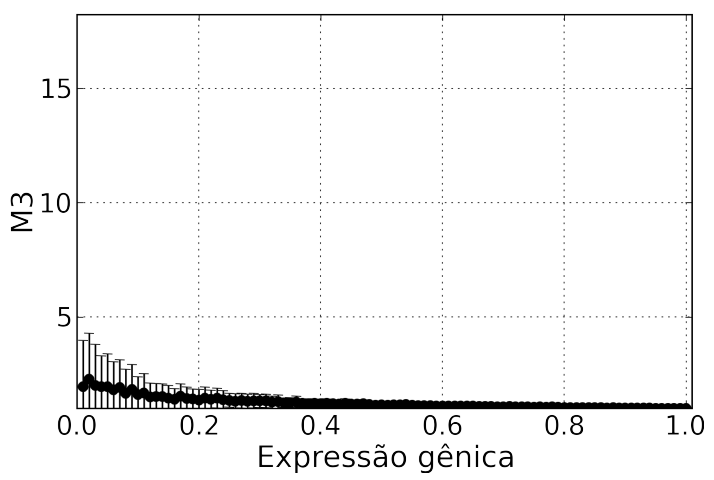

(c)

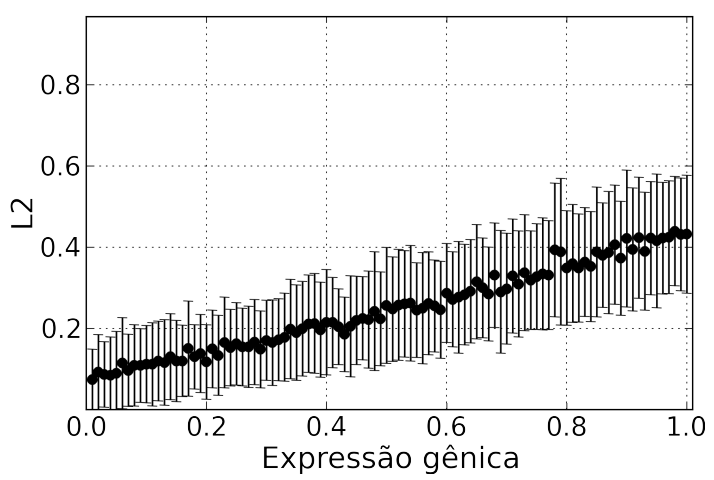

(e)

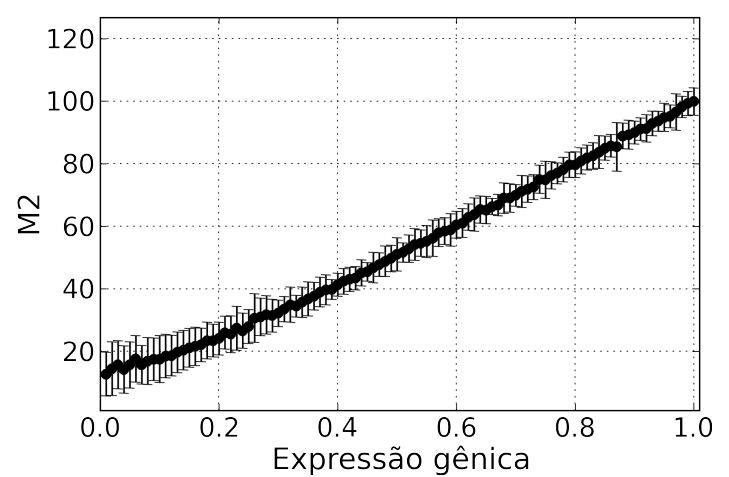

(b)

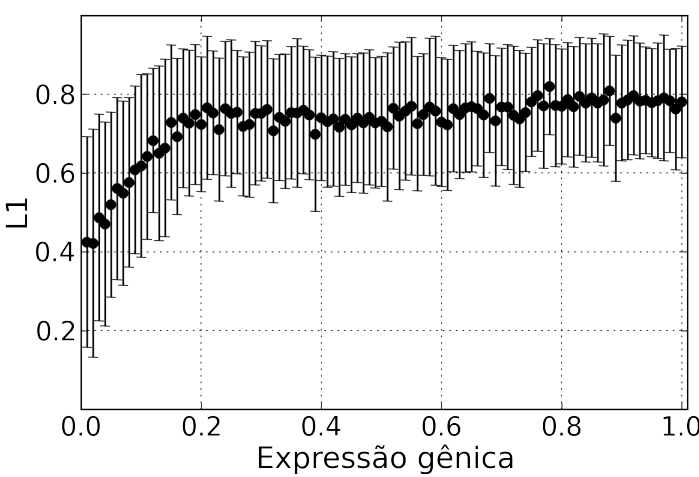

(d)

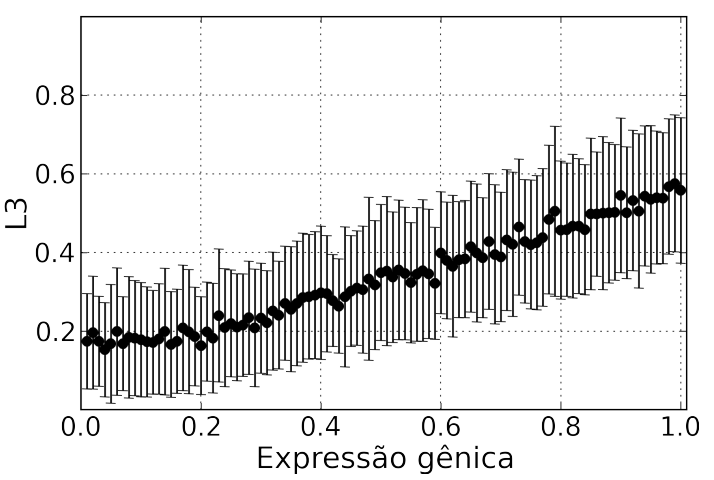

(f)

Figura 5.4: Relação entre medidas morfológicas e o nível de expressão do gênica do respectivo neurônio, considerando a rede RP. A curva representada na cor preta representa a média das medidas morfológica para cada valor de $\eta$ (expressão gênica).

pelos itens (a), (b) e (c) das Figuras 5.4 e 5.5, é evidente que existe uma influência de $\eta$ sobre estas medidas, mas os valores de informação mútua mostram uma influência moderada. As medidas de L1, L2 e L3, estão relacionadas com o tamanho dos neurônios, entretanto este fator não pode ser previsto unicamente a partir do valor de $\eta$, pois neste caso os valores de informação mútua são muito baixos. Ademais, pode-se perceber que na média estas medidas são influenciada pela expressão gênica, como pode ser observado 


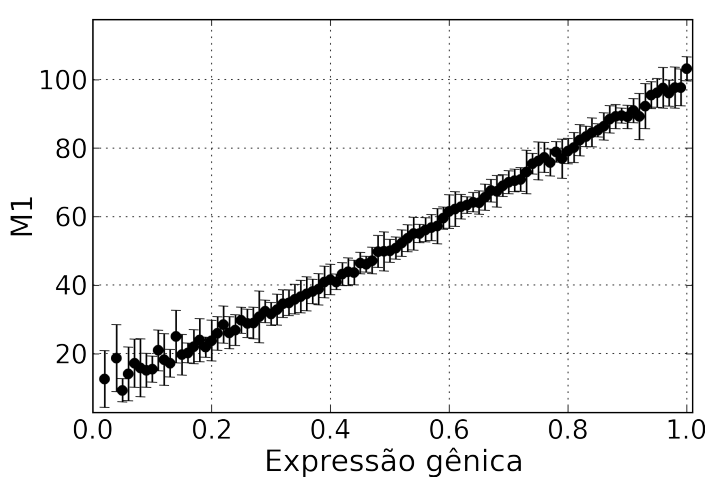

(a)

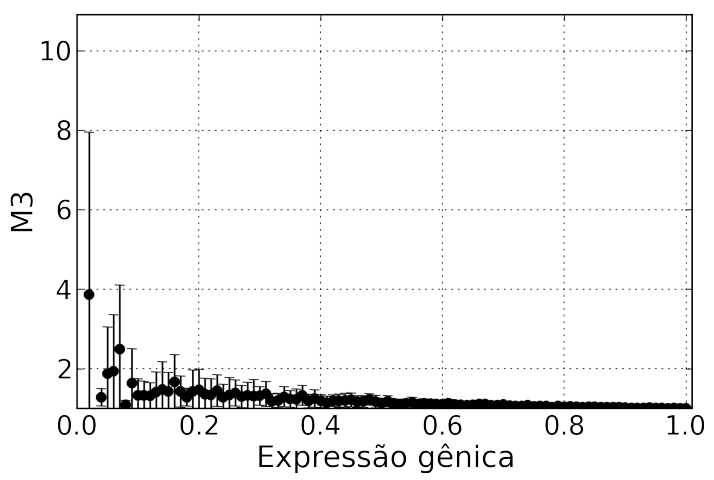

(c)

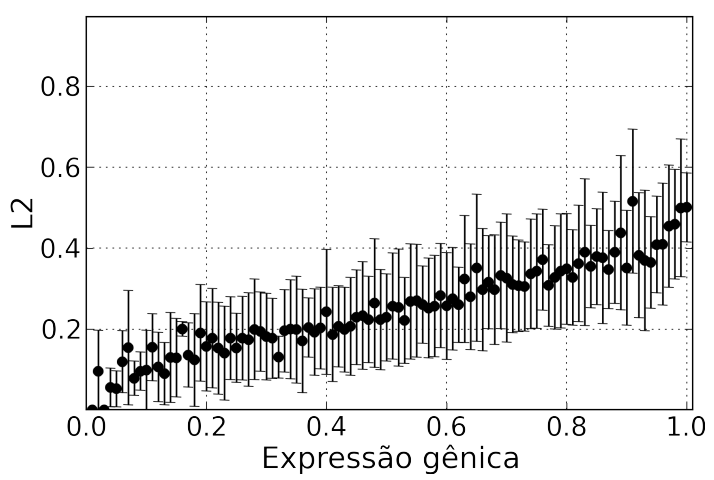

(e)

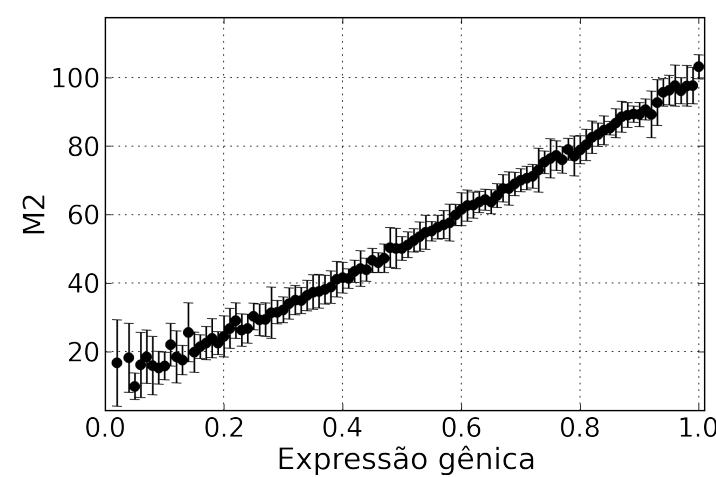

(b)

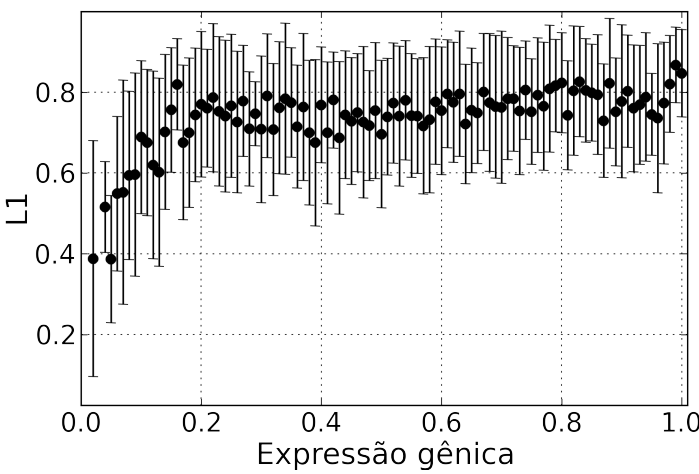

(d)

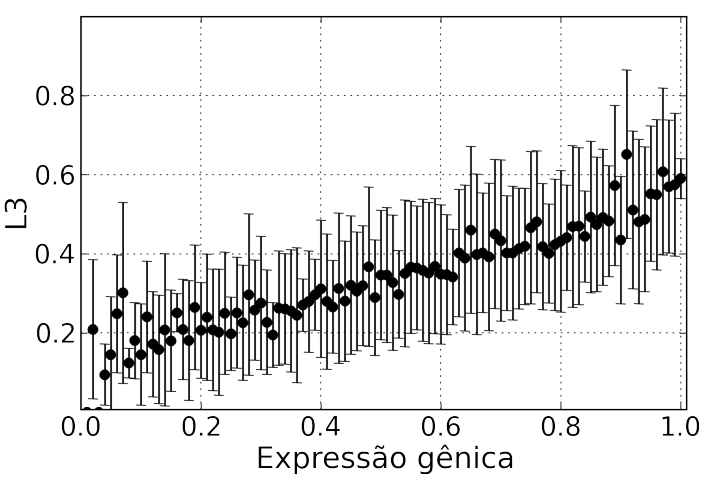

(f)

Figura 5.5: Relação entre medidas morfológicas e o nível de expressão do gênica do respectivo neurônio, considerando a rede RC. A curva representada na cor preta representa a média das medidas morfológica para cada valor de $\eta$ (expressão gênica).

nas curvas destacadas das Figuras 5.4 e 5.5, nos itens (d), (e) e (f).

Para mostrar a correlação linear entre a expressão gênica e as medidas neuronais, a correlação de Pearson foi calculada (como pode ser visto na Figura 5.7). Assim como na informação mútua, é possível observar que os resultados são similares para os as duas redes (RP e RC). Além disso, as medidas M1 e M2 são muito próximas de 1, ou seja, são quase totalmente correlacionadas linearmente. Para as demais medidas os valores não são 


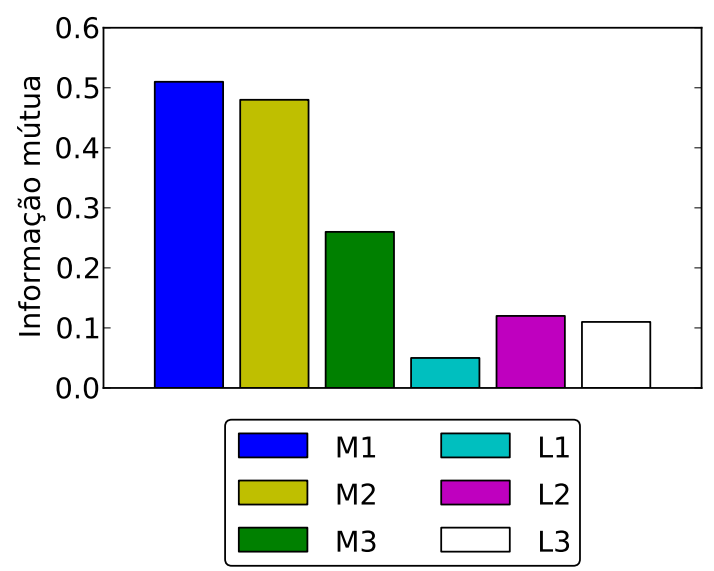

(a)

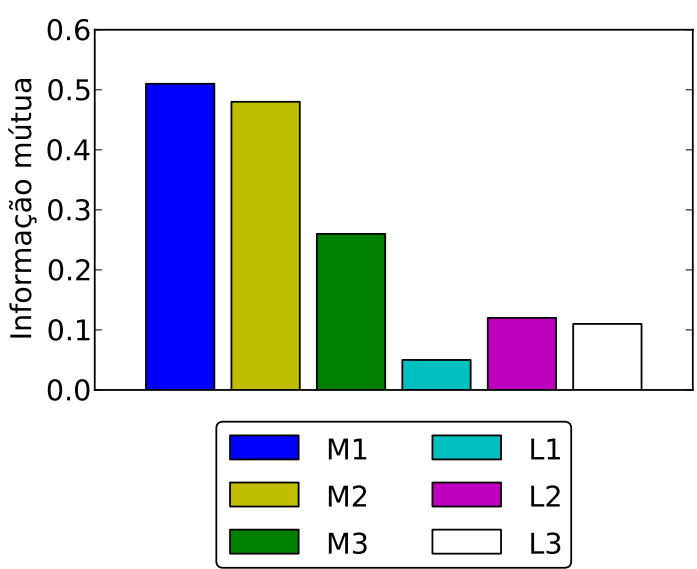

(b)

Figura 5.6: Informação mútua entre o valor de $\eta$ e as medidas morfológicas, o item (a) representa a rede $\mathrm{RP}$ e o item (b) representa a rede $\mathrm{RC}$.

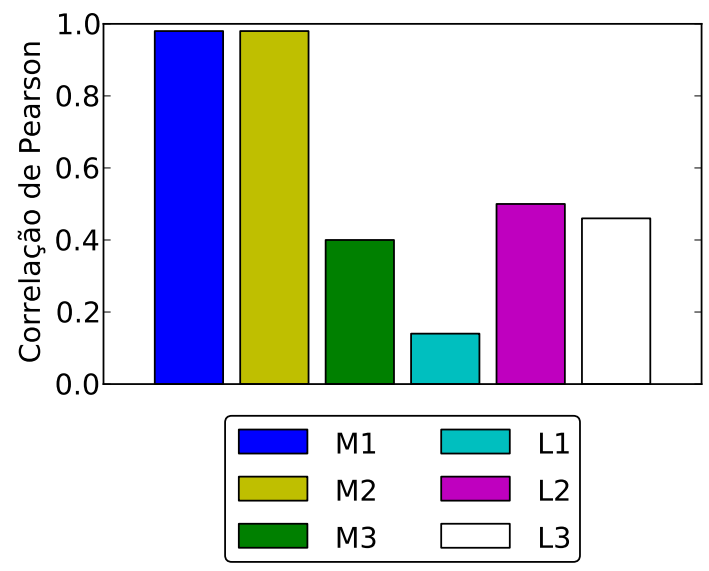

(a)

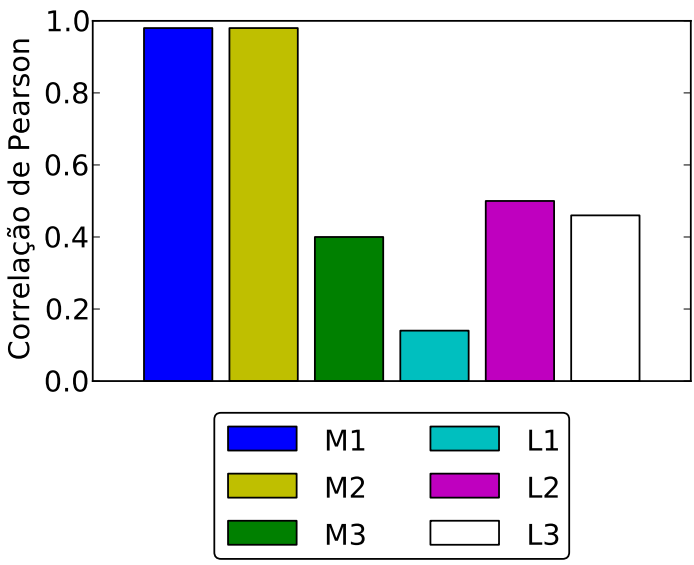

(b)

Figura 5.7: Correlação de Pearson (em módulo) entre o valor de $\eta$ e as medidas morfológicas, o item (a) representa a rede $\mathrm{RP}$ e o item (b) representa a rede $\mathrm{RC}$

tão significativos quanto o anterior, pois são moderadamente correlacionados, exceto em L1.

Considerando a informação mútua e a correlação de Pearson, a medida morfológica que refletiu melhor a expressão gênica foi M1, pois esta medida é influenciada diretamente por $\eta$ no processo de geração do neurônio. Este é um exemplo do tipo de relacionamento que pode ser encontrado por meio deste trabalho. Além disso, a medida M2 é indiretamente influenciada pelos valores de expressão gênica. As demais medidas (M3, L1, L2 e L3) 
também são influenciados pela expressão gênica, no entanto é difícil prever a morfologia de um neurônio para um dado valor de expressão gênica, como foi evidenciado nos gráficos, devido ao desvio mostrado nas curvas.

\subsection{Medidas de centralidade nas redes neuronais}

Cada uma das medidas de centralidade mostra, por meio de uma característica diferente, quais são os nós mais centrais da rede. Todas as medidas feitas nesta seção consideram apenas o maior componente fracamente conectado da rede. As Figuras 5.8 e 5.9, mostram os heat maps, onde as cores representam os valores das medidas de centralidade.

Por meio dos heat maps, é possível observar que existem diferenças entre as medidas nas duas redes ( $\mathrm{RP}$ e $\mathrm{RC})$. Isto ocorre, pois as organizações dos padrões de expressão gênica são diferentes. Assim, além da morfologia dos neurônios, a sua organização também gerou padrões de ligação distintos. O efeito de borda influencia todas as medidas, uma vez que os neurônios que estão perto das fronteiras têm menos possibilidades de fazer conexões do que os mais centrais. Ademais, as medidas de centralidade globais foram mais influenciadas pelo efeito de borda do que as locais.

Em ambas as redes (RP e RC), a medida de excentricidade forma regiões onde há uma mudança brusca da intensidade. Ou seja, podem ser observadas regiões adjacentes com uma mudança abrupta das intensidades. Este fenômeno ocorre devido à existência de mais de um componente fortemente conexo, formando o componente fracamente conexo.

A informação mútua (mostrado na Figura 5.10 mostra que, com a exceção do closeness centrality na rede RC, as medidas de centralidade são pouco influenciadas pelas alterações da expressão gênica. Entretanto, de acordo com a correlação de Pearson, existe uma correlação moderada entre $\eta$ e as medidas topológicas da rede, como é mostrado pela Figura 5.11. A correlação entre $\eta$ e o grau de saída ( $k^{\text {out }}$ ) ou clustering são similares para ambas as redes (RP e RC). Entretanto, as medidas de grau de entrada ( $\left.k^{i n}\right)$ e neighborhood connectivity (tanto de entrada quanto de saída), que também são locais, possuem valores de correlação distinto para cada um dos padrões de expressão. Desta forma, observa-se que, mesmo localmente, podem ocorrer alterações na topologia da rede. 


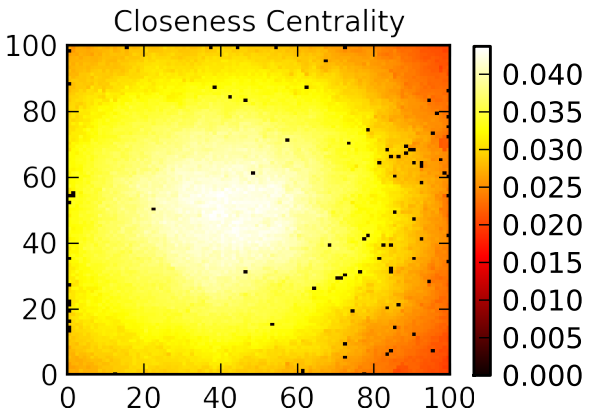

(a)

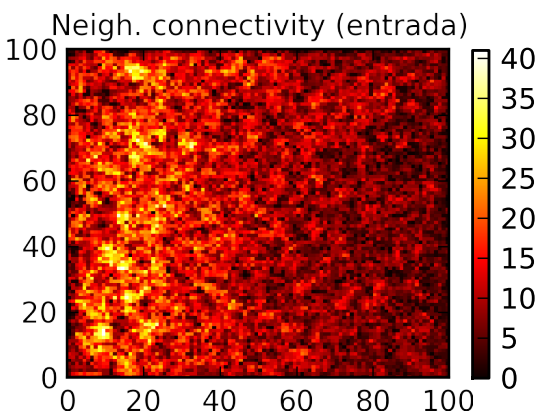

(c)

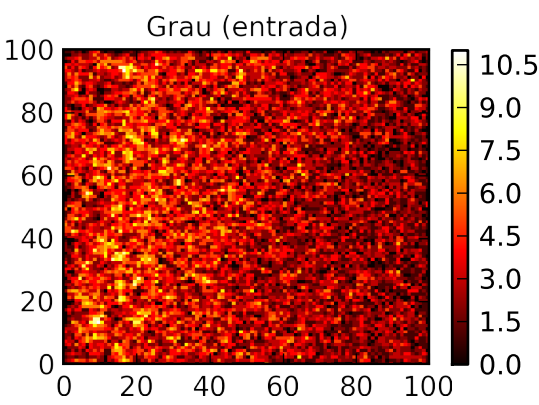

(e)

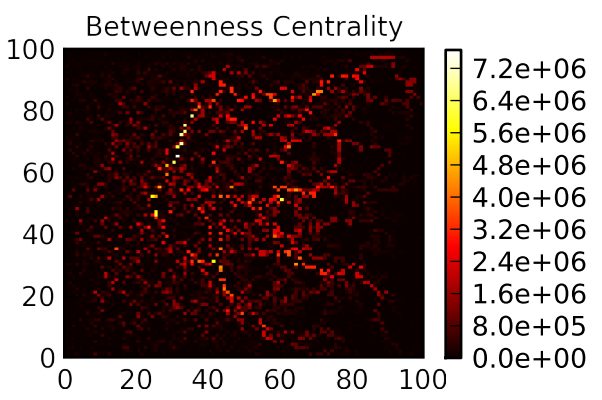

$(\mathrm{g})$

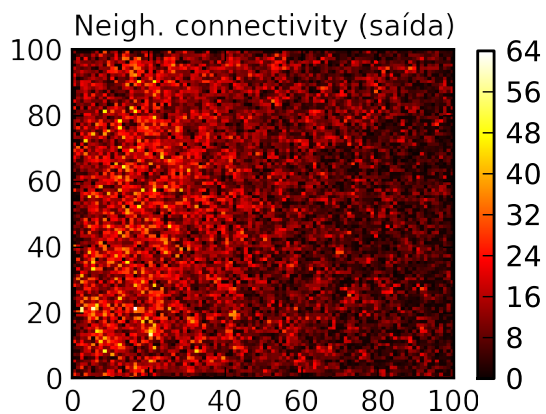

(b)

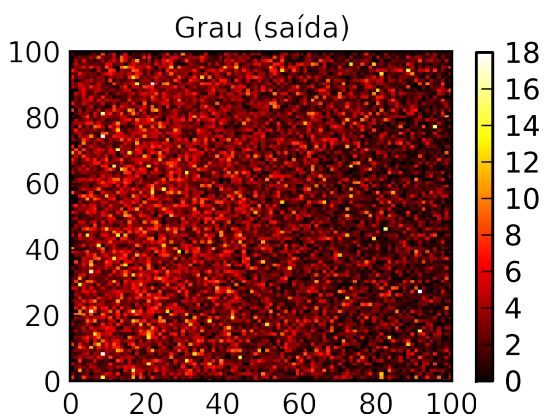

(d)

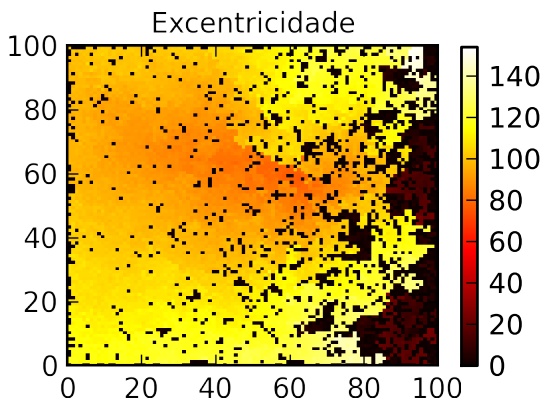

(f)

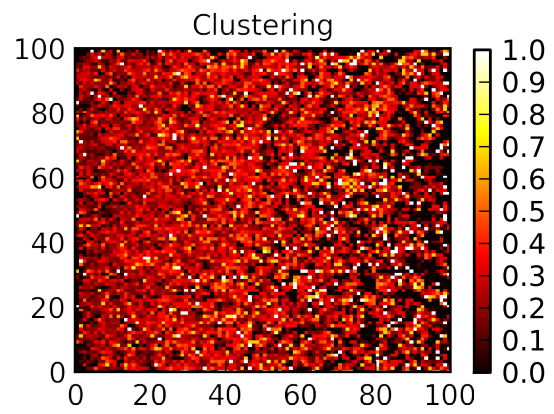

(h)

Figura 5.8: Relação entre os níveis de $\eta$ e as medidas topológicas para cada um dos vértices da rede RP. Os heat maps representados por (a) até (h) são, as medidas de closeness centrality, neighborhood connectivity (saída), neighborhood connectivity (entrada), grau (entrada), grau (saída), excentricidade, betweenness centrality e clustering. 


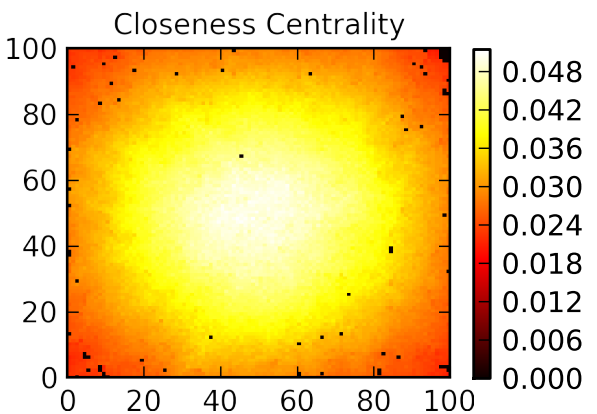

(a)

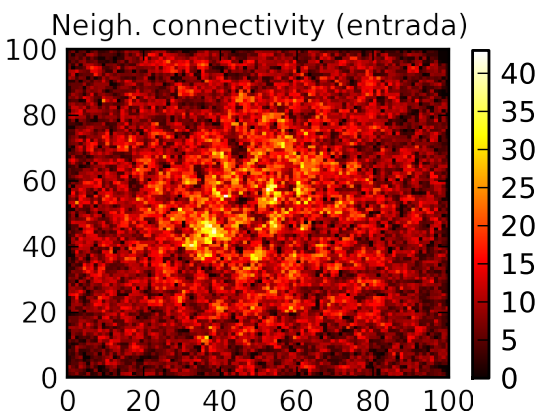

(c)

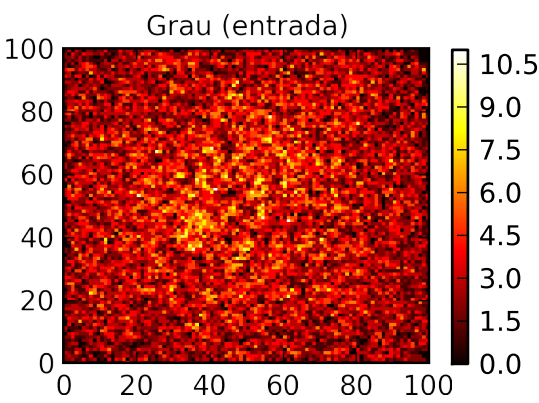

(e)

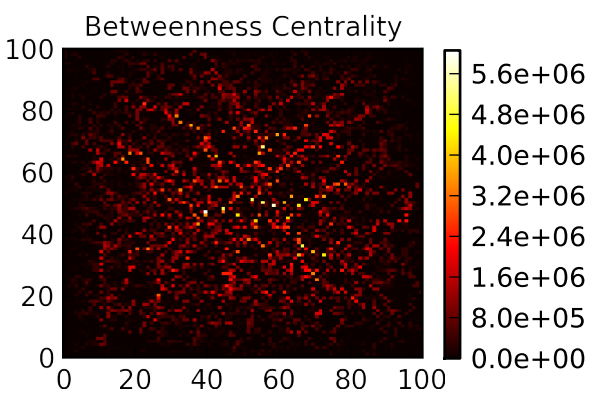

(g)

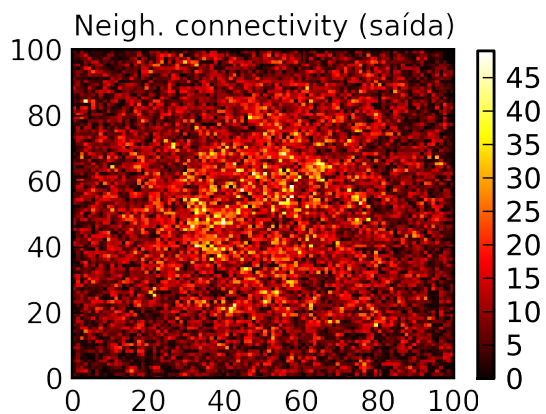

(b)

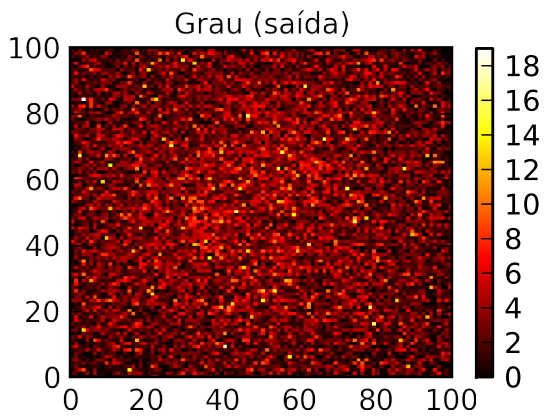

(d)

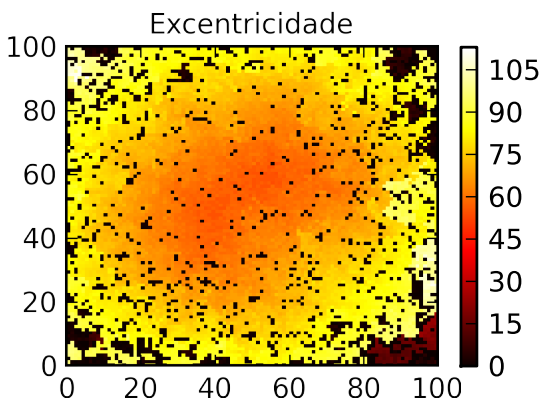

(f)

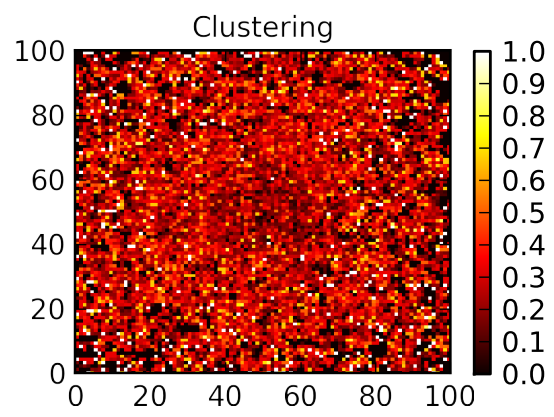

(h)

Figura 5.9: Relação entre os níveis de $\eta$ e as medidas topológicas para cada um dos vértices da rede RC. Os heat maps representados por (a) até (h) são, as medidas de closeness centrality, neighborhood connectivity (saída), neighborhood connectivity (entrada), grau (entrada), grau (saída), excentricidade, betweenness centrality e clustering. 


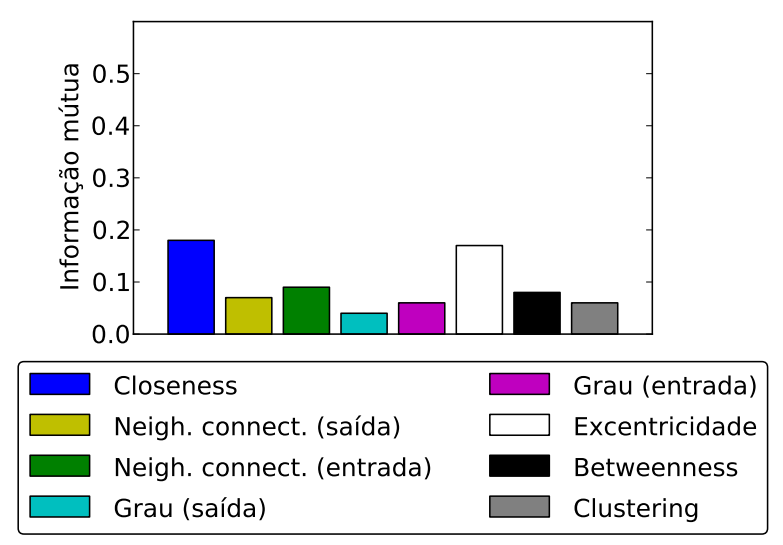

(a)

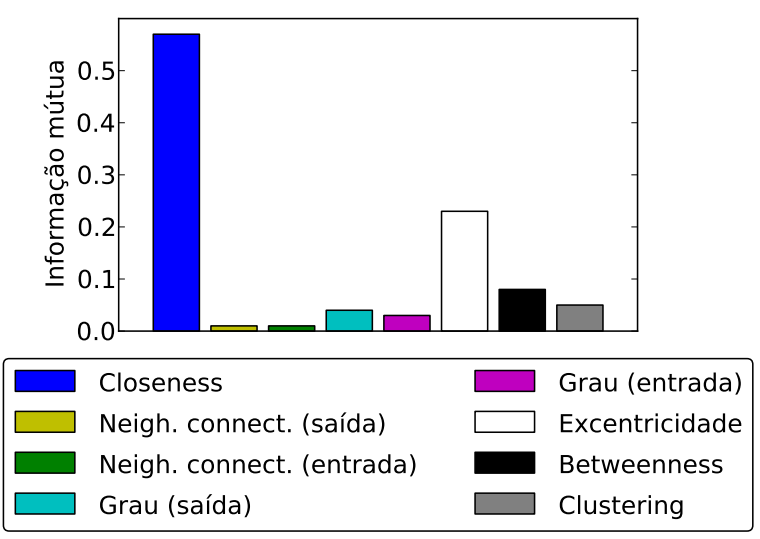

(b)

Figura 5.10: Informação mútua entre o valor de $\eta$ e as medidas morfológicas, o item (a) representa a rede $\mathrm{RP}$ e o item (b) representa a rede $\mathrm{RC}$.

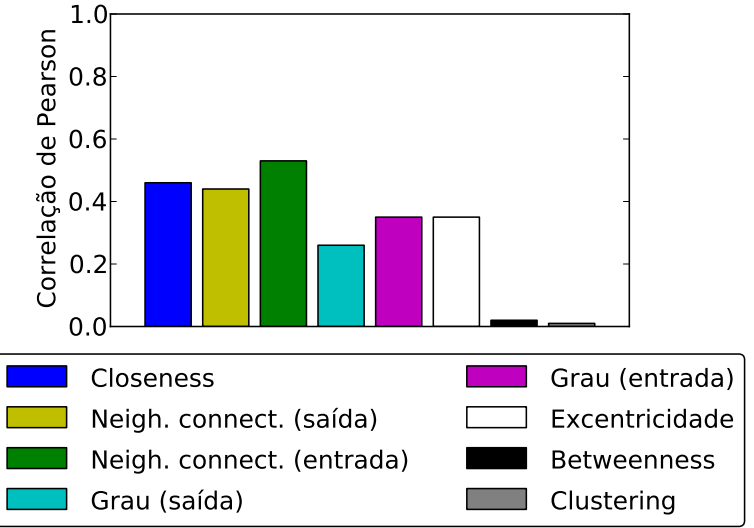

(a)
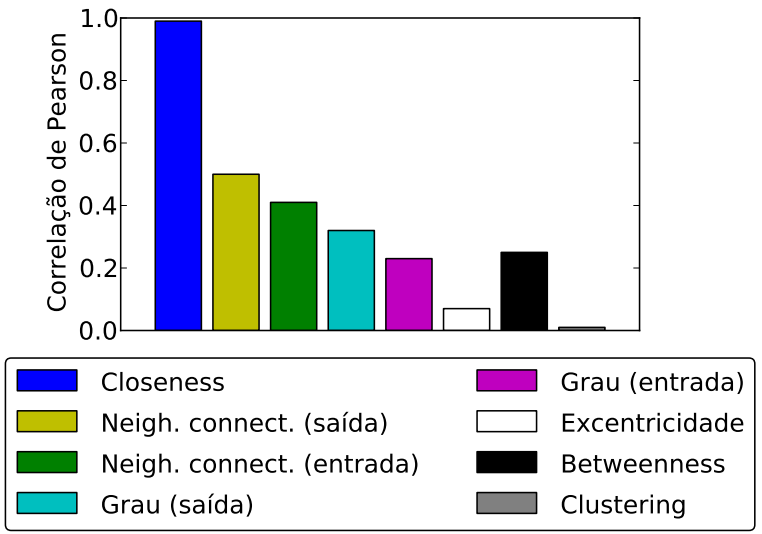

(b)

Figura 5.11: Correlação de Pearson (em módulo) entre o valor de $\eta$ e as medidas topológicas, o item (a) representa a rede $\mathrm{RP}$ e o item (b) representa a rede $\mathrm{RC}$

As medidas globais (closeness centrality, excentricidade e betweenness centrality) foram fortemente influenciados pelas padrões de expressão gênica. A medida de closeness centrality não é a única que difere entre os padrões, contudo é um exemplo claro do problema que existe em prever a expressão gênica por meio da topologia, pois para o padrão RC a expressão gênica pode ser prevista facilmente, no entanto para o padrão RP isto não é válido. Ademais, a correlação para a medida de excentricidade é maior na rede $\mathrm{RP}$ e a medida de betweenness centrality é maior na rede $\mathrm{RC}$, reafirmando as diferenças topológicas da rede.

Analisando todos estes resultados, é possível afirmar que o padrão de expressão gênica influencia a topologia da rede. 


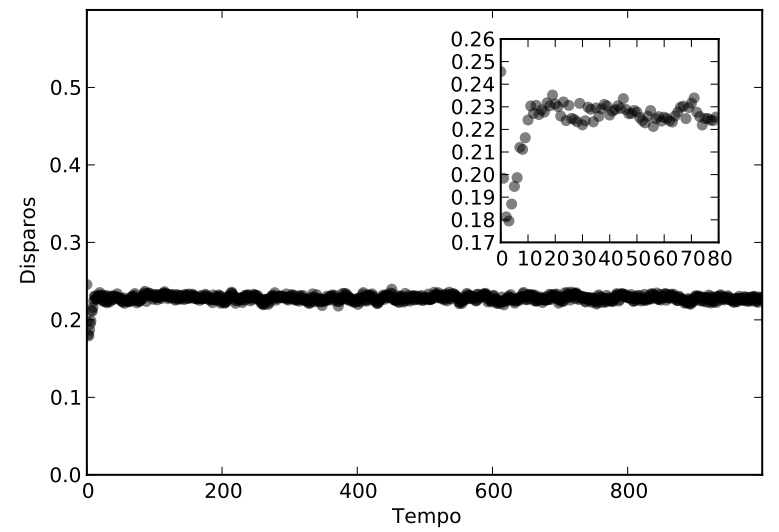

(a)

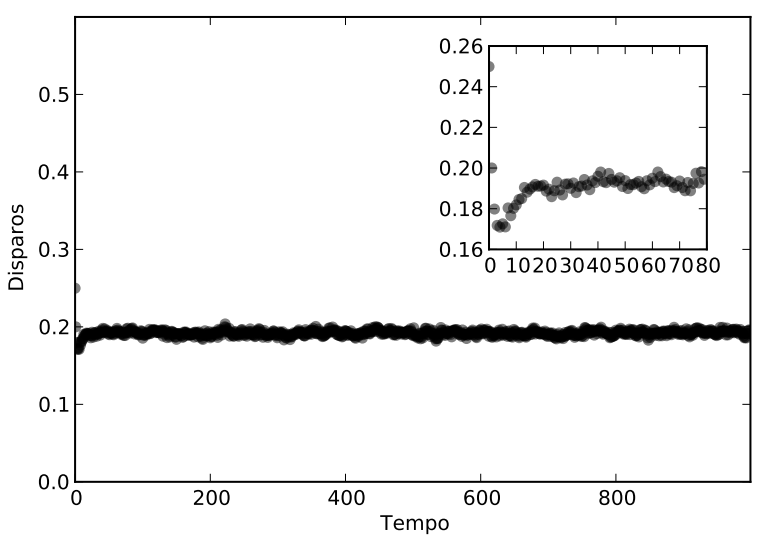

(b)

Figura 5.12: Gráfico mostrando o tempo pela quantidade média de disparos. O item (a) representa a rede RP e o item (b) representa a rede RC. As ampliações dos gráficos mostram o momento em que a dinâmica ainda não entrou em estado estacionário.

\subsection{Simulação da dinâmica neuronal integra-e-dispara}

Foi aplicada a dinâmica integra-e-dispara em ambas as redes (RC e RP), sendo esta a última etapa do pipeline.

O primeiro teste feito com o modelo integra-e-dispara foi a contagem do número de disparos para cada intervalo de tempo. A Figura 5.12 (a) mostra a contagem de disparos na rede RP, enquanto a Figura 5.12 (b) mostra a contagem de disparos na rede RC. Por meio delas é possível observar que as redes possuem um comportamento semelhante, independente da expressão gênica, pois em ambas há uma transição e, posteriormente, se mantém praticamente constantes.

Devido as variações que ocorrem no início da dinâmica, as demais medidas foram feitas considerando apenas o estado estacionário (foram consideradas as iterações a partir da centésima).

Além disso, as medidas utilizadas para caracterizar esta dinâmica foram:

1. Taxa de disparos;

2. Maior intervalo entre disparos;

3. Entropia do intervalo entre disparos.

A medida de maior intervalo entre os disparos foi analisada tanto na escala logarítmica 


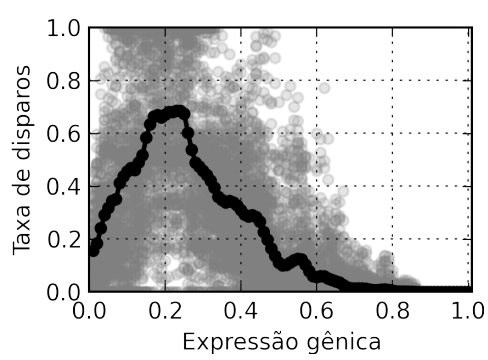

(a)

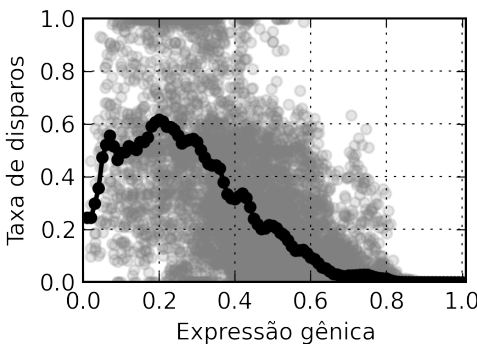

(d)

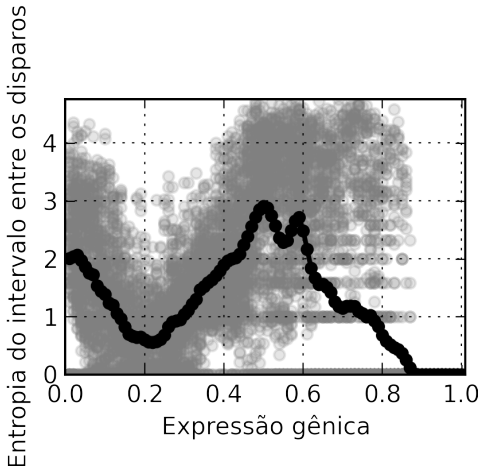

(b)

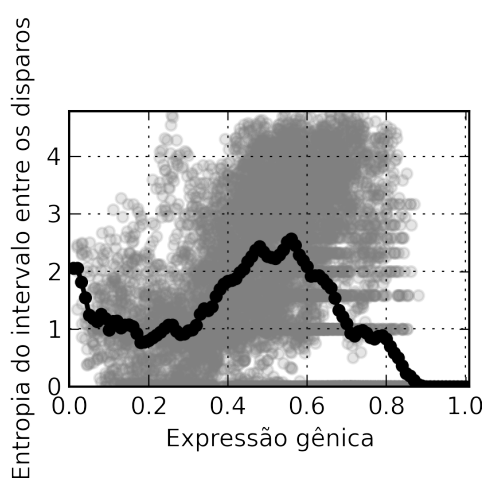

(e)

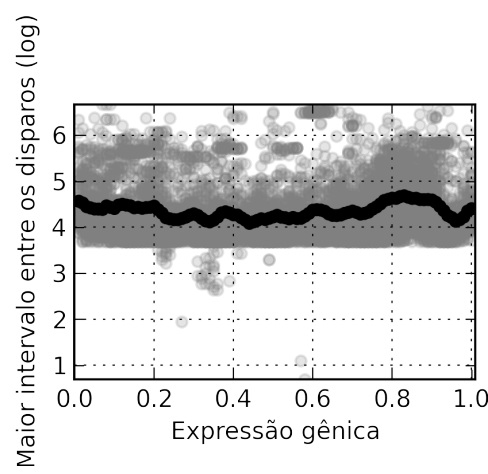

(c)

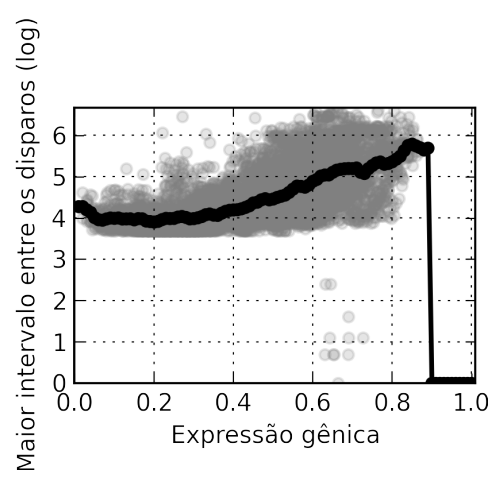

(f)

Figura 5.13: Gráficos de dispersão das medidas da dinâmica integra-e-dispara, nas redes RP e RC. Em todos os mapas de dispersão, o eixo x representa $\eta$ (expressão gênica) e os eixos y são: (a)Taxa de disparos em RP, (b) Entropia do intervalo entre disparos em RP, (c) Maior intervalo entre disparos (log) em RP, (d)Taxa de disparos RC, (e) Entropia do intervalo entre disparos em RC, (f) Maior intervalo entre disparos (log) em RC. As curvas representadas na cor preta são médias.

quanto em sua escala original, como houve uma maior correlação na escala logarítmica, apenas os resultados nesta escala foram mostrados. As medidas são mostradas nas Figuras 5.13 , representando as redes $\mathrm{RP}$ e $\mathrm{RC}$, respectivamente.

Os resultados das medidas de informação mútua, feitas a partir da dinâmica, podem ser vistos na Figura 5.14. Estes resultados indicam que a expressão gênica tem apenas uma influência indireta sobre a dinâmica integra-e-dispara.

Em contrapartida, a correlação de Pearson (que pode ser vista pela Figura 5.15) mostra variação entre as medidas. Para ambos os padrões de expressão gênica (RP e RC), a taxa de disparos teve o maior valor de correlação. Além disso, também é interessante observar que existem diferenças entre as medidas calculadas para cada uma das redes. Estas 


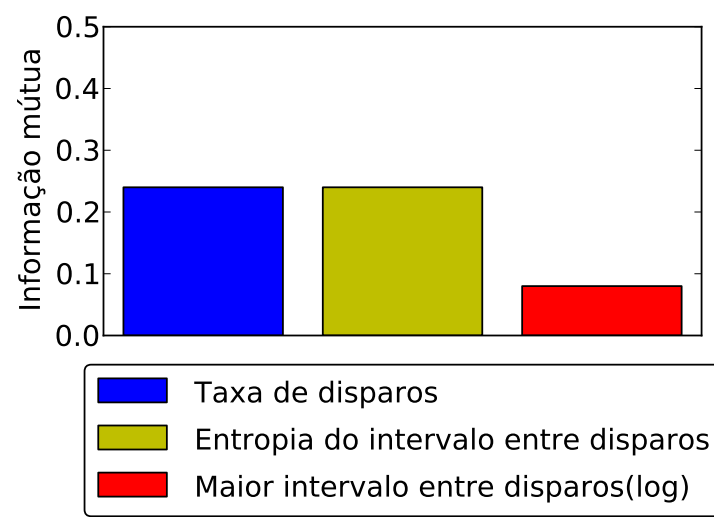

(a)

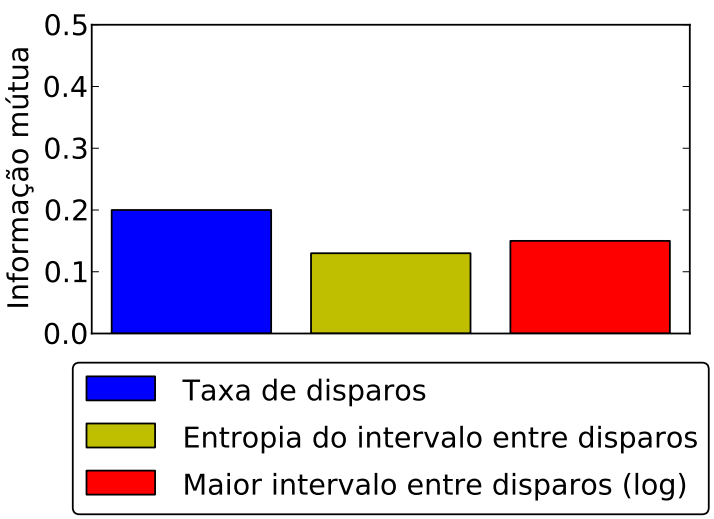

(b)

Figura 5.14: Informação mútua das medidas da dinâmica integra-e-dispara nas duas grades, onde item (a) representa a rede RP e o item (b) representa a rede RC. O valor da entropia do intervalo entre disparos não foi apresentado para a escala logarítmica, pois para medida os resultado é igual, independente da escala.

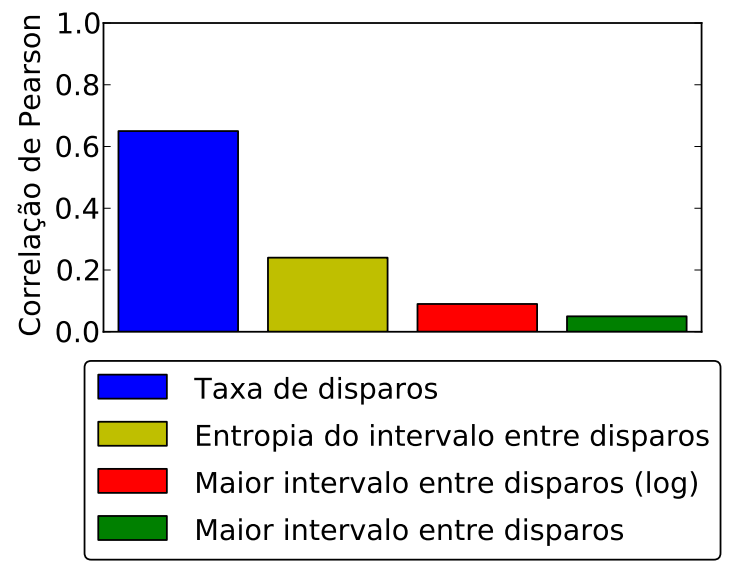

(a)

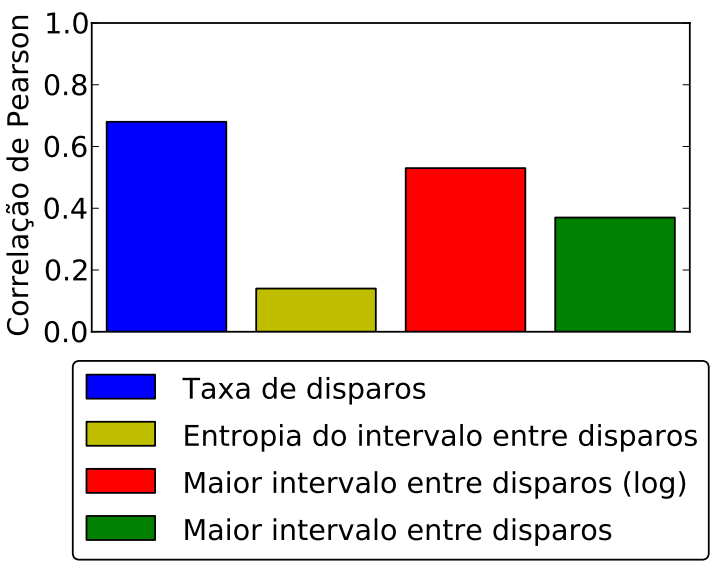

(b)

Figura 5.15: Correlação de Pearson (em módulo) das medidas da dinâmica integra-e-dispara nas duas grades, onde item (a) representa a rede RP e o item (b) representa a rede $\mathrm{RC}$.

diferenças são reflexo dos padrões diferentes de expressão gênica, mostrando que ela pode influenciar os resultados da dinâmica. Ademais, a correlação entre a expressão gênica e as medidas calculadas para a dinâmica tendem a ser mais fracas do que a correlação com as medidas morfológicas e de conectividade. Isto sugere que a influência dos diferentes padrões de $\eta$ nas características das medidas do sistema tornam-se mais indiretas. 


\subsection{Simulação do desenvolvimento hebbiano}

Além da simulação do modelo integra-e-dispara, que mostra apenas o comportamento coletivo dos neurônios na rede, foi executada outra dinâmica, que também representa a última etapa do pipeline, o desenvolvimento hebbiano, que modifica a topologia da rede.

Por meio da Figura 5.16 é possível observar diferenças entre as redes antes e depois do desenvolvimento. Para ambas as redes (RP e RC), é possível observar que existe uma tendência em reforçar as ligações na região onde os valores de $\eta$ são mais baixos. Por meio desta dinâmica foram alteradas as quantidades de vértices das redes, antes do desenvolvimento as redes RP e RC possuíam 9911 e 9926 vértices (para todos os testes foi considerado apenas o maior componente gigante), respectivamente e após o desenvolvimento o maior componente fracamente conectado de das redes RP e RC passaram a possuir 2179 e 1551 vértices, respectivamente. Esta redução ocorre, pois no desenvolvimento hebbiano as arestas podem aumentar, ou diminuir os seus pesos. Assim, algumas conexões podem deixar de existir, desconectando partes da rede do maior componente conexo.

Nos testes desta seção foram utilizadas as mesmas medidas aplicadas à dinâmica integra-e-dispara, os resultados podem ser vistos na Figura 5.17 (medidas feitas nas redes RP e RC). Comparando as duas figuras, é possível observar que a taxa de disparos (itens (a) e (d)), nas regiões onde $\eta=0,2$, os valores são maiores. Outro resultado interessante é a entropia dos intervalos entre os disparos, por meio dela podemos observar que na média a os valores de entropia são baixos, diferente do que aconteceu na dinâmica integra-e-dispara.

Além disso, é possível observar que existem diferenças entre a informação mútua na dinâmica integra-e-dispara (mostrado na Figura 5.14) e na dinâmica de desenvolvimento hebbiano (que é baseado em um integra-e-dispara), como pode ser observado por meio da Figura 5.18. No primeiro caso (na dinâmica integra-e-dispara), todos os valores são baixos (menores do que 0,24 ), mas no desenvolvimento hebbiano, na rede RP, os valores são mais elevados, assim, a informação refletida na expressão gênica é moderadamente refletida na taxa de disparos. Ademais, os valores são diferentes para cada uma das organizações de 


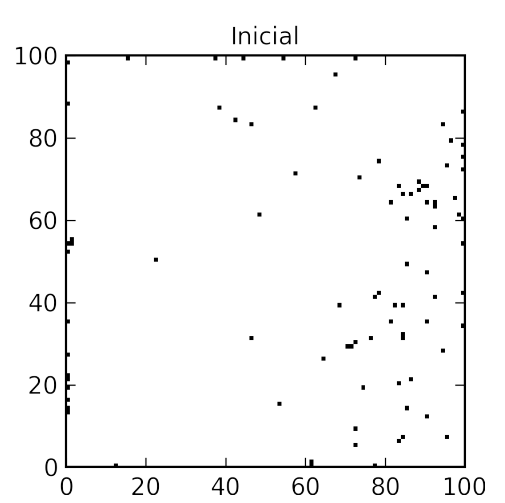

(a)

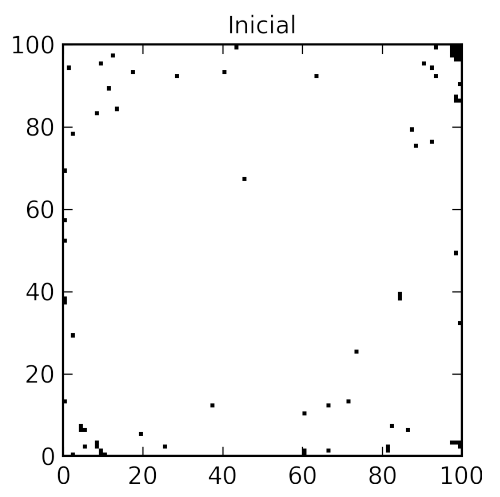

(c)

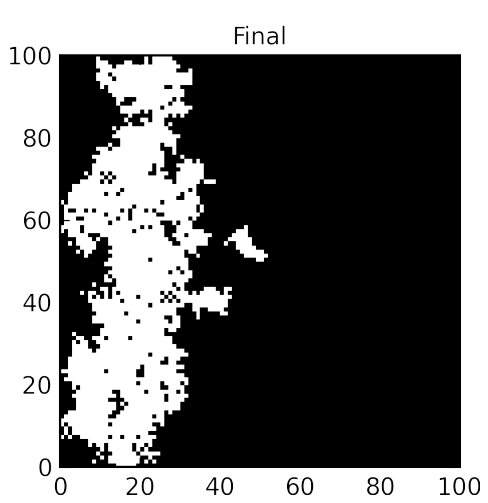

(b)

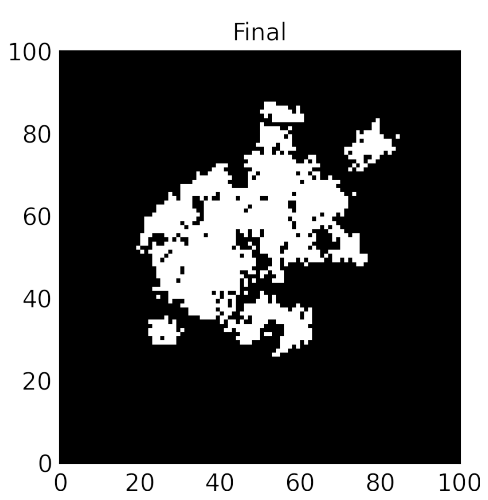

(d)

Figura 5.16: As figuras mostram as redes antes e depois do desenvolvimento hebbiano (para ambas as imagens foi considerado o componente gigante fracamente conectado), cada quadrado branco representa um vértice (neurônio) da rede. As Figuras (a) e (b) representam a rede RP antes e depois do desenvolvimento hebbiano, respectivamente e as Figuras (c) e (d) representam a rede $\mathrm{RC}$ antes e depois do desenvolvimento hebbiano, respectivamente.

expressão gênica, pois os resultados para RP e RC foram distintos.

Foi calculada, também, a correlação de Pearson para as medidas apresentadas. como pode ser visto na Figura 5.19 . No caso da medida de Pearson para a taxa de disparo as correlações foram significativas para dois padrões (RP e RC). Este resultado mostra que a dinâmica integra-e-dispara é semelhante para ambas as redes. Além disso, a entropia do intervalo entre os disparos é fracamente correlacionada para os dois padrões. Para os dois padrões, a medida de maior intervalo entre os disparo não é correlacionada, entretanto na dinâmica integra-e-dispara, é moderadamente correlacionada para a rede RC. Por fim, analisando a medida de máximo intervalo entre os disparos (usando as escalas de logarítmica e linear), em RP estas medidas não são correlacionadas, entretanto em RC elas são moderadamente correlacionados, na escala linear. Neste último caso (na rede 


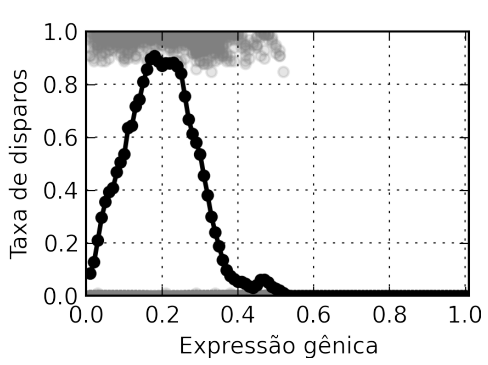

(a)

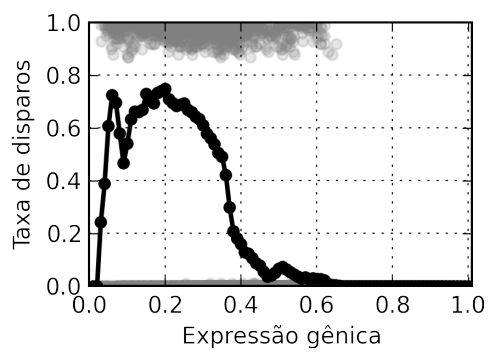

(d)

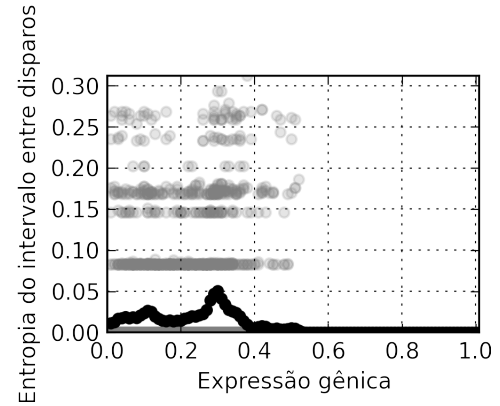

(b)

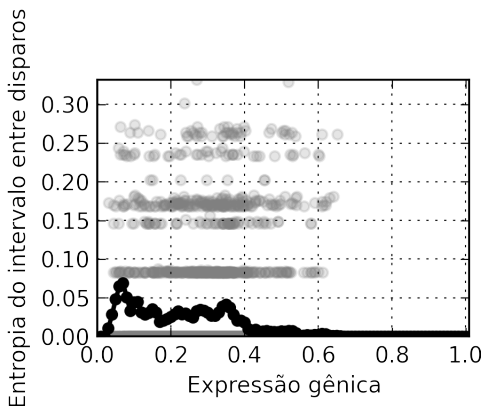

(e)

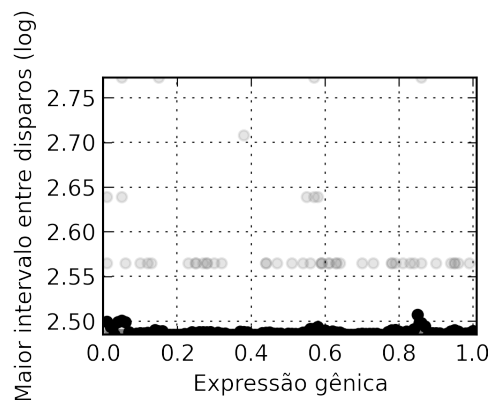

(c)

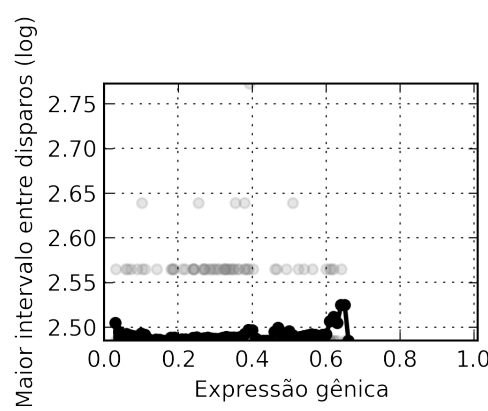

(f)

Figura 5.17: Gráficos de dispersão das medidas da dinâmica integra-e-dispara (contida no desenvolvimento hebbiano), nas redes RP e RC. Em todos os mapas de dispersão, o eixo x representa $\eta$ (expressão gênica) e os eixos y são: (a)Taxa de disparos em RP, (b) Entropia do intervalo entre disparos em RP, (c) Maior intervalo entre disparos (log) em RP, (d)Taxa de disparos RC, (e) Entropia do intervalo entre disparos em RC, (f) Maior intervalo entre disparos (log) em RC. As curvas representadas na cor preta são médias.

RC), a correlação é diferente do que ocorre na dinâmica (apresentada na seção anterior), pois a medida do máximo intervalo entre os disparos em escala logarítmica é menor do que para a mesma medida usando a escala linear.

\subsection{Caminhos mínimos entre comunidades}

Como na medida de betweenness centrality foi observada (visualmente) a presença de caminhos (mostrados pelas Figura 5.8(g) e Figura 5.9(g)), foi feita uma análise mais detalhada, para compreender como eles são gerados.

Por meio da medida de centralidade betweenness centrality foi possível observar a presença de cadeias de nós com valores mais elevados, sendo que a maior parte desses vértices estão conectados entre si. Assim, a maior parte deles possui grau dois. Neste 


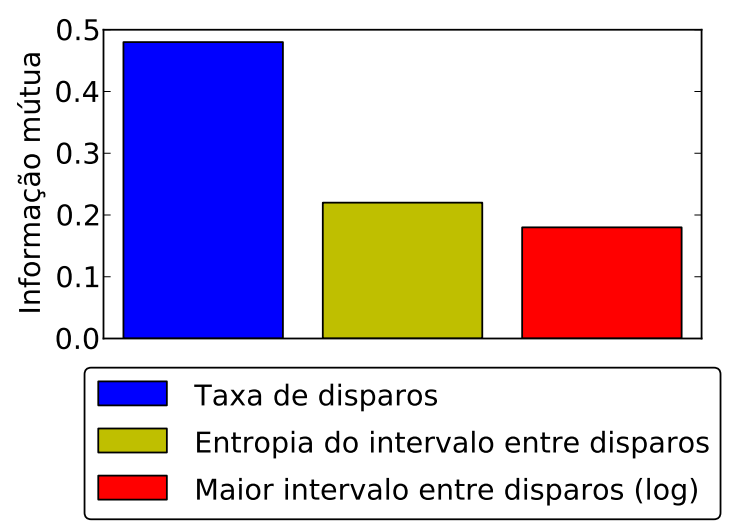

(a)

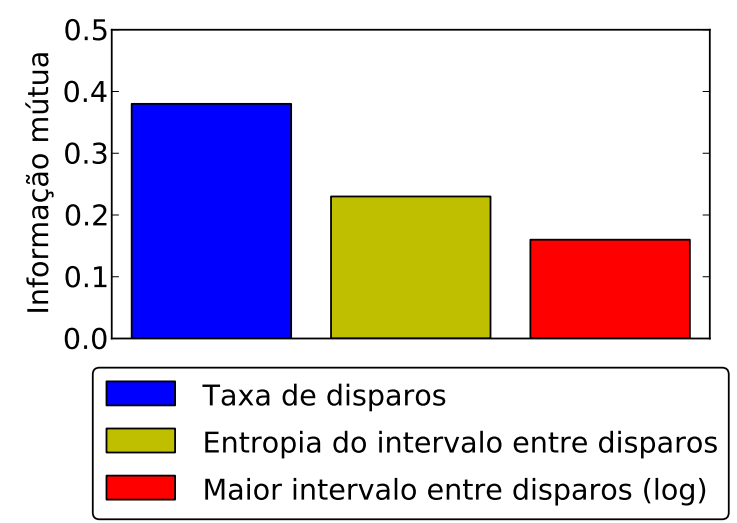

(b)

Figura 5.18: Informação mútua das medidas da dinâmica integra-e-dispara (contida no desenvolvimento hebbiano) nas duas grades, onde item (a) representa a rede RP e o item (b) representa a rede RC. O valor da entropia do intervalo entre disparos não foi apresentado para a escala logarítmica, pois para medida os resultado é igual, independente da escala.

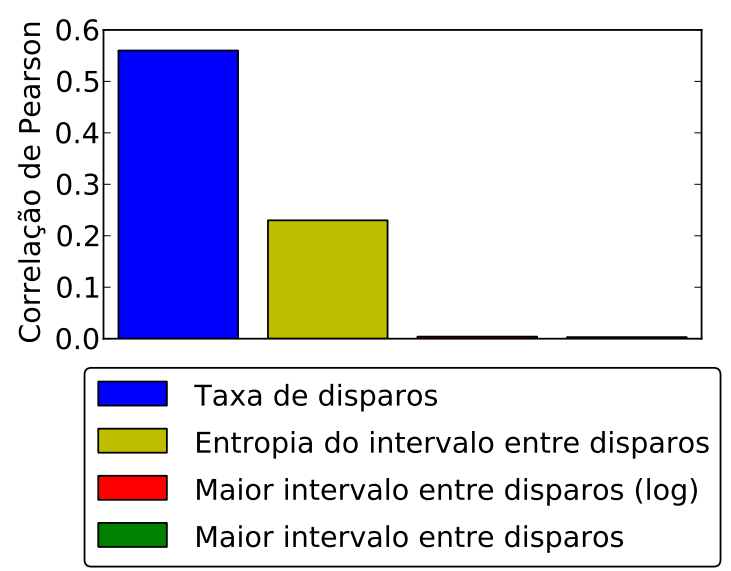

(a)

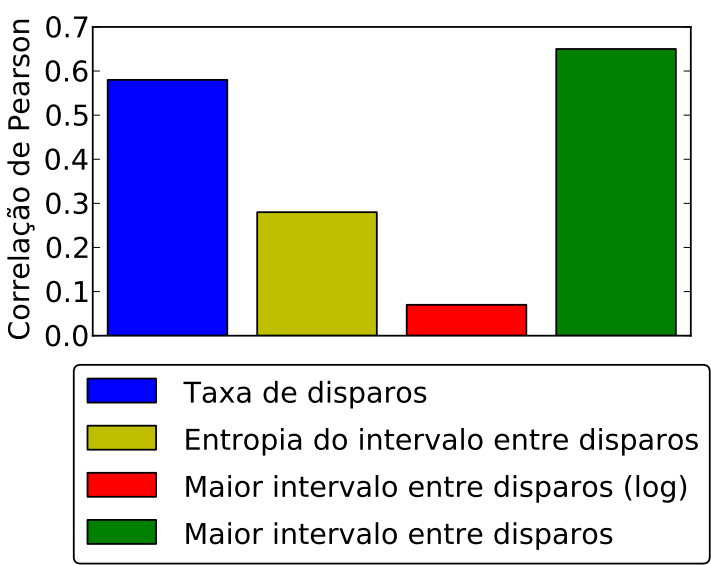

(b)

Figura 5.19: Correlação de Pearson (em módulo) das medidas da dinâmica integra-e-dispara (contida no desenvolvimento hebbiano) nas duas grades, onde item (a) representa a rede RP e o item (b) representa a rede $\mathrm{RC}$.

trabalho foi definido o caminho do betweenness como uma sub-rede considerando apenas os valores mais elevados da medida. Em outras palavras, foram selecionados apenas os vértices com valor maior ou igual a um determinado limiar (o valor utilizado foi de 20\%), com estes vértices foi criada uma sub-rede.

Nesta seção serão apresentados os fatores que geram estas redes, assim como a relação 


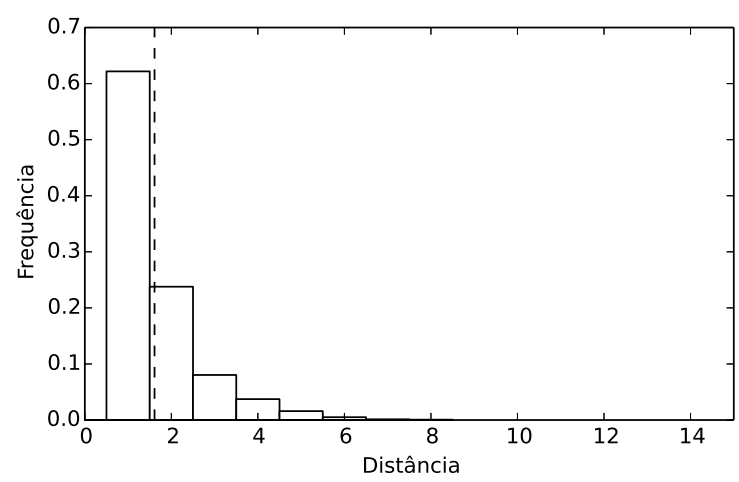

(a)

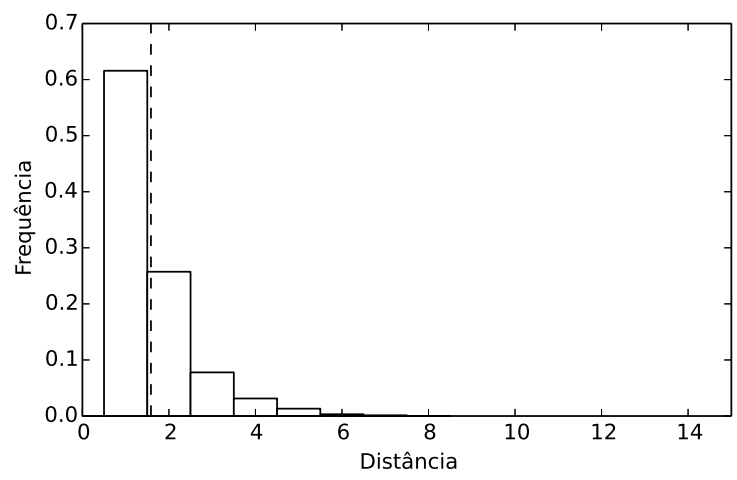

(b)

Figura 5.20: Histogramas mostrando a distância entre os vértices e os caminhos do betweenness. $\mathrm{O}$ item (a) representa a rede RP e o item (b) representa a rede RC.

entre eles e as comunidades.

\subsubsection{Caminhos nas redes neuronais}

Nesta subseção foram analisadas as redes RP e RC de acordo com os seus caminho do betweenness. Como estes caminhos não são totalmente conectados entre si, a primeira medida foi a o tamanho do maior caminho em relação aos demais. Nas redes RP e RC, os maiores caminhos representam $99 \%$ e $98 \%$ de todos os caminhos de betweenness da rede, respectivamente. Nesta seção todas as redes foram consideradas não direcionadas, pois foi observado que a formação dos caminhos não depende da direção das arestas da rede.

Outra análise foi a medida da capacidade dos caminhos de cobrir a rede, ou seja, quão acessíveis eles são. Assim, foi calculada a menor distância entre cada vértice (que não pertence aos caminhos) e todos os vértices dos caminhos. Os resultados são mostrados na forma de histogramas, como pode ser visto na Figura 5.20. É possível observar que, de acordo com esta medida, não houve quase nenhuma diferença entre as duas redes RP e RC. Assim, os diferentes padrões de expressão gênica não modificaram esta característica.

\subsubsection{Outras redes espaciais}

A medida de betweenness centrality foi aplicada em outras redes espaciais com a finalidade de mostrar se esta é uma característica particular das redes neuronais, ou se é uma 
característica comum em redes espaciais. Foram testadas quatro redes, sendo que as duas primeiras são modelos de redes espaciais e as demais são redes de ruas. Os modelos espaciais foram o Waxman e o grafo geométrico aleatório, já as redes de rua foram de San Joaquin County nos EUA e cidade Oldenburg, na Alemanha.

A Figura 5.21 mostra as redes e os seus respectivos caminhos do betweenness. A rede de San Joaquin County não foi mostrada na figura, pois como a quantidade de vértices é muito grande a visualização fica comprometida. A rede referente ao modelo de Waxman possui 1321 vértices, com grau médio igual a 2,16 (esta rede pode ser vista na Figura 5.21(a)). A rede gerada pelo modelo do grafo geométrico aleatório possui 4944 vértices e grau médio 6,18 (esta rede é representada pela Figura 5.21(b)). A cidade de Oldenburg possui uma rede com 2873 vértices e grau médio 2,57 (mostrada na Figura 5.21(c)). Para as ruas de San Joaquin County, a rede possuí 14503 vértices e grau médio de 2,75. Em todas as características mostradas foi considerado apenas o componente gigante (fracamente conectado) de cada uma das redes.

Para todas essas redes, é possível observar que existe mais de um caminho conectado formado pela medida de betweenness centrality. Ou seja, se estes caminhos forem considerados como uma outra rede, é possível observar que são formados por mais de um componente conectado. Os tamanhos destes componentes são distintos para cada uma das redes. Na rede do grafo geométrico aleatório o maior caminho representa $85 \%$ de todos os vértices que pertencem a um caminho de betweenness. Nas demais redes estes caminhos representam mais de $98 \%$ de todos os vértices que pertencem a um caminho. $\mathrm{Na}$ rede das ruas de Oldenbrug (Figura 5.21(c)), é possível observar que existe uma relação entre as comunidades e os caminhos, pois visualmente eles podem ser considerados caminhos preferenciais que conectam as comunidades.

Foi feita, também, a medida da capacidade dos caminhos de cobrir a rede. De forma equivalente ao que foi aplicado na subseção anterior, foi feita a medida da menor distância entre cada vértice (que não faz parte dos caminhos) e os caminhos. Os resultados são mostrados na forma de histogramas, como pode ser visto na Figura 5.22 É possível observar que no modelo geométrico aleatório, a fração de vértices com distância um é maior 


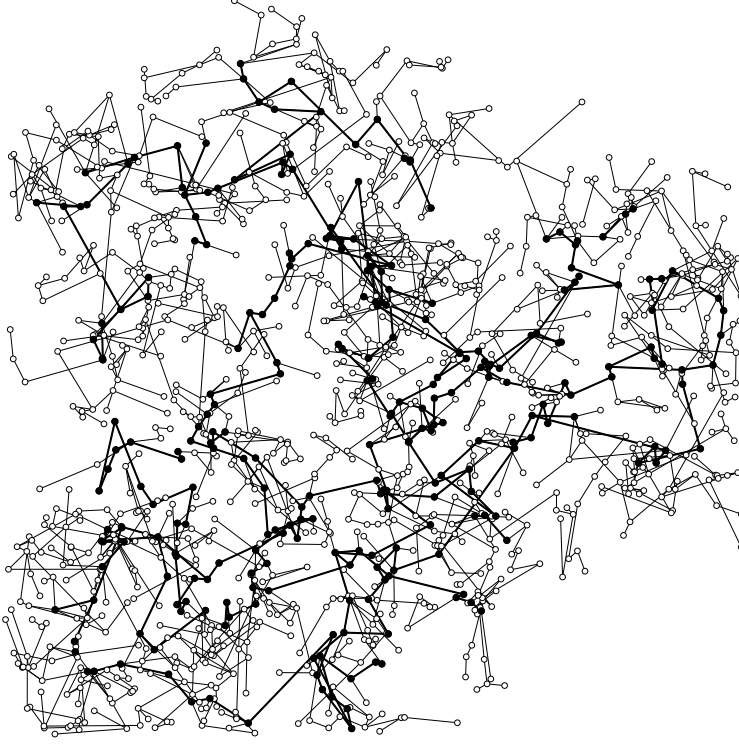

(a)

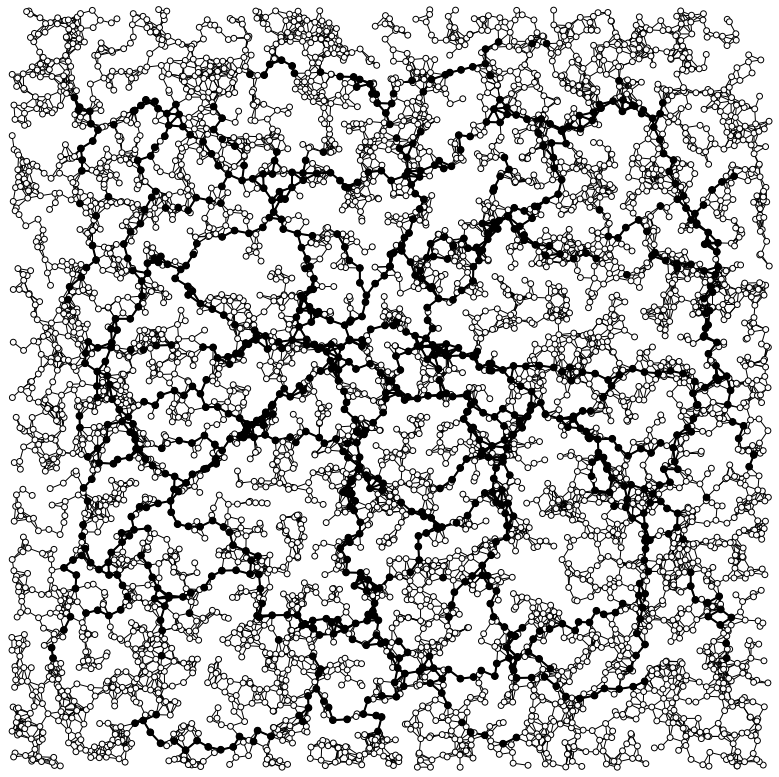

(b)

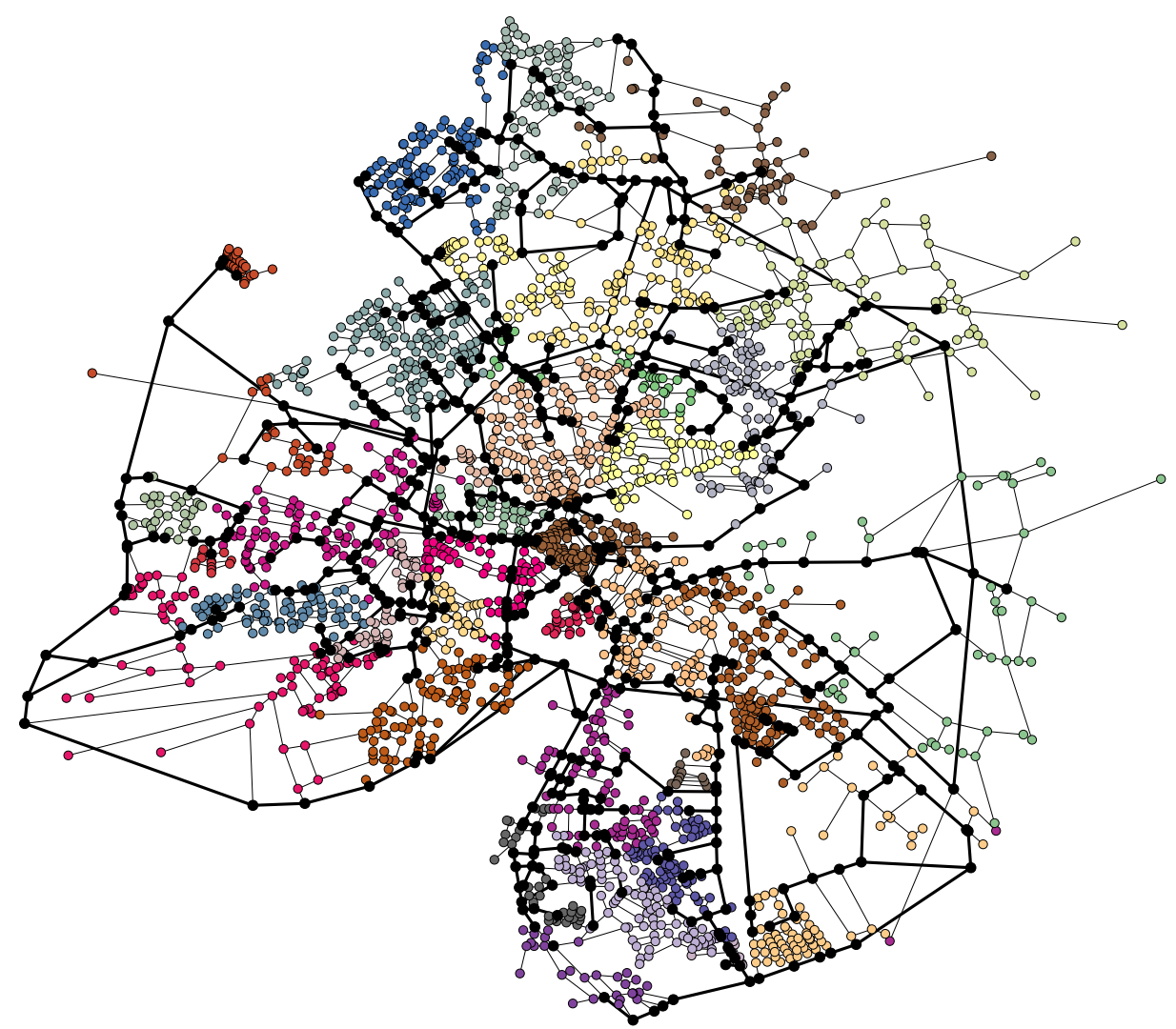

(c)

Figura 5.21: Redes geográficas, os círculos representados pela cor preta são os caminhos do betweenness (o limiar utilizado foi de 20\%). O item (a) representa a rede gerada pelo modelo de Waxman, o item (b) representa a rede gerada pelo modelo do grafo geométrico aleatório e o item (c) representa a rede de ruas de Oldenburg, neste grafo as cores representam as comunidades (exceto a cor preta). 


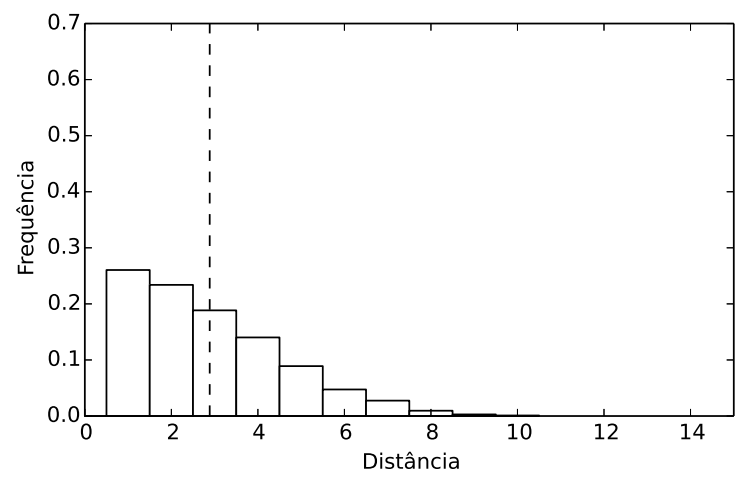

(a)

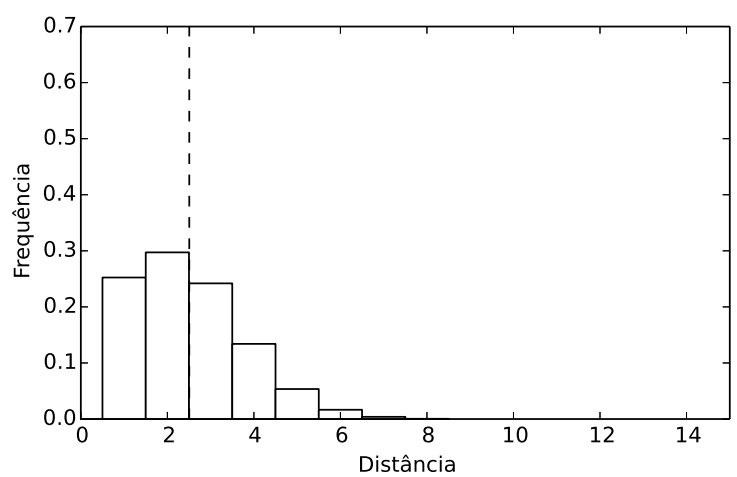

(c)

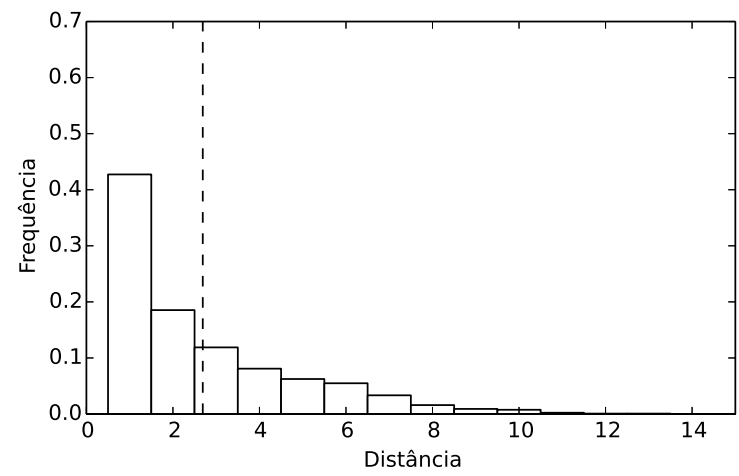

(b)

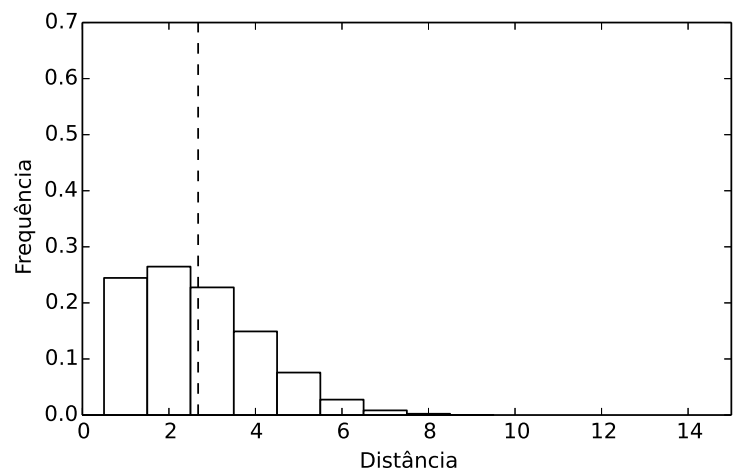

(d)

Figura 5.22: Histogramas mostrando a distância entre os vértices e os caminhos preferenciais. O item (a) representa a rede do modelo de Waxman, o item (b) representa a rede do modelo do grafo geométrico aleatório, o item (c) representa a rede de Oldenburg e o item (d) representa a rede de San Joaquin County.

do que na rede gerada pelo modelo de Waxman, entretanto nesta rede a maior distância é menor do que na primeira (como pode ser visto nas Figuras 5.22(a) e (b)). Nas redes de ruas, os histogramas são semelhantes (como pode ser visto nas Figuras 5.22 (c) e (d)). Além disso, as maiores distâncias entre os menores caminhos é menor do que nos modelos. Desta forma, é possível mostrar que estas redes são semelhantes, se considerarmos os seus caminhos do betweenness. Entretanto, as redes dos neurônios ( $\mathrm{RC}$ e RP) possuem, na média, distâncias menores do que nas demais. (Figura 5.20).

\subsubsection{Modelo de rede com caminhos}

Como na rede de Oldenburg é possível observar a existência de uma possível relação entre os caminhos e as comunidades, para estudar melhor este conceito foi utilizado o modelo de 


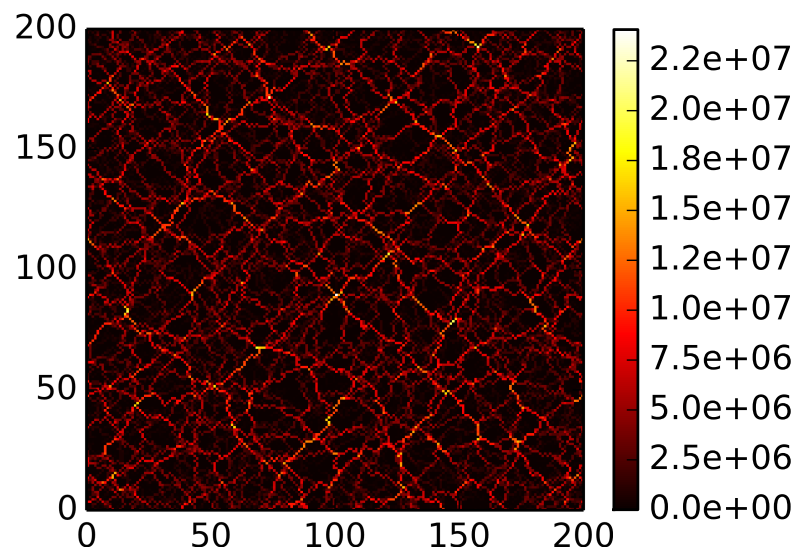

(a)

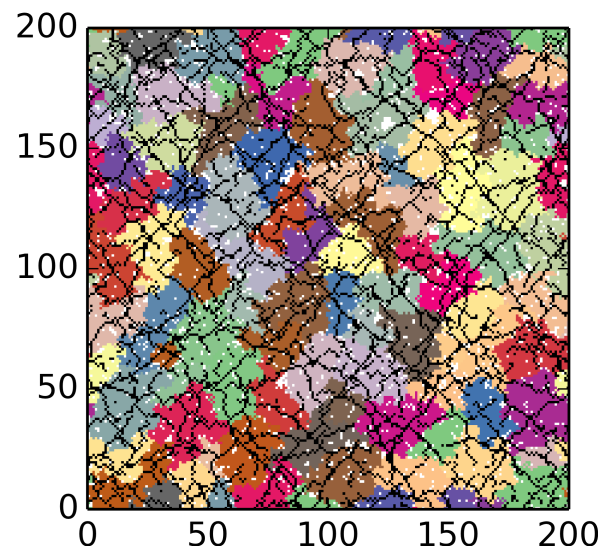

(b)

Figura 5.23: A imagem do item (a) representa o heat map da medida de betweenness centrality nos vértices da rede do modelo proposto (nas regiões sem vértices o valor do betweenness centrality é considerado como zero). O item (b) mostra as comunidade, sendo que cada uma delas possuí uma cor distinta, a cor preta mostra os caminhos (com um limiar de 20\%) e a cor branca mostra as regiões sem vértices.

rede que gera os caminhos do betweenness centrality. Além disso, este modelo foi utilizado para observar e fazer comparações entre as características topológicas e geográficas da rede. Por meio da Figura 5.23, é possível ver a medida de betweenness centrality para cada um dos vértices (Figura $5.23(\mathrm{a})$ ) e os caminhos, que são selecionados pelo limiar (20\%), juntamente com as comunidades da rede (Figura 5.23(b)).

Com a finalidade de comparar o modelo com as demais redes, foram feitas as mesmas medidas apresentadas nesta seção. O modelo difere na quantidade de componentes que formam os caminhos do betweenness, entretanto o maior componente representa $92 \%$ de todos os caminhos. Considerando a cobertura da rede, o histograma da distância entre os vértices que não fazem parte dos caminhos e os caminhos do betweenness possui um comportamento semelhante aos modelos apresentados, exceto das redes formadas pelos neurônios (RP e RC) (o histograma pode ser visto na Figura 5.24). Como neste modelo os vértices estão organizados em uma grade e podem se conectar apenas com seus vizinhos, este modelo pode ser utilizado para gerar um padrão de cobertura em uma região.

Para compreender a relação entre as comunidades e os caminhos foi calculada a modularidade de todas as redes, como é mostrado na Tabela 5.1. Assim, pode-se afirmar que todas as redes analisadas possuem comunidades bem definidas, devido aos altos valores 


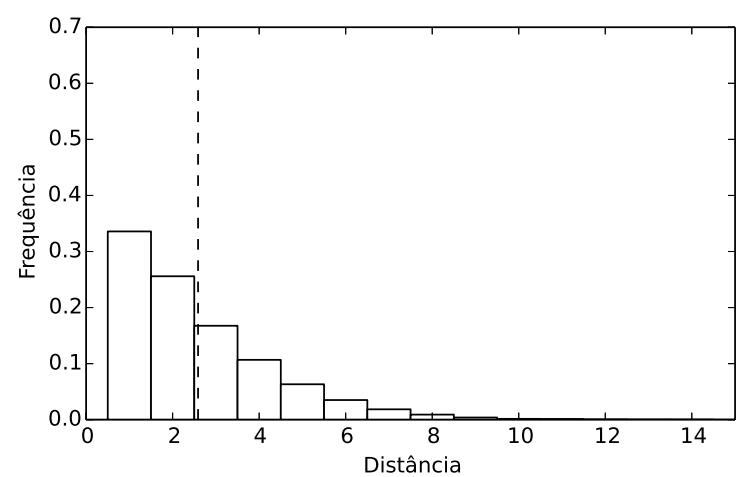

Figura 5.24: Histogramas mostrando a distância entre os vértices e os caminhos preferenciais no modelo de rede.

de modularidade.

Tabela 5.1: Modularidade das redes.

\begin{tabular}{l|c}
\hline Rede & Modularidade \\
\hline RC & 0,85 \\
RP & 0,85 \\
Waxman & 0,92 \\
Grafo geométrico aleatório & 0,96 \\
Oldenburg & 0,92 \\
San Joaquin County & 0,96 \\
Modelo de rede com caminhos & 0,97 \\
\hline
\end{tabular}

Como as comunidades são bem definidas, foram feitas comparações entre a borda topológica, a borda geográfica e os vértices internos das comunidades, mostrando como as comunidades e os caminhos do betweenness são formados. Sendo que borda topológica é o conjunto de vértices que pertencem a uma determinada comunidade e possuem arestas que se conectam a outra, a borda geográfica é definida como o conjunto de vértices que pertencem a uma determinada comunidade e possuem um ou mais vizinhos de outra, geograficamente (foi considerada a vizinhança de oito da grade) e os vértices internos das comunidades são os vértices que não pertencem a nenhum dos tipos de bordas.

Para mostrar como as comunidades foram criadas foi utilizada a medida de grau (neste rede o grau médio é de 2,92), foi feita a comparação entre o grau médio dos vértices internos da comunidade e os vértices da borda geográfica (como pode ser visto pela Figura 5.25(a)). Nesta medida, para todos os casos, a média das bordas é mais baixa do que a média interna 


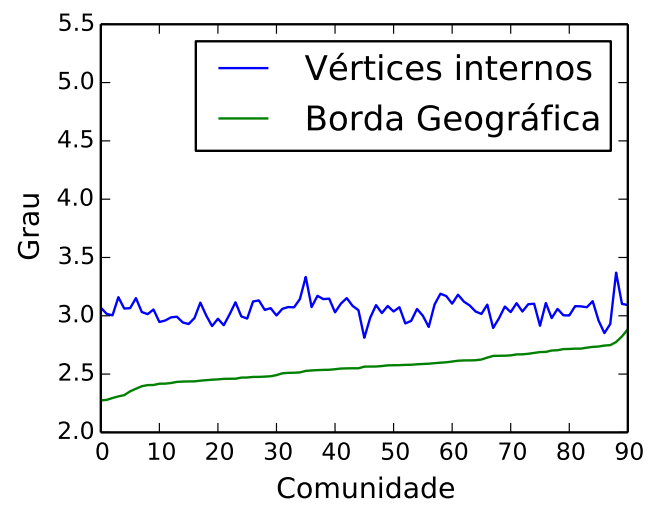

(a)

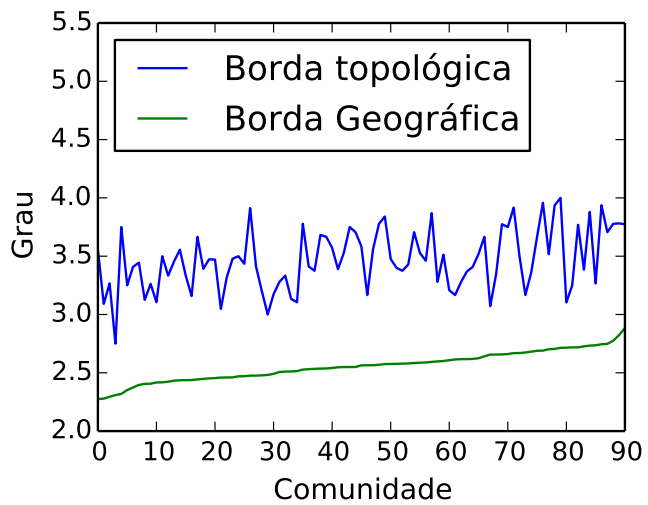

(b)

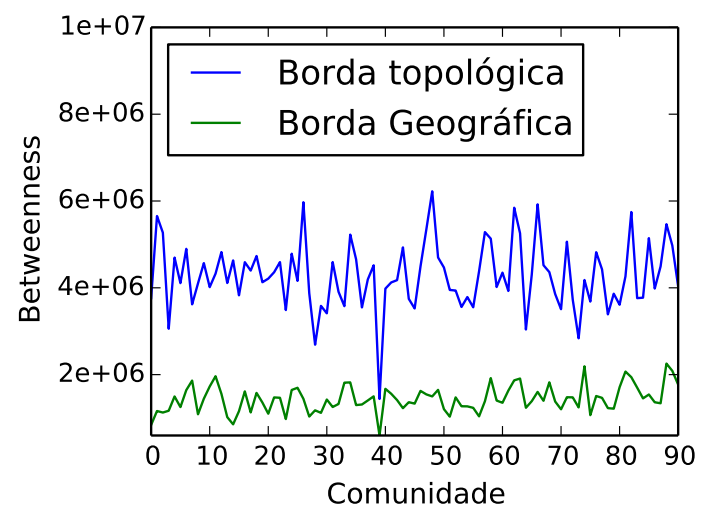

(c)

Figura 5.25: A imagem (a) mostra a comparação entre entre o grau dos vértices internos das comunidades e os vértices das bordas geográficas, a imagem (b) mostra a comparação entre entre o grau dos vértices da borda topológica das comunidades e os vértices das bordas geográficas e a imagem (c) mostra o betweenness centrality mostra a comparação entre entre o grau dos vértices da borda topológica das comunidades e os vértices das bordas geográficas. Os índices das comunidades foram ordenados em ordem crescente, de acordo com o grau das bordas geográficas.

da comunidade.

Para descrever como os vértices dos caminhos do betweenness conectam as comunidades, foi feita a medida de grau médio nas bordas geográficas das comunidades e nas bordas topológicas das comunidades, como pode ser visto na Figura 5.25(b). Neste teste, para todas as comunidades, o grau médio dos vértices pertencentes à borda geográfica são menores do que os vértices contidos na fronteira topológica. Desta forma, há um indício de que os vértices com grau mais elevado estão criando as conexões entre as comunidades.

Além das comparações feitas com a medida de grau, foi feita a comparação entre as bordas geográficos e topológicos, usando a medidas de betweenness centrality (como pode ser visto na Figura 5.25 (c)). Esta medida mostra que as conexões entre as comunidades 


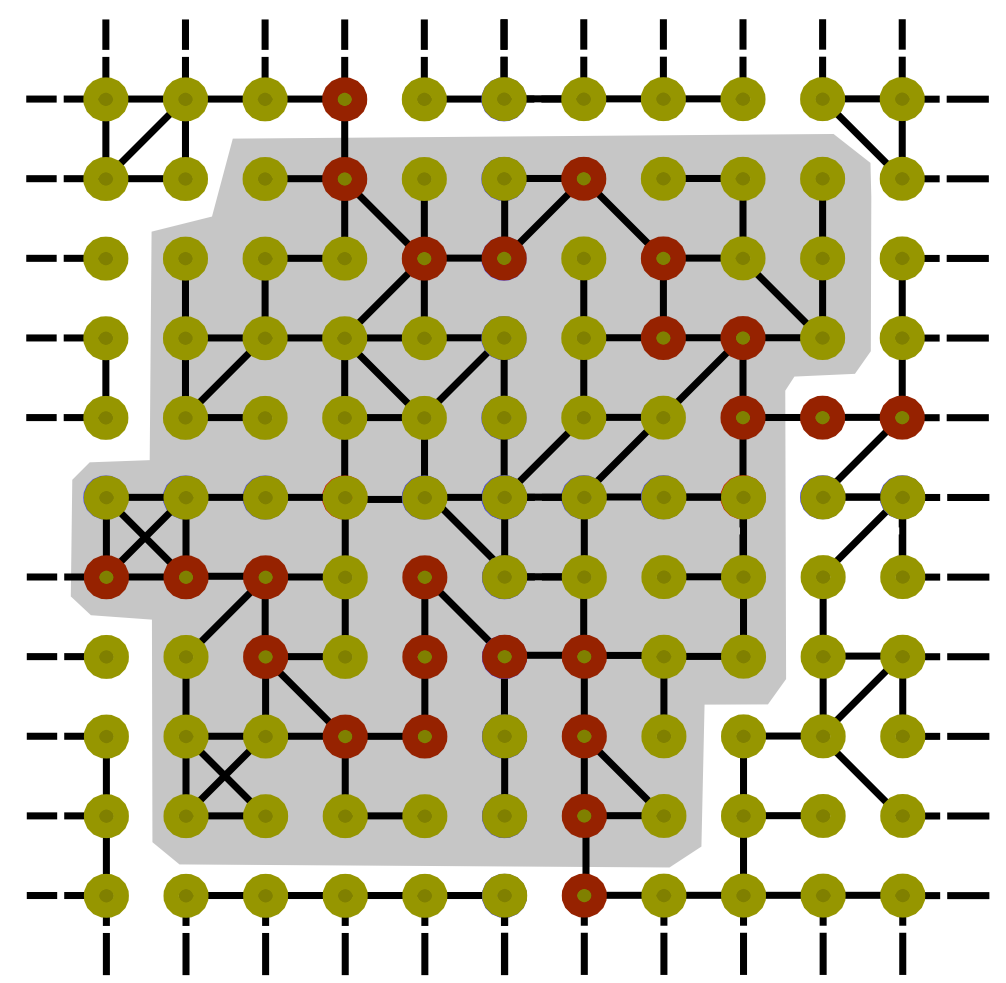

(a)

Figura 5.26: Exemplo de comunidade e os seus respectivos caminhos do betweenness. A região em destaque representa a comunidade e os vértices vermelhos representam os caminhos do betweenness.

(borda topológica) estão criando o caminho característico do betweenness. Neste caso, nas bordas geográficas, o valor médio do betweenness centrality é menor do que na mesma medida das bordas topológicas, para todas as comunidades. Assim, em média, os vértices onde os caminhos atravessam as fronteiras da comunidade têm maiores valores de betweenness e grau do que as fronteiras geográficas. Os vértices de caminhos do betweenness fazem parte da fronteira topológica. Desta forma, eles estão conectando comunidades.

Os resultados indicam que os caminhos representam vias de comunicação eficiente entre as comunidades, pois é possível observar que os vértices que conectam as diferentes comunidades (borda topológica) possuem, em média, maiores valores de betweenness centrality. Um exemplo de comunidade está ilustrado na Figura 5.26. Os vértices da região em destaque pertencem à mesma comunidade. A comunidade possuí quatro vértices na sua fronteira topológica e os caminhos preferenciais (caminhos do betweenness) são representados pela cor vermelha.

Com o intuito de entender a relação entre a quantidade de menores caminhos que 


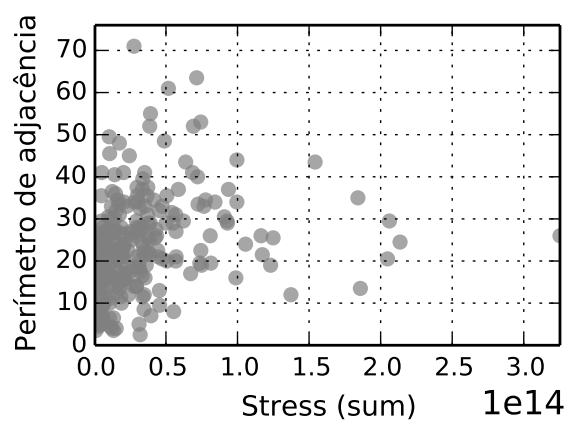

Figura 5.27: Gráfico de dispersão mostrando a relação entre a soma do stress de todos os vértices que conetam as comunidades e o perímetro de adjacência. O valor da correlação de Pearson é de 0,27 .

conectam as comunidades e o seus respectivos perímetros de adjacência (quantidade de vértices que possuem vizinhos geográficos pertencentes a outras comunidades), foi criado um gráfico de dispersão entre o somatório do valor do stress centrality de todos os vértices que participam das conexões entre cada par de comunidades vizinhas e o perímetro de adjacência do mesmo par de comunidades (que pode ser observado pela Figura 5.27). A partir deste gráfico foi calculada a correlação de Pearson, que foi de 0,27. Desta forma, pode-se afirmar que não existe correlação linear entre as medidas. Assim, o tamanho do perímetro de uma comunidade não implica na quantidade de menores caminhos conectando com outras.

\subsubsection{Rede de comunidades}

A fim de observar a relação entre as características topológicas e geográficas da rede, foi criada a rede de comunidades apresentada na subseção 4.4. Esta rede pode ser vista por meio da Figura 5.28.

Com a rede formada pela adjacência das comunidades, podemos comparar as suas características geográficas e topológicas. Por meio da Figura 5.28 é possível observar pequenas comunidades podem possuir alto peso de ligação, indicando que tais caminhos são a intermediação entre outras comunidades. Além disso, existem comunidades maiores com baixo peso nas ligações, mostrando que os principais caminhos preferenciais cruzam outras comunidades.

Foram comparadas as características locais topológicas de adjacência entre as comu- 


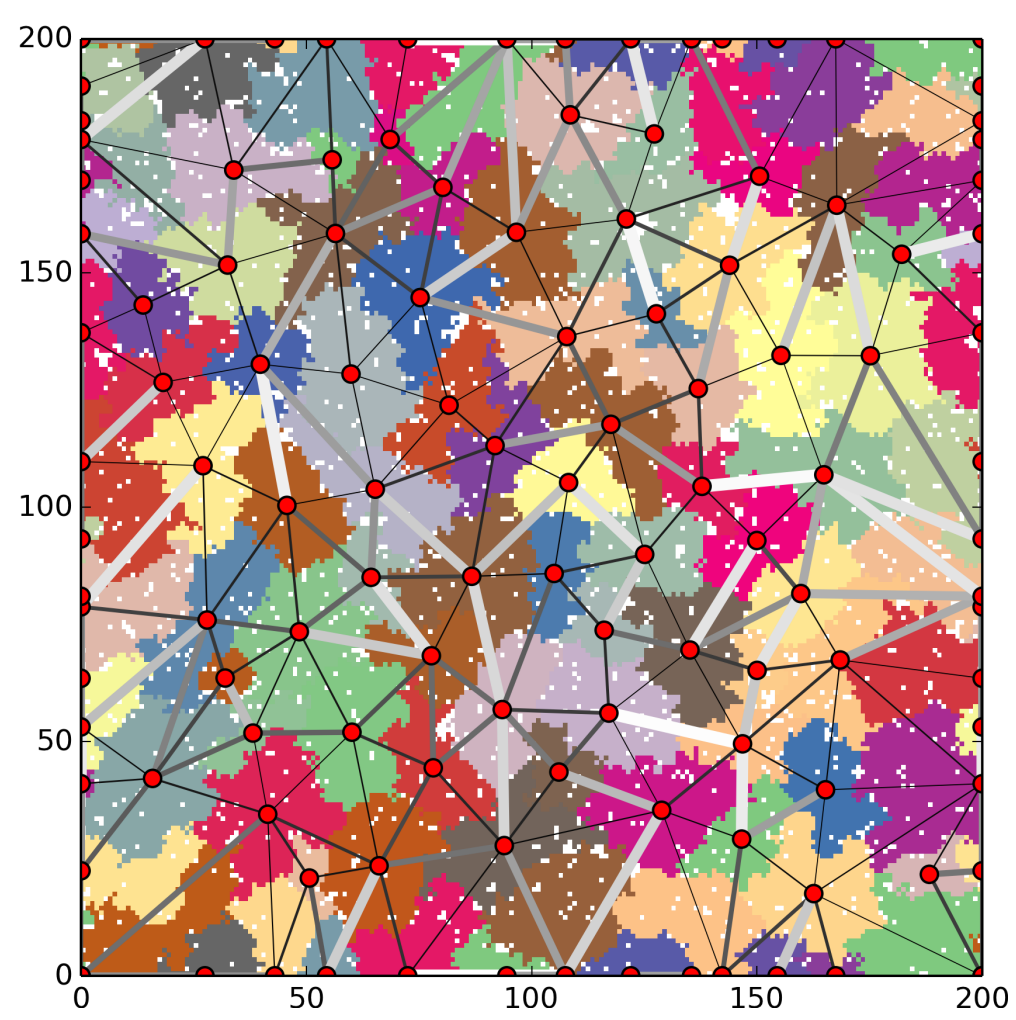

Figura 5.28: Heat map mostrando a rede criada pela adjacência das comunidades. Os círculos vermelhos representam os vértices e as arestas variam entre a cor preta até branca (preto é zero e branco é um), representando os pesos das ligações.

nidades com as características espaciais (os resultados são mostrados pelos gráficos de dispersão e podem ser visto na Figura 5.29). As Figuras 5.29(a), (b) e (c) mostram o grau pela área, perímetro e diâmetro, respectivamente e as Figuras 5.29(d), (e) e (f) mostram as mesmas medidas utilizando o strength no lugar do grau. Nestas medidas, a correlação de Pearson foi de 0,70 na relação entre grau pela área, e 0,71 na relação entre grau e perímetro, e 0,68 na relação entre grau e diâmetro. É possível observar que, a partir destes resultados, o grau está correlacionado com as características geográficas das comunidades. Nas demais medidas, que consideram o peso dos vértices, a correlação de Pearson foi de 0,16 na relação entre strength e área, 0,18 na relação entre strength e perímetro, e 0,20 na relação entre strength e diâmetro. Estes resultados mostram que o strength não está correlacionado com as características geográficas das comunidades. 


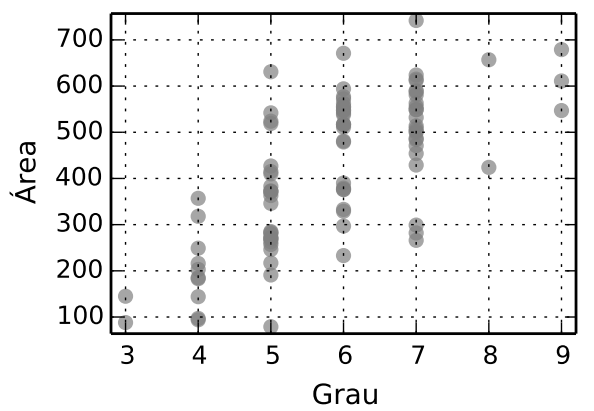

(a)

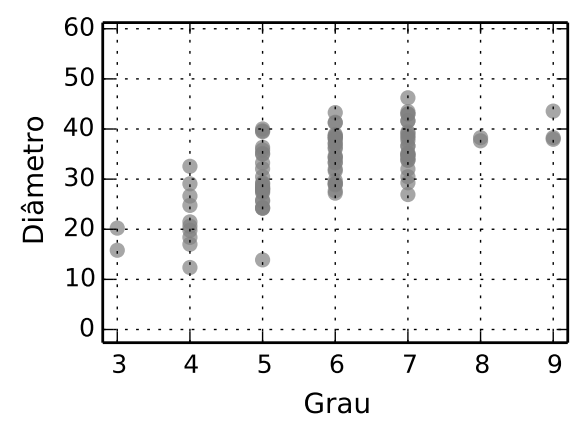

(c)

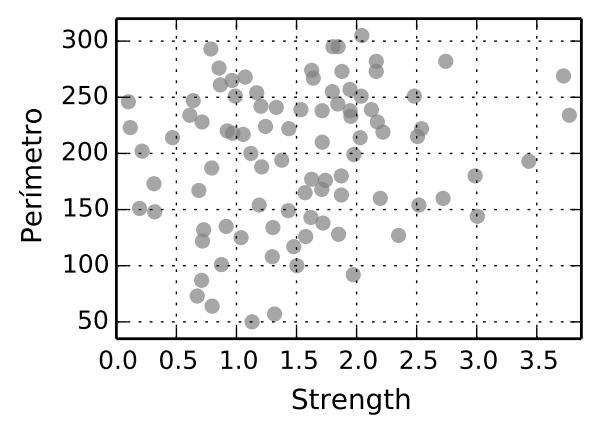

(e)

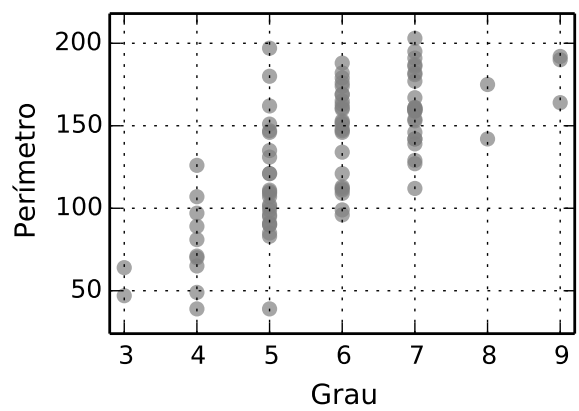

(b)

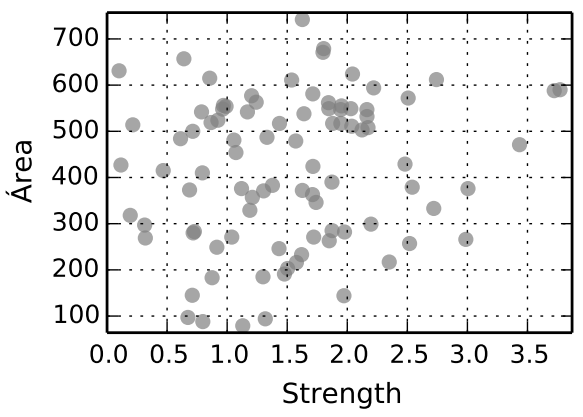

(d)

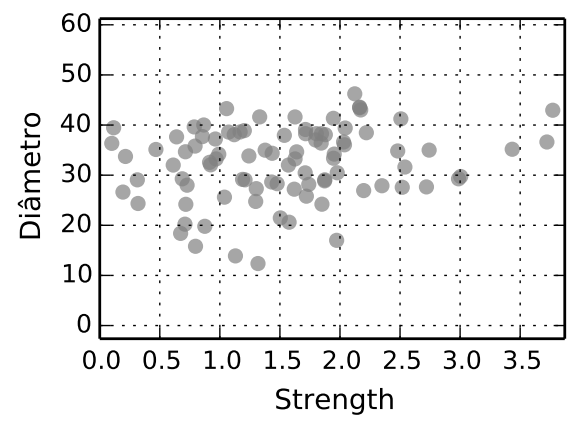

(f)

Figura 5.29: Gráficos de dispersão comparando medidas geográficas e topológicas na rede de comunidades. Os itens (a), (b), e (c) representam a medida de grau (sem peso) pelas características geográficas e os itens (d), (e), e (f) representam o strength pelas características geográficas. 


\section{Capítulo 6}

\section{Conclusões e trabalhos futuros}

Neste capítulo são descritas as conclusões do trabalho, suas principais contribuições, os trabalhos futuros e as publicações geradas.

\subsection{Conclusões}

Neste trabalho foi proposto um modelo de criação de forma neuronal, baseado em um parâmetro de expressão gênica, que gera redes neuronais. Por meio deste modelo foram criadas redes influenciadas por dois padrões de expressão gênica distintos, plano e circular (RP e RC). Posteriormente, foram calculadas medidas de centralidade para mostrar as diferenças geradas pelos dois padrões. Além disso, foram executadas as dinâmicas integra-e-dispara, que simula uma dinâmica neuronal, e o desenvolvimento hebbiano, que modifica a estrutura da rede. Ademais, foram calculadas as medidas de informação mútua e correlação de Pearson, para quantificar as relações entre as etapas e a expressão gênica.

Devido ao modelo de geração de neurônios artificiais (variando de acordo com a expressão gênica), que modifica a conectividade da rede, há diferenças entre os padrões de ligação, ou seja, nas regiões onde a influência da expressão gênica é menor existem ligações entre neurônios mais distantes (geograficamente) do que nas demais regiões, mostrando, assim, que a expressão gênica influencia diretamente a morfologia neuronal e indiretamente a topologia da rede neuronal.

A partir da rede criada, foram feitas diversas medidas de centralidade, sendo que 
todas elas mostram que as regiões de menor expressão gênica tendem a ser mais centrais, reafirmando que este fator influencia indiretamente a topologia da rede.

Na simulação da dinâmica integra-e-dispara há uma grande diferença no padrão de entropia entre disparos das redes, de acordo com o padrão de expressão gênica. Existe uma tendência para as regiões com valores maiores de expressão gênica de possuírem menores valores de entropia entre disparos. Além disso, o que influencia a dinâmica são os padrões de ligação, ou seja a topologia da rede. É possível perceber que esta etapa também é influenciada indiretamente pela expressão gênica.

Por meio do desenvolvimento hebbiano, foi possível mostrar como a expressão gênica afeta o desenvolvimento da rede. Uma característica encontrada foi que as regiões com valores menores de expressão gênica tendem a se manter conectadas na nova rede. Ademais, os resultados mostram que os diferentes padrões de expressão influenciam as características do desenvolvimento hebbiano, pois os resultados foram distintos entre as duas redes (RP e RC), como na medida do maior intervalo entre os disparos. Além de haver um comportamento diferente no desenvolvimento de cada uma das redes, houveram também diferenças entre este modelo de desenvolvimento hebbiano e a dinâmica integra-e-dispara.

Dentre as medidas de centralidade, um resultado interessante foi na medida de betweenness centrality para as duas redes, por meio do heat map é possível perceber que existem caminhos preferenciais entre neurônios. Assim, se um caminhante sai de um vértice para chegar a outro, utilizando os menores caminhos, provavelmente estas serão as vias mais utilizadas.

Foi feito um estudo direcionado para compreender o motivo pelo qual este fenômeno ocorre. Uma das características encontradas é que a estrutura de uma rede espacial tem um impacto direto sobre os caminhos formados na rede, sendo que eles podem ser encontrados em modelos de redes espaciais, bem como em redes reais. Os caminhos do betweenness foram caracterizados em termos da distância entre cada vértice de rede e o caminho mais próximo. Tal medida pode ser relacionada com a cobertura da rede. Em todos os casos estudadas, os caminhos do betweenness geram uma boa cobertura do sistema. Ademais, foi proposto um modelo que gera estes caminhos. Por meio dele é 
possível fazer comparações entre as características topológicas e geográficas da rede.

Os caminhos do betweenness possuem uma forte relação com a presença de comunidades bem definidas nas redes. Desta forma, por meio do modelo de rede geográfica foram feitas medidas para compreender como as comunidades são formadas e sua influência sobre os caminhos. Uma característica interessante é o número de caminhos mais curtos que passam através da fronteira topológica das comunidades adjacentes, que não é dependente da sua geometria. Isto foi revelado pela ausência de correlação entre o stress das ligações e o perímetro de adjacência entre as comunidades.

Além do modelo de rede para gerar os caminhos do betweenness, foi criada outra rede, mostrando a relação entre as diferentes comunidades. Assim, ao caracterizar esta estrutura, foi mostrado que as características geográficas podem influenciar a conectividade entre as comunidades.

\subsection{Principais contribuições}

As principais contribuições deste trabalho são:

- Uso de características diferentes das que foram propostas por Miazaki (2012). Desta forma foi possível mostrar a possibilidade de encontrar características diferentes utilizando o mesmo pipeline. Uma das diferenças foi a criação de rede direcionada, sendo que a direção representa o sentido das sinapses, que são axo-dendríticas, para deixar o modelo mais próximo do real;

- Uso de diferentes medidas de centralidade, sendo que algumas delas são específicas para redes direcionadas;

- Uso da medida de informação mútua, para medir a informação contida a expressão gênica e a morfologia, topologia e as dinâmicas. Esta medida não depende dos dados serem linearmente correlacionados, diferente do que ocorre na correlação de Pearson;

- Realização de experimentos que permitem concluir por meio da informação mútua 
e a correlação de Pearson que todas as etapas foram influenciadas pela expressão gênica;

- Realização de experimentos em que foi possível observar que a organização dos padrões de expressão gênica são um fator importante para as demais etapas, pois apesar das regras aplicadas nas duas redes serem iguais, os padrões diferentes de expressão gênica (circular e plano) geraram resultados distintos em todas as etapas;

- Apesar de ser a última etapa do pipeline, o desenvolvimento hebbiano também foi influenciado pela expressão gênica. Ademais, o comportamento desta dinâmica foi diferente para cada um dos padrões de expressão gênica (plano e circular).

- Foi possível observar diferenças nos padrões dos disparos dos neurônios na comparação entre a dinâmica integra-e-dispara (que não altera a topologia da rede) e o desenvolvimento hebbiano (que altera a topologia da rede);

- Foram encontrados os caminhos do betweenness nas redes neuronais. Por meio de comparações com outros tipos de redes, foi possível observar que os caminhos do betweenness são uma característica das redes espaciais;

- Os caminhos do betweenness estão relacionados com a presença de comunidades na rede e refletem a comunicação entre elas. Além disso,os caminhos do betweenness geram uma boa cobertura da rede;

- Comparações entre as características topológicas e geográficas da rede, de acordo com os caminhos do betweenness.

\subsection{Trabalhos Futuros}

Nos sistemas biológicos não existe apenas um gene, ou outro fator, que influencia o crescimento neuronal. Desta forma, é possível modelar um sistema que possui diversos fatores distintos influenciando a sua formação. A partir de outras redes, é necessário fazer todas as medidas apresentadas por este trabalho, além disso, correlacionar separadamente os 
fatores que influenciam a forma neuronal, para identificar como cada um deles influencia o sistema separadamente.

Todas as etapas do pipeline podem ser modificadas, para testar possibilidades diferentes. A etapa de criação de neurônio artificial pode ser modificada para usar neurônios reais, ou para utilizar outro modelo. Desta forma, tendo dados reais de uma das etapas, é possível simular as demais.

Nos caminhos encontrados para a medida de betweenness centrality, seriam interessantes outras análises, como por exemplo estudar redes que não são espaciais, para entender se este efeito também ocorre. Ademais, outro fator interessante é estudar como estes caminhos afetam as dinâmicas aplicadas na rede.

\subsection{Publicações}

Utilizando a metodologia desta dissertação foram gerados dois artigos.

O primeiro trabalho, que é sobre o pipeline de expressão gênica nas redes neuronais foi $A$ framework for analyzing the relationship between gene expression and morphological, topological, and dynamical patterns in neuronal networks (Arruda et al., 2015), sendo que este trabalho foi publicado na revista Journal of neuroscience methods.

O segundo trabalho, que é referente aos caminhos do betweenness, foi Minimal paths between communities induced by geographical networks (Arruda et al., 2015), este trabalho está hospedado no repositório arXiv e foi submetido para a revista Physical Review E. 


\section{Referências bibliográficas}

Arruda, H. F.; Comin, C. H.; Costa, L. da F. Minimal paths between communities induced by geographical networks. ArXiv e-prints, Janeiro 2015.

Arruda, H. F.; Comin, C. H.; Miazaki, M.; Viana, M. P.; Costa, L. da F. A framework for analyzing the relationship between gene expression and morphological, topological, and dynamical patterns in neuronal networks. Journal of neuroscience methods, 245: $1-14,2015$.

Ascoli, Giorgio A.; Krichmar, Jeffrey L. L-neuron: A modeling tool for the efficient generation and parsimonious description of dendritic morphology. Neurocomputing, 32-33:1003-1011, 2000.

Baaré, William F. C.; Pol, H. E. H.; Boomsma, D. I.; Posthuma, D.; de Geus, E. J. C.; Schnack, H. G.; van Haren, N. E. M.; van Oel, C. J.; Kahn, R. Quantitative genetic modeling of variation in human brain morphology. Cerebral Cortex, 11(9):816-824, 2001.

Barkovich, A. J.; Guerrini, R.; Kuzniecky, R. I.; Jackson, G. D.; Dobyns, W. B. A developmental and genetic classification for malformations of cortical development: update 2012. Brain, 135(5):1348-1369, 2012.

Barrat, A.; Barthlemy, M.; Vespignani, A. Dynamical Processes on Complex Networks. Cambridge University Press, New York, NY, USA, 2008. ISBN 9-780-521-879-507.

Barrett, K.E.; Barman, S.M.; Boitano, S.; Brooks, H. Ganong's Review of Medical Physiology, 23rd Edition. Lange medical book. Mcgraw-hill, 2009. ISBN 9780071605687. 
Barthélemy, Marc. Spatial networks. Physics Reports, 499(1):1-101, 2011.

Bertrand, N.; Castro, D. S.; Guillemot, F. Proneural genes and the specification of neural cell types. Nature Reviews Neuroscience, 3(7):517-530, 2002.

Blackwood, D. H. R.; Fordyce, A.; Walker, M. T.; St Clair, D. M.; Porteous, D. J.; Muir, W. J. Schizophrenia and affective disorders - cosegregation with a translocation at chromosome 1q42 that directly disrupts brain-expressed genes: clinical and p300 findings in a family. The American Journal of Human Genetics, 69(2):428-433, 2001.

Boccaletti, S.; Latora, V.; Moreno, Y.; Chavez, M.; Hwang, D.U. Complex networks: Structure and dynamics. Physics reports, 424(4-5):175-308, 2006. ISSN 0370-1573.

Bodmer, R.; Jan, Y. N. Morphological differentiation of the embryonic peripheral neurons in drosophila. Roux's archives of developmental biology, 196(2):69-77, 1987.

Borgatti, Stephen P. Centrality and network flow. Social networks, 27(1):55-71, 2005.

Bota, M.; Swanson, L. W. The neuron classification problem. Brain research reviews, 56 (1):79-88, 2007.

Brandes, U. A faster algorithm for betweenness centrality. Journal of Mathematical Sociology, 25(163), 2001.

Brandes, U. On variants of shortest-path betweenness centrality and their generic computation. Social Networks, 30(2):136-145, 2008.

Brinkhoff, Thomas. A framework for generating network-based moving objects. Geoinformatica, 6(2):153-180, Junho 2002. ISSN 1384-6175. doi: 10.1023/A:1015231126594.

Brown, T. H.; Kairiss, E. W.; Keenan, C. L. Hebbian synapses: biophysical mechanisms and algorithms. Annual review of neuroscience, 13(1):475-511, 1990.

Campbell, D. S.; Holt, C. E. Chemotropic responses of retinal growth cones mediated by rapid local protein synthesis and degradation. Neuron, 32(6):1013-1026, 2001. 
Carnevale, N. T.; Hines, M. L. The NEURON Book. Cambridge University Press, New York, NY, USA, 2006. ISBN 0521843219.

Clauset, A.; Newman, M. E. J.; Moore, C. Finding community structure in very large networks. Phys. Rev. E, 70:066111, Dec 2004. doi: 10.1103/PhysRevE.70.066111.

Colosimo, M. E.; Brown, A.; Mukhopadhyay, S.; Gabel, C.; Lanjuin, A. E.; Samuel, A. D. T.; Sengupta, P. Identification of thermosensory and olfactory neuron-specific genes via expression profiling of single neuron types. Current biology, 14(24):2245-2251, 2004.

Costa, L da F; Rodrigues, F.A.; Travieso, G.; Boas, P.R.V. Characterization of Complex Networks: A Survey of Measurements. Advances in Physics, 56(1):167-242, 2007. ISSN 0001-8732.

Costa, L da F; Zawadzki, K.; Miazaki, M.; Viana, M. P.; Taraskin, S. N. Unveiling the neuromorphological space. Frontiers in Computational Neuroscience, 4:150, 2010.

Cover, T. M.; Thomas, J. A. Elements of Information Theory (Wiley Series in Telecommunications and Signal Processing). Wiley-Interscience, 2006. ISBN 0471241954.

Crucitti, P.; Latora, V.; Porta, S. Centrality measures in spatial networks of urban streets. Phys. Rev. E, 73:036125, Mar 2006a. doi: 10.1103/PhysRevE.73.036125.

Crucitti, P.; Latora, V.; Porta, S. Centrality in networks of urban streets. Chaos: An Interdisciplinary Journal of Nonlinear Science, 16(1):015113, 2006b. doi: http://dx. doi.org/10.1063/1.2150162.

Csardi, G.; Nepusz, T. The igraph software package for complex network research. InterJournal, Complex Systems:1695, 2006. URL http://igraph.sf.net.

Duan, X.; Chang, J. H.; Ge, S.; Faulkner, R. L.; Kim, J. Y.; Kitabatake, Y.; Liu, X.; Yang, C.-H.; Jordan, J. D.; Ma, D. K.; others, . Disrupted-in-schizophrenia 1 regulates integration of newly generated neurons in the adult brain. Cell, 130(6):1146-1158, 2007. 
Eberwine, J.; Yeh, H.; Miyashiro, K.; Cao, Y.; Nair, S.; Finnell, R.; Zettel, M.; Coleman, P. Analysis of gene expression in single live neurons. Proceedings of the National Academy of Sciences, 89(7):3010-3014, 1992.

Freeman, L.C. A Set of Measures of Centrality Based on Betweenness. Sociometry, 40: 35-41, 1977.

Freeman, Linton C; Borgatti, Stephen P; White, Douglas R. Centrality in valued graphs: A measure of betweenness based on network flow. Social networks, 13(2):141-154, 1991.

Gao, F.; Brenman, J. E; Jan, L. Y.; Jan, Y. N. Genes regulating dendritic outgrowth, branching, and routing in drosophila. Genes \& development, 13(19):2549-2561, 1999.

Gough, B. GNU Scientific Library Reference Manual - Third Edition. Network Theory Ltd., 3rd edição, 2009. ISBN 0954612078, 9780954612078.

Guardiola, X.; Díaz-Guilera, A.; Llas, M.; Pérez, C. J. Synchronization, diversity, and topology of networks of integrate and fire oscillators. Phys. Rev. E, 62:5565-5570, 2000.

Hagberg, A. A.; Schult, A. D.; Swart, P. J. Exploring network structure, dynamics, and function using NetworkX. In Proceedings of the 7th Python in Science Conference (SciPy2008), páginas 11-15, Pasadena, CA USA, Agosto 2008.

Halavi, M.; Polavaram, S.; Donohue, D. E.; Hamilton, G.; Hoyt, J.; S., Kenneth P.; Ascoli, G. A. Neuromorpho.org implementation of digital neuroscience: Dense coverage and integration with the nif. Neuroinformatics, 6(3):241-252, 2008.

Halavi, M.; S., Polavaram; E., Donohue D.; G., Hamilton; J., Hoyt; P., Smith K.; A., Ascoli G. NeuroMorpho.org, 2013. URL http://neuromorpho.org/. [Online; Acesso em 27-Novembro-2013].

Halavi, M.; S., Polavaram; E., Donohue D.; G., Hamilton; J., Hoyt; P., Smith K.; A., Ascoli G. NeuroMorpho.org, 2014. URL http://neuromorpho.org/. [Online; Acesso em 25-Dezembro-2014]. 
Harary, F. Graph theory. Addison-Wesley series in mathematics. Addison-Wesley Pub. Co., 1969.

Hatakeyama, J.; Bessho, Y.; Katoh, K.; Ookawara, S.; Fujioka, M.; Guillemot, F.; Kageyama, R. Hes genes regulate size, shape and histogenesis of the nervous system by control of the timing of neural stem cell differentiation. Development, 131(22):55395550, 2004.

Haykin, S. Neural Networks: A Comprehensive Foundation. Prentice Hall, 1999. ISBN 9780780334946.

Hebb, D.O. The Organization of Behavior: A Neuropsychological Theory. Taylor \& Francis, 1949. ISBN 9781135631901.

Hedley, P. L.; Jørgensen, P.; Schlamowitz, S.; Wangari, R.; Moolman-Smook, J.; Brink, P. A.; Kanters, J. K.; Corfield, V. A.; Christiansen, M. The genetic basis of long qt and short qt syndromes: a mutation update. Human mutation, 30(11):1486-1511, 2009.

Jan, Y.-N.; Jan, L.Y. The Control of Dendrite Development. Neuron, 40(2):229-242, 2003. ISSN 0896-6273. doi: 10.1016/S0896-6273(03)00631-7.

Jolliffe, I.T. Principal Component Analysis. Springer Verlag, 1986.

Kandel, Eric R; Schwartz, James H; Jessell, Thomas M; others, . Principles of neural science, volume 4. McGraw-Hill New York, 2000.

Kiyasova, V.; Fernandez, S. P.; Laine, J.; Stankovski, L.; Muzerelle, A.; Doly, S.; Gaspar, P. A genetically defined morphologically and functionally unique subset of 5-ht neurons in the mouse raphe nuclei. The Journal of Neuroscience, 31(8):2756-2768, 2011.

Kriegstein, A. R.; Dichter, M. A. Morphological classification of rat cortical neurons in cell culture. The Journal of Neuroscience, 3(8):1634-1647, 1983.

Lai, W.-S.; Xu, B.; Westphal, K. G. C.; Paterlini, M.; Olivier, B.; Pavlidis, P.; Karayiorgou, M.; Gogos, J. A. Akt1 deficiency affects neuronal morphology and predisposes to 
abnormalities in prefrontal cortex functioning. Proceedings of the National Academy of Sciences, 103(45):16906-16911, 2006.

LeBlanc, David C. Statistics: concepts and applications for science, volume 2. Jones \& Bartlett Learning, 2004.

Lee, T.; Luo, L. Mosaic analysis with a repressible cell marker for studies of gene function in neuronal morphogenesis. Neuron, 22(3):451-461, 1999. doi: 10.1016/S0896-6273(00) 80701-1.

Lein, E. S.; Hawrylycz, M. J.; Ao, N.; Ayres, M.; Bensinger, A.; Bernard, A.; et al., . Genome-wide atlas of gene expression in the adult mouse brain. Nature, 445:168-176, 2007. doi: $10.1038 /$ nature05453.

Lodish, H.; Berk, A.; Kaiser, C. A.; Krieger, M.; Scott, M. P.; Bretscher, A.; Ploegh, H.; Matsudaira, P. Molecular Cell Biology (Lodish, Molecular Cell Biology). W. H. Freeman, 6th edição, Junho 2007. ISBN 0716776014.

Marconi, E.; Nieus, T.; Maccione, A.; Valente, P.; Simi, A.; Messa, M.; Dante, S.; Baldelli, P.; Berdondini, L.; Benfenati, F. Emergent functional properties of neuronal networks with controlled topology. PLoS ONE, 7(4):e34648, 2012. doi: 10.1371/journal.pone. 0034648 .

Mason, P. Medical neurobiology. Oxford University Press, 2011.

Meyer-Lindenberg, A.; Mervis, C. B.; Berman, K. F. Neural mechanisms in williams syndrome: a unique window to genetic influences on cognition and behaviour. Nature Reviews Neuroscience, 7(5):380-393, 2006.

Miazaki, M. Estudo de forma, função e expressão gênica em neurociência. Doutorado, Instituto de Física de São Carlos - USP, 2012.

Mirzasoleiman, Baharan; Babaei, Mahmoudreza; Jalili, Mahdi; Safari, MohammadAli. Cascaded failures in weighted networks. Physical Review E, 84(4):046114, 2011. 
Mole, S. E.; Williams, R. E.; Goebel, H. H. Correlations between genotype, ultrastructural morphology and clinical phenotype in the neuronal ceroid lipofuscinoses. Neurogenetics, 6(3):107-126, 2005.

Mong, J. A.; Pfaff, D. W. Hormonal and genetic influences underlying arousal as it drives sex and aggression in animal and human brains. Neurobiology of aging, 24:S83-S88, 2003.

Motter, A. E.; Lai, Y. C. Cascade-based attacks on complex networks. Phys Rev E, Dezembro 2002.

Newman, M. E. J. Scientific collaboration networks. I. Network construction and fundamental results. Physical Review E, 64(1):016131+, Junho 2001a. doi: 10.1103/ PhysRevE.64.016131.

Newman, M. E. J. Scientific collaboration networks. II. Shortest paths, weighted networks, and centrality. Physical Review E, 64(1):016132+, Junho 2001b. doi: 10.1103/PhysRevE.64.016132.

Newman, M. E. J. Modularity and community structure in networks. Proceedings of the National Academy of Sciences, 103(23):8577-8582, 2006. doi: 10.1073/pnas. 0601602103.

Newman, M. E. J. Networks: An Introduction. Oxford University Press, New York, 2010.

Newman, M. E. J.; Girvan, M. Finding and evaluating community structure in networks. Phys. Rev. E, 69(2):026113, Fevereiro 2004. doi: 10.1103/PhysRevE.69.026113.

Newman, Mark EJ. A measure of betweenness centrality based on random walks. Social networks, 27(1):39-54, 2005.

Penrose, M. Random geometric graphs. Oxford studies in probability. Oxford University Press, Oxford, New York, 2003. ISBN 0-19-850626-0. Réimpression : 2004. 
Peper, J.S.; Brouwer, R. M.; Boomsma, D. I.; Kahn, R. S.; Pol, H.; Hilleke, E. Genetic influences on human brain structure: a review of brain imaging studies in twins. Human brain mapping, 28(6):464-473, 2007.

Pérez-Reche, F. J.; Taraskin, S. N.; Costa, L. da F.; Neri, M. F.; Gilligan, A. C. Complexity and anisotropy in host morphology make populations less susceptible to epidemic outbreaks. J. R. Soc. Interface, 7(48):1083-1083, 2010. doi: 10.1098/rsif.2009.0475.

Pernice, V.; Staude, B.; Cardanobile, S.; Rotter, S. How structure determines correlations in neuronal networks. PLoS Comput Biol, 7(5):e1002059, 2011. doi: 10.1371/journal. pcbi.1002059.

Qiu, Z.; Ghosh, A. A brief history of neuronal gene expression: regulatory mechanisms and cellular consequences. Neuron, 60(3):449-455, 2008.

Ramachandran, P.; Varoquaux, G. Mayavi: a package for 3d visualization of scientific data. CoRR, abs/1010.4891, 2010.

Ramakers, G. J. A. Rho proteins, mental retardation and the cellular basis of cognition. Trends in neurosciences, 25(4):191-199, 2002.

Roxin, A.; Riecke, H.; Solla, S. A. Self-Sustained Activity in a Small-World Network of Excitable Neurons. Phys. Rev. Lett., 92:198101, 2004.

Scorcioni, R.; Polavaram, S.; Ascoli, G. A. L-Measure: a web-accessible tool for the analysis, comparison and search of digital reconstructions of neuronal morphologies. Nature protocols, 3(5):866-876, 2008. ISSN 1750-2799. doi: 10.1038/nprot.2008.51.

Scott, E. K.; Luo, L. How do dendrites take their shape? Nat Neurosci, 4(4):359-365, Abril 2001. ISSN 1097-6256. doi: 10.1038/86006.

Selkoe, D. J.; Podlisny, M. B. Deciphering the genetic basis of alzheimer's disease. Annual Review of Genomics and Human Genetics, 3(1):67-99, 2002.

Shimbel, A. Structural parameters of communication networks. Bulletin of Mathematical Biophysics, 15:501-507, 1953. 
Sisk, C. L.; Foster, D. L. The neural basis of puberty and adolescence. Nature neuroscience, 7(10):1040-1047, 2004.

Sporns, O.; Tononi, G.; Edelman, G. M. Theoretical neuroanatomy: Relating anatomical and functional connectivity in graphs and cortical connection matrices. Cereb. Cortex, 10(2):127-141, 2000. doi: 10.1093/cercor/10.2.127.

Thompson, P. M.; Cannon, T. D.; Narr, K. L.; Van Erp, T.; Poutanen, V.-P.; Huttunen, M.; Lönnqvist, J.; Standertskjöld-Nordenstam, C.-G.; Kaprio, J.; Khaledy, M.; others, . Genetic influences on brain structure. Nature neuroscience, 4(12):1253-1258, 2001.

Vervoort, M.; Merritt, D. J.; Ghysen, A.; Dambly-Chaudière, C. Genetic basis of the formation and identity of type i and type ii neurons in drosophila embryos. Development, 124(14):2819-2828, 1997.

Watts, D. J.; Strogatz, S. H. Collective dynamics of 'small-world' networks. Nature, 393 (6684):440-442, Junho 1998. ISSN 00280836.

Waxman, B. M. Routing of multipoint connections. IEEE Journal on Selected Areas in Communications, 6(9):1617-1622, 1988.

Wen, Quan; Chklovskii, Dmitri B. A cost-benefit analysis of neuronal morphology. Journal of Neurophysiology, 99(5):2320-2328, 2008. ISSN 0022-3077. doi: 10.1152/jn.00280. 2007.

Zadeh, A. S. M.; Rajabi, M. A. Analyzing the effect of the street network configuration on the efficiency of an urban transportation system. Cities, 31(0):285-297, 2013. ISSN 0264-2751. doi: 10.1016/j.cities.2012.08.008. 